\title{
Behavioural interventions for smoking cessation: an overview and network meta-analysis (Review)
}

Hartmann-Boyce J, Livingstone-Banks J, Ordóñez-Mena JM, Fanshawe TR, Lindson N, Freeman SC, Sutton AJ, Theodoulou A, Aveyard P

Hartmann-Boyce J, Livingstone-Banks J, Ordóñez-Mena JM, Fanshawe TR, Lindson N, Freeman SC, Sutton AJ, Theodoulou A, Aveyard P.

Behavioural interventions for smoking cessation: an overview and network meta-analysis.

Cochrane Database of Systematic Reviews 2021, Issue 1. Art. No.: CD013229.

DOI: 10.1002/14651858.CD013229.pub2.

www.cochranelibrary.com 
TABLE OF CONTENTS

HEADER 1

ABSTRACT

PLAIN LANGUAGE SUMMARY

BACKGROUND

OBJECTIVES

METHODS

RESULTS

Figure 1.

Figure 2.

Figure 3.

Figure 4.

Figure 5.

Figure 6.

Figure 7.

DISCUSSION

Figure 8.

AUTHORS' CONCLUSIONS

ACKNOWLEDGEMENTS

REFERENCES

ADDITIONAL TABLES

APPENDICES

HISTORY

CONTRIBUTIONS OF AUTHORS

DECLARATIONS OF INTEREST

SOURCES OF SUPPORT

DIFFERENCES BETWEEN PROTOCOL AND REVIEW 
[Overview of Reviews]

\title{
Behavioural interventions for smoking cessation: an overview and network meta-analysis
}

\author{
Jamie Hartmann-Boyce ${ }^{1}$, Jonathan Livingstone-Banks ${ }^{1}$, José M Ordóñez-Mena ${ }^{1}$, Thomas R Fanshawe ${ }^{1}$, Nicola Lindson ${ }^{1}$, Suzanne C \\ Freeman², Alex J Sutton², Annika Theodoulou¹, Paul Aveyard ${ }^{1}$ \\ ${ }^{1}$ Nuffield Department of Primary Care Health Sciences, University of Oxford, Oxford, UK. ${ }^{2}$ Department of Health Sciences, University of \\ Leicester, Leicester, UK
}

Contact address: Jamie Hartmann-Boyce, jamie.hartmann-boyce@phc.ox.ac.uk.

Editorial group: Cochrane Tobacco Addiction Group.

Publication status and date: New, published in Issue 1, 2021.

Citation: Hartmann-Boyce J, Livingstone-Banks J, Ordóñez-Mena JM, Fanshawe TR, Lindson N, Freeman SC, Sutton AJ, Theodoulou A, Aveyard P. Behavioural interventions for smoking cessation: an overview and network meta-analysis. Cochrane Database of Systematic Reviews 2021, Issue 1. Art. No.: CD013229. DOI: 10.1002/14651858.CD013229.pub2.

Copyright @ 2021 The Cochrane Collaboration. Published by John Wiley \& Sons, Ltd.

\section{A B S T R A C T}

\section{Background}

Smoking is a leading cause of disease and death worldwide. In people who smoke, quitting smoking can reverse much of the damage. Many people use behavioural interventions to help them quit smoking; these interventions can vary substantially in their content and effectiveness.

\section{Objectives}

To summarise the evidence from Cochrane Reviews that assessed the effect of behavioural interventions designed to support smoking cessation attempts and to conduct a network meta-analysis to determine how modes of delivery; person delivering the intervention; and the nature, focus, and intensity of behavioural interventions for smoking cessation influence the likelihood of achieving abstinence six months after attempting to stop smoking; and whether the effects of behavioural interventions depend upon other characteristics, including population, setting, and the provision of pharmacotherapy.

To summarise the availability and principal findings of economic evaluations of behavioural interventions for smoking cessation, in terms of comparative costs and cost-effectiveness, in the form of a brief economic commentary.

\section{Methods}

This work comprises two main elements. 1. We conducted a Cochrane Overview of reviews following standard Cochrane methods. We identified Cochrane Reviews of behavioural interventions (including all non-pharmacological interventions, e.g. counselling, exercise, hypnotherapy, self-help materials) for smoking cessation by searching the Cochrane Library in July 2020. We evaluated the methodological quality of reviews using AMSTAR 2 and synthesised data from the reviews narratively. 2. We used the included reviews to identify randomised controlled trials of behavioural interventions for smoking cessation compared with other behavioural interventions or no intervention for smoking cessation. To be included, studies had to include adult smokers and measure smoking abstinence at six months or longer. Screening, data extraction, and risk of bias assessment followed standard Cochrane methods. We synthesised data using Bayesian component network meta-analysis (CNMA), examining the effects of 38 different components compared to minimal intervention. Components included behavioural and motivational elements, intervention providers, delivery modes, nature, focus, and intensity of the behavioural intervention. We used component network meta-regression (CNMR) to evaluate the influence of population characteristics, provision of pharmacotherapy, and intervention intensity on the component effects. We evaluated certainty of the evidence using GRADE domains. We assumed an additive effect for individual components. 


\section{Main results}

We included 33 Cochrane Reviews, from which 312 randomised controlled trials, representing 250,563 participants and 845 distinct study arms, met the criteria for inclusion in our component network meta-analysis. This represented 437 different combinations of components. Of the 33 reviews, confidence in review findings was high in four reviews and moderate in nine reviews, as measured by the AMSTAR 2 critical appraisal tool. The remaining 20 reviews were low or critically low due to one or more critical weaknesses, most commonly inadequate investigation or discussion (or both) of the impact of publication bias. Of note, the critical weaknesses identified did not affect the searching, screening, or data extraction elements of the review process, which have direct bearing on our CNMA. Of the included studies, 125/312 were at low risk of bias overall, 50 were at high risk of bias, and the remainder were at unclear risk. Analyses from the contributing reviews and from our CNMA showed behavioural interventions for smoking cessation can increase quit rates, but effectiveness varies on characteristics of the support provided. There was high-certainty evidence of benefit for the provision of counselling (odds ratio (OR) $1.44,95 \%$ credibility interval (Crl) 1.22 to $1.70,194$ studies, $n=72,273$ ) and guaranteed financial incentives (OR $1.46,95 \% \mathrm{Crl} 1.15$ to $1.85,19$ studies, $n=8877$ ). Evidence of benefit remained when removing studies at high risk of bias. These findings were consistent with pair-wise meta-analyses from contributing reviews. There was moderate-certainty evidence of benefit for interventions delivered via text message (downgraded due to unexplained statistical heterogeneity in pair-wise comparison), and for the following components where point estimates suggested benefit but Crls incorporated no clinically significant difference: individual tailoring; intervention content including motivational components; intervention content focused on how to quit. The remaining intervention components had low-to very low-certainty evidence, with the main issues being imprecision and risk of bias. There was no evidence to suggest an increase in harms in groups receiving behavioural support for smoking cessation. Intervention effects were not changed by adjusting for population characteristics, but data were limited. Increasing intensity of behavioural support, as measured through the number of contacts, duration of each contact, and programme length, had point estimates associated with modestly increased chances of quitting, but Crls included no difference. The effect of behavioural support for smoking cessation appeared slightly less pronounced when people were already receiving smoking cessation pharmacotherapies.

\section{Authors' conclusions}

Behavioural support for smoking cessation can increase quit rates at six months or longer, with no evidence that support increases harms. This is the case whether or not smoking cessation pharmacotherapy is also provided, but the effect is slightly more pronounced in the absence of pharmacotherapy. Evidence of benefit is strongest for the provision of any form of counselling, and guaranteed financial incentives. Evidence suggested possible benefit but the need of further studies to evaluate: individual tailoring; delivery via text message, email, and audio recording; delivery by lay health advisor; and intervention content with motivational components and a focus on how to quit. We identified 23 economic evaluations; evidence did not consistently suggest one type of behavioural intervention for smoking cessation was more cost-effective than another. Future reviews should fully consider publication bias. Tools to investigate publication bias and to evaluate certainty in CNMA are needed.

\section{PLAIN LANGUAGE SUMMARY}

\section{Does behavioural support help people to stop smoking?}

\section{Key messages}

Behavioural support can help more people to stop smoking for six months or longer, without causing unwanted effects.

Some types of support appear to work better than others. More studies are needed to identify the best ways to support people who are trying to stop smoking, and to identify the best people to support them.

\section{Stopping smoking}

The best thing people who smoke can do for their health is to stop smoking.

Most people who smoke want to stop, but many find it difficult. People who smoke may use medicines to help them stop. Behavioural support provides an alternative - or additional - way to help people stop smoking. Sometimes behavioural support can be combined with nicotine replacement or other medicines to help people stop smoking.

Types of behavioural support can include: advice and counselling on ways to make it easier to stop smoking; information about why or how to stop; or a combination. Behavioural support can be given in group sessions or one-to-one.

\section{Why we did this Cochrane Review}

We wanted to find out:

- which types of behavioural support work best to help people stop smoking;

- the best ways to give behavioural support (including the best people to give it); and

- what aspects of behavioural support help someone to stop smoking. 
We also wanted to know if behavioural support can cause any unwanted effects.

\section{What did we do?}

We searched for Cochrane Reviews of behavioural support to stop smoking, to identify relevant studies of adults who smoked. We then compared the studies with each other, to find out how well the different types of behavioural support helped people to stop smoking.

Search date: we included evidence published up to July 2020.

\section{What we found}

We found 33 Cochrane Reviews, from which we identified 312 relevant studies in 250,503 adults (aged 18 to 63 years) who smoked cigarettes. The studies investigated 437 different combinations of ways to stop smoking.

Most studies were conducted in the USA or Western Europe; 115 studies took place in healthcare settings and 195 took place in the community. On average, people taking part in the studies were followed up for 10.5 months.

The studies compared the effects of behavioural support with:

- no behavioural support;

- usual or standard care;

- less-intense forms of the behavioural support; or other approaches.

We compared all treatments with each other using a mathematical method called network meta-analysis.

\section{What are the main results of our review?}

Compared with no behavioural support it was clear that some types of behavioural support increased people's chances of quitting for six months or longer, including: counselling and giving them money for successfully stopping smoking. More people stopped smoking with these types of support whether or not they were also taking medicines to help them stop smoking.

Behavioural support by text messages probably helped more people to stop smoking than no support.

Compared with no support, tailoring behavioural support to the person, or group of people, trying to stop smoking probably slightly increased how many of them stopped smoking, as did support that focused on how to stop smoking.

Increasing the intensity of the support given, such as contacting people more often or having longer sessions, modestly increased how many people stopped smoking.

We are uncertain about:

- the effects of other types of behavioural support, including hypnotherapy, exercise-based support, and entering competitions; and

- the effect of who gives the behavioural support.

Only some studies reported results for unwanted effects; in these, behavioural support did not increase the numbers of any unwanted effects.

\section{How confident are we in our results?}

We are confident that counselling and rewards of money help people to stop smoking; we do not expect that more evidence will change these results.

We are less confident in our results for other types of behavioural support, and about who gives the support and how. We found limitations with some of the studies, including how they were designed, conducted, and reported. These results are likely to change when more evidence becomes available. More studies are needed. 


\section{B A C K G R O U N D}

\section{Description of the condition}

Smoking is hazardous to health, shortening life by a mean of 10 to 11 years in people who smoke their whole lives and killing more than seven million people each year (Doll 2004; Pirie 2013; WHO 2018). Tobacco kills up to half of its users, increasing mortality primarily through cardiovascular disease, lung cancer, and chronic obstructive pulmonary disease (WHO 2018). It is also causally associated with other cancer- and non-cancer-related health conditions, giving rise to premature morbidity and mortality (USDHHS 2014). Fortunately, smoking cessation reverses much of the damage. Stopping smoking before the age of 35 years prevents almost all early mortality; stopping by age 60 years improves life expectancy by three years; and stopping after 60 still reduces mortality, cardiovascular disease, and cancer risk (Doll 2004; Mons 2015; Müezzinler 2015; Ordóñez-Mena 2016).

Worldwide, over one billion people are current tobacco smokers, with approximately $80 \%$ living in low- and middle-income countries (WHO 2018). In the UK, as in many other high-income countries, smoking is a major contributory factor to health inequalities, with the burden of smoking-related disease disproportionately impacting people of lower socioeconomic status (SES) and people belonging to certain social groups, including ethnic minorities and people living with mental health conditions (ASH 2016). Aside from the risks to the individual, smoking remains the prime preventable cause of morbidity and mortality, making it an important population health concern (GBD 2016).

Smoking places an enormous economic burden on societies. The economic costs of smoking include healthcare expenditures for treatment of smoking-related diseases and those affected by second-hand smoke, loss of earnings and workplace productivity, disability-adjusted life-years (DALY) lost, and other indirect costs, including fire damage and environmental harm from growing tobacco (ERS 2013). In 2012, 5.7\% of global health expenditure was due to smoking-attributable diseases. Combining the costs of health expenditures and productivity losses, the total economic cost of smoking was an estimated USD 1436 billion, which is equivalent to $1.8 \%$ of the world's annual gross domestic product (GDP). Forty percent of this cost occurred in low- and middleincome countries (Goodchild 2018).

Among smokers who know it is hazardous to their health, most want to quit (WHO 2018). However, quitting is challenging, and most smokers make multiple attempts before successfully quitting (Chaiton 2016). There is a strong evidence base showing that both behavioural therapies and pharmacotherapies can help people quit, either alone, or in combination (Cahill 2013; Hartmann-Boyce 2014a; Lancaster 2017; Matkin 2019; Stead 2016; Stead 2017).

\section{Description of the interventions}

Behavioural therapies for smoking cessation vary widely in their content, delivery, and availability. Typically, they include advice to quit smoking, information on how to quit smoking, or a combination of both, but may use different techniques and theoretical frameworks to achieve these aims. They can range from one-off brief advice from a healthcare professional (Stead 2013), or a printed leaflet (Livingstone-Banks 2019a), to more intensive programmes involving multiple counselling sessions (Lancaster
2017; Matkin 2019; Stead 2017), with or without added components such as financial incentives and partner support (Faseru 2018; Notley 2019). They may be delivered in conjunction with, or independent from, smoking cessation pharmacotherapy, and may be delivered to people motivated to quit or to people not interested in quitting. Some interventions may be tailored to the individual or a particular subgroup (pregnant women, parents, teenagers, people with pre-existing conditions), while other interventions may be more general or applicable to all. Evidence on whether tailoring increases effectiveness is inconclusive (Livingstone-Banks 2019a; Taylor 2017), as is evidence on whether increasing intensity (e.g. length of sessions, duration of intervention) is associated with increased effectiveness (Hartmann-Boyce 2019; Matkin 2019).

\section{How the intervention might work}

Behavioural therapies for smoking cessation can work by prompting a quit attempt or by helping to maintain abstinence once a person has tried to quit, or both. Factors that seem to prompt quit attempts are typically related to motivation, such as concern over the long-term health effects or the financial cost of smoking. Factors associated with long-term success after a quit attempt mostly relate to the strength of the underlying addiction to smoking (Vangeli 2011). However, most attempts are made without the aid of behavioural support, and it is plausible that factors influencing motivation, resilience to overcome the challenges of quitting, or other psychological processes may mediate the impact of various components of behavioural support.

\section{Why it is important to do this overview}

Globally, smoking is the leading cause of preventable death and disease. Accordingly, governments and healthcare systems invest in smoking cessation services, but these vary in their effectiveness (West 2013). Much of this variation is the result of differences in the behavioural support provided (Brose 2011; Dobbie 2015). It is important to pinpoint which types of behavioural support work best for smoking cessation and focus available resources and training on the most effective approaches. This requires data on comparative effectiveness.

Existing Cochrane Reviews in this area primarily focus on mode of delivery (e.g. in-person support either one-to-one (Lancaster 2017) or in groups (Stead 2017), telephone-delivered (Matkin 2019), delivered without in-person contact by mobile phone (Whittaker 2019), by printed media (Livingstone-Banks 2019a), or Internet (Taylor 2017) or provider (e.g. nurse (Rice 2017)). These reviews all show these interventions are effective but include few or no direct comparisons between these different modes of delivery, and little investigation of other components of these programmes which may impact effectiveness.

Network meta-analysis provides an opportunity to compare many different types and components of behavioural interventions with each other simultaneously. By conducting a Cochrane Overview of reviews, we can also summarise relevant interventions that fall outside the scope of a network meta-analysis (Pollock 2020).

Given the economic impact of smoking, and the limited resources with which to provide smoking cessation services, it is important to critically evaluate and summarise current evidence on the comparative costs and cost-effectiveness of behavioural interventions for smoking cessation. 


\section{O B JECTIVES}

To summarise the evidence from Cochrane Reviews that assessed the effect of behavioural interventions designed to support smoking cessation attempts and to conduct a network metaanalysis to determine how modes of delivery; person delivering the intervention; and the nature, focus and intensity of behavioural interventions for smoking cessation influence the likelihood of achieving abstinence six months after attempting to stop smoking and whether the effects of behavioural interventions depend upon other characteristics, including population, setting, and the provision of pharmacotherapy.

To summarise the availability and principal findings of economic evaluations of behavioural interventions for smoking cessation, in terms of comparative costs and cost-effectiveness, in the form of a brief economic commentary.

\section{METHODS}

\section{Criteria for considering reviews for inclusion}

\section{Types of reviews/studies}

We restricted this overview to Cochrane Reviews of randomised controlled trials of behavioural therapies for smoking cessation. We restricted the component network meta-analysis (CNMA) to randomised controlled trials already listed as included or excluded in eligible Cochrane Reviews. We screened all included studies in eligible reviews and queried lists of excluded studies to check if those studies that had been excluded on the basis of comparator (e.g. where a study had been excluded from a review because it was a head-to-head comparison of two behavioural interventions) were eligible for inclusion in this review.

\section{Types of participants}

At the overview level, we included all participants covered by the reviews included in this overview. These were normally adult smokers. Following the methods used by Cahill 2013, we did not include reviews that focused on particular populations of smokers (e.g. adults with mental health problems) (e.g. Tsoi 2013; van der Meer 2013). These reviews cover a range of interventions beyond the behavioural interventions considered by this overview, and the relevant reviews of specific behavioural interventions will already include studies in specific subgroups (e.g. the review of 'Individual counselling for smoking cessation' includes studies conducted in people with mental health problems (Lancaster 2017)).

To ensure comparability between studies and to ensure joint randomisability, inclusion criteria for studies in the CNMA were narrower than for the overview in general. We only included studies in which participants were adult cigarette smokers (aged 18 years or older), who were randomised prior to quitting, and who were not selected on the basis of a pre-existing condition (e.g. pregnancy, heart disease). The latter was because interventions targeting particular populations of smokers (e.g. smoking cessation interventions to protect infants from the harms of parental smoking; smoking cessation interventions delivered with the explicit motivational purpose of preventing a second myocardial infarction) were not considered 'jointly randomisable' as members of the population without such circumstances could not realistically be referred to such interventions.

\section{Types of interventions}

We included reviews that tested behavioural interventions for smoking cessation, delivered at the individual or group level (as opposed to public health interventions such as standardised packaging), and those defined by intervention type (e.g. 'Individual counselling for smoking cessation' (Lancaster 2017)), person delivering the intervention (e.g. 'Nursing interventions for smoking cessation' (Rice 2017)), and theoretical basis of intervention (e.g. 'Motivational interviewing for smoking cessation' (Lindson 2019a)). To meet the condition of joint randomisability, we restricted interventions in the network meta-analysis to those that a person might receive from, or be referred to by, a healthcare professional (e.g. not workplace interventions (Cahill 2014)), or to which an individual could plausibly self-refer. As such, we excluded interventions tailored to specific population groups as these violate the assumption of joint-randomisability (or transitivity), though we included interventions tailored at the individual level (e.g. interventions where content varied based on participants' baseline motivation to quit). We also excluded from the network metaanalysis any historical interventions that would not plausibly be offered in the present day (e.g. aversive smoking), along with interventions that targeted multiple lifestyle changes (e.g. dietary change in addition to smoking cessation), and interventions targeted at smoking outcomes other than abstinence (e.g. smoking reduction).

We excluded reviews or trials that evaluated the effects of pharmacotherapies for smoking cessation, though included studies in which both intervention and control arms received the same pharmacotherapy, and that met all other inclusion criteria (e.g. studies testing behavioural interventions as adjuncts to pharmacotherapy, as per Stead 2017).

We considered the following components in our CNMA.

\section{Motivational components}

- Focus: how to quit

- Focus: why quit

- Nature: motivation

- Nature: self-regulation

- Nature: adjuvant activities

(motivation, self-regulation and adjuvant activities were defined as per Michie 2011)

\section{Behavioural components}

- Counselling

- Biofeedback

- Hypnotherapy

- Exercise

- Financial incentives: guaranteed

- Financial incentives: not guaranteed

- Tailoring

Delivery mode

- Group

- Individual

- Face-to-face 
- Telephone

- Web/computer

- Print

- SMS

- App

- Video (static)

- Video (interactive)

- Audio

- Interactive voice response

- Quitline

- Email

- Other

Intervention provider

- Nurse (general)

- Nurse (specialist)

- Stop smoking advisor

- Psychologist/counsellor

- Physician

- Pharmacist

- Dentist

- Lay health advisor

- Hypnotist

- Exercise specialist

- Other

Intensity of the intervention

- Duration of the intervention (i.e. time between first and last session (weeks))

- Mean length of each session offered (minutes)

- Number of sessions offered

In our CNMA, we compared the components to 'minimal intervention' (i.e. no smoking cessation support). For pair-wise comparisons from contributing reviews, the comparator group often included low-intensity interventions (e.g. self-help materials only, or one-off brief advice).

\section{Types of comparators}

We included reviews in the overview regardless of comparators investigated.

To be included in the CNMA, trials must have compared a behavioural intervention for smoking cessation with another behavioural intervention for smoking cessation or with a 'minimal' control (e.g. no treatment or a waiting list control).

\section{Types of outcome measures}

In accordance with standard methods from the Cochrane Tobacco Addiction Group, the primary outcome for this overview and CNMA was smoking cessation at six months or longer from baseline. The preferred measurement of cessation was biochemically validated continuous or prolonged abstinence, measured at the longest reported time point, and including all participants randomised in their original groups.
Studies of behavioural interventions for smoking cessation often do not measure adverse events. Where included reviews reported on adverse events, we summarised findings narratively.

\section{Search methods for identification of reviews}

To identify eligible reviews, we searched the Cochrane Database of Systematic Reviews (CDSR) in the Cochrane Library for any reviews with 'smoking' or 'tobacco' in the title, abstract, or keyword fields (most recent search 28 July 2020). Since Cochrane Reviews strive for methodological rigour and are regularly updated, we did not include non-Cochrane reviews in this overview.

We identified studies to include in the CNMA by screening the reviews that met our inclusion criteria. In one case (Carr 2012), the searches for the review had been updated by our information specialist but the published review update was not yet available; we summarised the published review in our overview, but included studies identified in the most recent search for the purposes of the CNMA. The review update of Carr 2012 will also include these studies, but we anticipate this update will be published after this overview.

We ran a separate search to identify relevant economic evidence (20 May 2019). This included:

- searching the NHS Economic Evaluation Database (EED) using the following terms: tobacco OR smok ${ }^{\star}$ OR cigaret* OR nicotine;

- searching MEDLINE, Embase, and CINAHL from 1 December 2015 , to capture any relevant evaluations published since NHS EED ceased being updated, using specialist search terms for economic evidence derived from Scottish Intercollegiate Guideline Network (SIGN) guidance ((SIGN 2018); see Appendix 1 for MEDLINE strategy).

\section{Data collection and analysis}

\section{Selection of reviews}

Two authors independently assessed all potentially eligible reviews for inclusion in the overview. We raised uncertainties with the broader project team, and the whole project team approved the final list of included reviews. We listed key excluded reviews in a table of excluded reviews, along with reasons for exclusion (Table $1)$.

\section{Selection of studies}

Two authors independently screened the included and excluded studies in each included review for inclusion in the CNMA. We resolved discrepancies through discussion or referral to a third author. We did not include ongoing studies identified from existing reviews in the CNMA, as these were not formally screened for inclusion by the original authors. We created a table listing studies included in the original reviews but excluded from the CNMA along with reasons for exclusion from the CNMA (S4 Excluded studies).

\section{Data extraction and management}

Two authors independently performed data extraction; we resolved disagreements by discussion or by referring to a third author. We extracted data in two stages: review level, and study level. Both are described in more detail below. We used Microsoft Excel 2016 (Redmond, WA) to collate the data. 


\section{Review level}

Review level data extraction followed the process used by Cahill 2013. Two authors independently extracted data and input them into a prespecified and piloted data extraction form, including details of the number of included studies, participants, interventions, comparisons, outcomes, and certainty in the evidence (as per GRADE 'Summary of findings' tables, where available).

\section{Study level}

We only extracted data from studies that were eligible for inclusion in the CNMA. We extracted the following characteristics for each study.

- Population: number randomised to each group; mean age across study population; percentage women across study population; presence of pre-existing conditions (defined as healthy or less-healthy based on inclusion criteria and whether pre-existing conditions were prevalent in demographic data); percentage pregnant; SES (defined as high or low depending on whether the majority of participants exceeded a high-school education); motivation to quit (determined by inclusion criteria: motivated to quit, seeking help to quit, or both; not motivated to quit; general population not selected on motivation); mean cigarettes per day at baseline.

- Intervention and comparator group content: behavioural components; nature of intervention focus (categorised as: intervention focused on reasons why a person might quit smoking; intervention focused on methods to quit smoking; intervention has approximately equal focus on both elements); nature of support provided (categorised as: addressing motivation; maximising self-regulation; promoting adjuvant activities, as per Michie 2011; categories are not mutually exclusive); delivery mode; setting; intervention provider; duration of intervention; session length; frequency of sessions; total number of sessions; tailoring; provision of financial incentives; type of pharmacotherapy provided.

- Risk of bias (see Assessment of risk of bias in included studies).

- Smoking cessation: number who quit in each group at longest follow-up using the strictest measure available; definition of cessation; number available at follow-up.

Two authors independently extracted data, first from information provided in the original reviews in which the studies were included, and then any information not supplied in the original review was extracted from the full-text study report. Some reviews had overlap (i.e. the same study was included in more than one review). We recorded where this was the case and data from each study was only used once in the CNMA. Where there were different assessments or data extracted for the same study, two authors extracted data from the original publication in duplicate.

\section{Assessment of methodological quality of included reviews}

Two authors independently assessed the quality of each review using the AMSTAR 2 measurement tool; disagreements were resolved by discussion or by referral to a third author (Shea 2017). Seven of the 16-items of the AMSTAR 2 tool were identified as critical domains, as defined in Shea 2017, due to their greater effect on the validity of review findings and as such, were weighted more heavily when rating overall confidence in the results of the review. One or more critical flaw, with or without non-critical weaknesses, resulted in an overall confidence rating of low or critically low, respectively.

Where overview authors were also authors on included reviews, two overview authors not involved in the original review conducted quality assessment for the review in question.

We did not exclude reviews on the basis of AMSTAR 2 ratings, but considered the ratings in our interpretation of our results.

\section{Assessment of risk of bias in included studies}

Where risk of bias had already been assessed for the studies in reviews included in the CNMA, we checked that this was performed consistently in accordance with Cochrane Tobacco Addiction Group guidance for assessing each domain. Where this had been done, we used these 'Risk of bias' assessments and did not re-evaluate. Where it appeared that the risk of bias guidance had not been consistently applied, or where specific domains had not been evaluated for specific reviews, two authors independently assessed risk of bias as part of the data extraction process, with discrepancies resolved by discussion or referral to a third author, where necessary.

For studies that required further assessment, we used the Cochrane 'Risk of bias' tool $v 1$ for the following domains: random sequence generation, allocation concealment, blinding of outcome measure, attrition, and other bias. Random sequence generation, allocation concealment, and other bias were assessed based on standard methods set out in the Cochrane Handbook for Systematic Reviews of Interventions (Higgins 2011). Following standard Cochrane Tobacco Addiction Group methods for reviews of behavioural interventions where blinding is not possible, we did not assess performance bias, and assessed detection bias in the following way.

- We judged studies to be at low risk of bias if smoking status was measured objectively (i.e. biochemical validation) or if smoking status was measured by self-report, but the intervention and control arms received similar amounts of face-to-face contact (or none).

- We judged studies to be at high risk of detection bias if smoking status was measured by self-report only, and participants in the intervention arm had more personal contact than in the control arm, as results may be prone to differential misreport.

Attrition is often substantial in smoking cessation trials. To assess attrition bias, we followed standard Cochrane Tobacco Addiction Group methods.

- We judged studies to be at low risk of bias when the following conditions were all met: numbers lost to follow-up were clearly reported for each group (not just overall, unless the overall percentage lost was less than $10 \%$ ); the overall number of participants lost was not greater than 50\%; and the difference in percentage followed up between groups was not greater than $20 \%$. We also considered results at low risk of attrition bias if the authors reported sensitivity analyses that indicated the overall direction of effect was not sensitive to different imputation methods for loss to follow-up.

- We judged studies to be at high risk of bias when the above thresholds were not met, or in the case of cluster-randomised trials, where entire clusters were not followed up. 
- We judged studies at unclear risk when the number lost to follow-up in each group was not clear, and authors did not report sensitivity analyses based on loss to follow-up.

We judged studies at low risk of bias overall if judged to be of low risk for all domains. We considered them at high risk of bias overall if they were judged to be at high risk of bias in one or more domains. We considered all other studies at unclear risk of bias overall. We presented the results of the risk of bias assessment in a 'Risk of bias' summary figure.

\section{Measures of treatment effect}

Included reviews, for the most part, reported smoking cessation at the longest follow-up using risk ratios (RR), calculated as: (number of quitters in intervention group/number randomised to intervention group)/(number of quitters in control group/number randomised to control group). In the CNMA, we reported pooled results as odds ratios (OR) with 95\% credibility intervals (Crls) as the statistical model described in Data synthesis is conducted on the log-OR scale, as in Cahill 2013. However, we also considered the absolute effect sizes implied by these pooled estimates.

\section{Unit of analysis issues}

For cluster-randomised trials, we used the effect size reported in the systematic review (or if not available, in the original trial paper), and checked that allowance for clustering was made in performing the analysis. In the majority of studies, the trial papers made allowance for clustering; otherwise, this was done in the review before the trial's results were entered into a meta-analysis.

If in a trial at least two arms shared the same components, these arms were combined into one. If in a trial at least two arms shared the same components but differed in the provision of pharmacotherapy (and included a comparison with additional $\operatorname{arm}(\mathrm{s})$ with pharmacotherapy), then we excluded the arms without the pharmacotherapy.

\section{Dealing with missing data}

Any participants lost to follow-up were assumed to be smoking, excluding deaths, as is standard in the field (West 2005), and is standard across reviews produced by the Cochrane Tobacco Addiction Group. For studies in the CNMA, we noted in the 'Risk of bias' tables the proportion of participants for whom the outcome was imputed in this way, and whether there was either high or differential loss to follow-up. The assumption that 'missing = smoking' provides conservative absolute quit rates, and makes little difference to the OR unless dropout rates differ substantially between groups.

\section{Assessment of reporting biases}

There is no established way of assessing reporting bias within CNMA. We extracted information from the included systematic reviews regarding any investigation or presence of reporting or publication bias.

\section{Data synthesis}

We synthesised data from the included reviews on both smoking cessation and adverse events (where reported), producing tables with key characteristics of each included review (title, publication year, number of included studies, number of included participants, key findings, and certainty in the evidence, where assessed) as per standard guidance for Cochrane Overviews (Pollock 2020). We did not attempt to standardise numerical results in this table, as data on effectiveness and comparative effectiveness was derived from the CNMA, and information on adverse events was heterogeneously measured and reported, precluding comparisons between interventions.

We used Bayesian CNMA and meta-regression (CNMR) randomeffects models, with adjustment for multi-arm studies, to evaluate the comparative effectiveness of the components identified above and draw conclusions about which components were most strongly associated with smoking cessation. We did not attempt to evaluate adverse events or harms using CNMA as most studies of behavioural interventions for smoking cessation do not record adverse events, and in those that do, event data is heterogeneously collected and summarised. Models were constructed similarly to those used by Freeman and colleagues (Freeman 2018) and adapted to include a binomial likelihood with logit link for binary outcome. The main results model included all motivational, behavioural, provider, and delivery components described earlier (excluding intensity components) and assumed their effects were additive (i.e. no interactions between components). The model including intensity components was run in a smaller sample, including only those trials that provided details on all intensity components.

Bayesian analyses were run using WinBugs version 1.4.3 (Cambridge, UK) and R (version 4.0.0) using the R2WinBUGS package (Sturtz 2005). For each model, three different chains with different initial values were run, each with at least 30,000 iterations, discarding the first 15,000 iterations and with the default thinning interval set by the R2WinBUGS package to compute summary estimates. Trace plots were used to evaluate convergence for each chain. Flat priors for the trials' baseline risks (defined as quit rates in control arms), component effects, and between-trial standard deviation (SD, measured on the log-odds scale) were chosen as in Freeman 2018. A common between-trial SD was assumed.

We analysed intensity variables for interventions which involved sessions (e.g. interventions such as counselling; interventions such as one-off print-mailings were not included in this analysis). Intensity variables were duration of intervention, total length of sessions, and number of sessions; we excluded studies that did not report data for all these three variables. This left 92 studies eligible for this analysis. We used a continuous model which assumes linearity; we a priori decided not to use a categorical model for this variable as some of the included studies involved incremental increases in intensity variables; collapsing into categories would have thus rendered arms from these studies ineligible for this analysis, which already had a substantially reduced sample size compared to the main analysis because of incomplete reporting in this area.

\section{Meta-regression}

In the CNMR, a common interaction between the covariates and each of the component effects was assumed (i.e. the same for each component), with flat priors. Models with independent component-specific interactions were also considered but as they did not indicate an improvement in fit, as measured by reduction in the Deviance Information Criterion (DIC), we opted for the simpler model assuming the same interaction effect for all components. All models were fitted in a sample of all trials with complete information for the selected covariate. Models including 
continuous covariates were centred on the mean of the covariate across all studies.

We considered the following as covariates, which were extracted (where available) for each trial.

- Mean age at baseline.

- Percentage female.

- Study setting: community or healthcare.

- SES, defined as a binary variable due to the variation in reporting across studies: 'low' where $50 \%$ or more of the study population had their highest level of education as high school or less or where mean years of education was less than or equivalent to completing high school in that country, or where income or deprivation level was reported instead of education, where $50 \%$ or more were below the median deprivation/income level for that community; 'high' where the opposite applied.

- Pre-exisiting conditions at baseline, defined as a binary variable due to variation in reporting across studies: 'low' was coded where the population was healthier than might be expected in a general population of smokers (e.g. studies in which both arms were given pharmacotherapy and study investigators excluded people with pre-existing health conditions); 'high' was coded where more than $50 \%$ of study participants reported preexisting conditions or where inclusion criteria were tailored to a less healthy population.

- Mean cigarettes per day at baseline.

- Length of follow-up.

- Quit rates in control arms (described as 'baseline risk'; we applied a continuity correction of 0.5 when fitting this covariate as the presence of arms with 0 events prevented convergence of the statistical model).

We had originally planned to also consider pregnancy and motivation to quit as covariates. In our final models, we did not analyse pregnancy, as no eligible studies reported including pregnant people. We also did not analyse motivation to quit, as it seemed likely that these trials mostly recruited people who were actively wanting to quit smoking, but this was not explicitly reported for most trials and so could not be inferred directly.

We did not conduct separate subgroup analyses, but where individual reviews present these data, we considered it when reporting their findings.

\section{Assessment of heterogeneity}

We considered heterogeneity between interventions first by examining how the contributing reviews reported heterogeneity. For pooled results from individual included reviews, we used the 12 statistic to represent heterogeneity. $I^{2}$ values over $50 \%$ are typically considered substantial. The 12 statistic cannot be used in CNMA, so for our CNMA, we considered the $95 \% \mathrm{Crl}$, the median betweentrial SD, and the DIC as indicators of heterogeneity and relative model fit. When adding variables to our analyses, we considered the impact they had on the SD and DIC. This informed our choice of which model to present as our primary model. We created contour plots to identify the studies contributing the most deviance. We then conducted three post hoc analyses to explore the impact of reducing possible causes of variation; these are described in more detail in the Results section.

\section{Sensitivity analysis}

We tested whether findings from our model were sensitive to the exclusion of studies at high overall risk of bias (based on risk of bias assessments for individual studies, not on overall quality or certainty judgements for the reviews in which they were contained), and whether they were sensitive to removal of the studies contributing the most deviance.

\section{Evaluating certainty of the evidence}

When included reviews used a GRADE approach to evaluate certainty of the evidence, we reported these findings in the overview.

We present three modified 'Summary of findings' tables presenting effect estimates and GRADE evaluations for each of the components, grouped as 1. behavioural/motivational components; 2. provider; 3 . delivery mode, using an adapted version of the approach set forward in Yepes-Nuñez 2019. The effect estimates and GRADE ratings in these tables refer to individual component effects, but, where relevant, we used data from pair-wise metaanalysis to inform rating decisions.

To the best of our knowledge, there is no agreed best method for evaluating certainty in CNMA. Therefore, we evaluated certainty for the component effect estimates by drawing upon the principles set for GRADE evaluations for network meta-analysis (Puhan 2014), with adaptations to assessment of some GRADE domains to better suit CNMA.

- We assessed risk of bias by evaluating whether the sensitivity analysis removing studies at high risk of bias meaningfully altered the effect estimate, by evaluating the risk of bias in studies that included the component of interest, and, where relevant, in the context of findings from pair-wise metaanalyses.

- We assessed imprecision using the Crls for individual components and number of events in studies including that component. We used predefined thresholds in which point estimates or Crls greater than 0.95 and less than 1.05 were judged to indicate no clinically significant difference.

- We assessed inconsistency by considering and comparing data from the original reviews which conducted pair-wise comparisons with the estimates from the CNMA.

- We assessed indirectness by considering data from both pairwise comparisons (as per the reviews included in the overview) and the CNMA, as well as considering the impact of covariates on component effect estimates.

- We assessed publication bias using judgements from the pairwise meta-analyses in the original included reviews, where possible.

\section{Incorporating economic evidence}

We developed a brief economic commentary to summarise the availability and principal findings of trial-based and modelbased full economic evaluations that compared the behavioural interventions of interest for smoking cessation in this overview (Shemilt 2020). The commentary focuses on the extent to which principal findings of eligible economic evaluations indicate that a behavioural intervention for smoking cessation might be judged favourably (or unfavourably) from an economic 
perspective when compared with other behavioural interventions for smoking cessation (which could include comparisons between interventions of a similar intensity, or between interventions of different intensities), when implemented in different settings.

Following Cochrane guidance, a single author screened and selected eligible studies and classified them by type and analytic framework (Higgins 2011). We extracted data on the analytic perspective, time horizon, main cost items (classified into health sector costs, other sector costs, patient and family costs, and productivity impacts), and setting, as well as on the principal findings (verbatim text on conclusions drawn by the author of each evaluation, and text summarising uncertainty surrounding authors' principal conclusions). We used these to inform the development of the brief economic commentary, which we included in the Discussion section of the review. We did not critically appraise any of the identified economic evaluations, as we did not attempt to draw any firm or general conclusions on the relative costs or efficiency of the included interventions.

\section{RES U L T S}

Note: some of the tables below are hosted on an open-access repository, as due to their size, incorporating them in the main text was not feasible. These are referred to as supplemental files throughout, annotated as S1, S2, etc., and can be found at: https:// doi.org/10.5287/bodleian:aZVzqNNk8.

\section{Results of the search}

We searched the Cochrane Library for eligible reviews in July 2020 and found 246 Cochrane Reviews. Of these, we included 33 reviews. See Figure 1 for a PRISMA flow diagram. For a summary of the characteristics of included reviews, see S1 Characteristics of included studies. 
Figure 1. Overview study flow diagram.

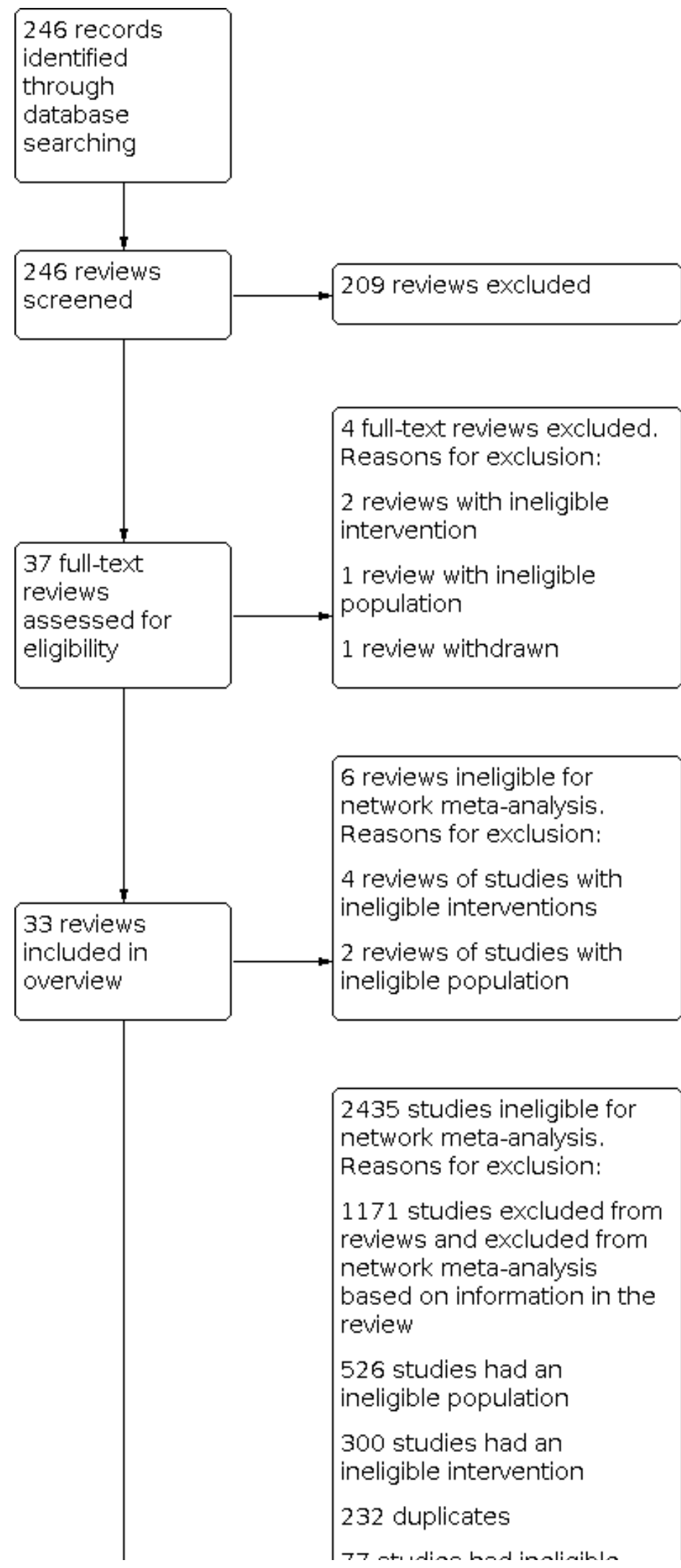


Figure 1. (Continued)

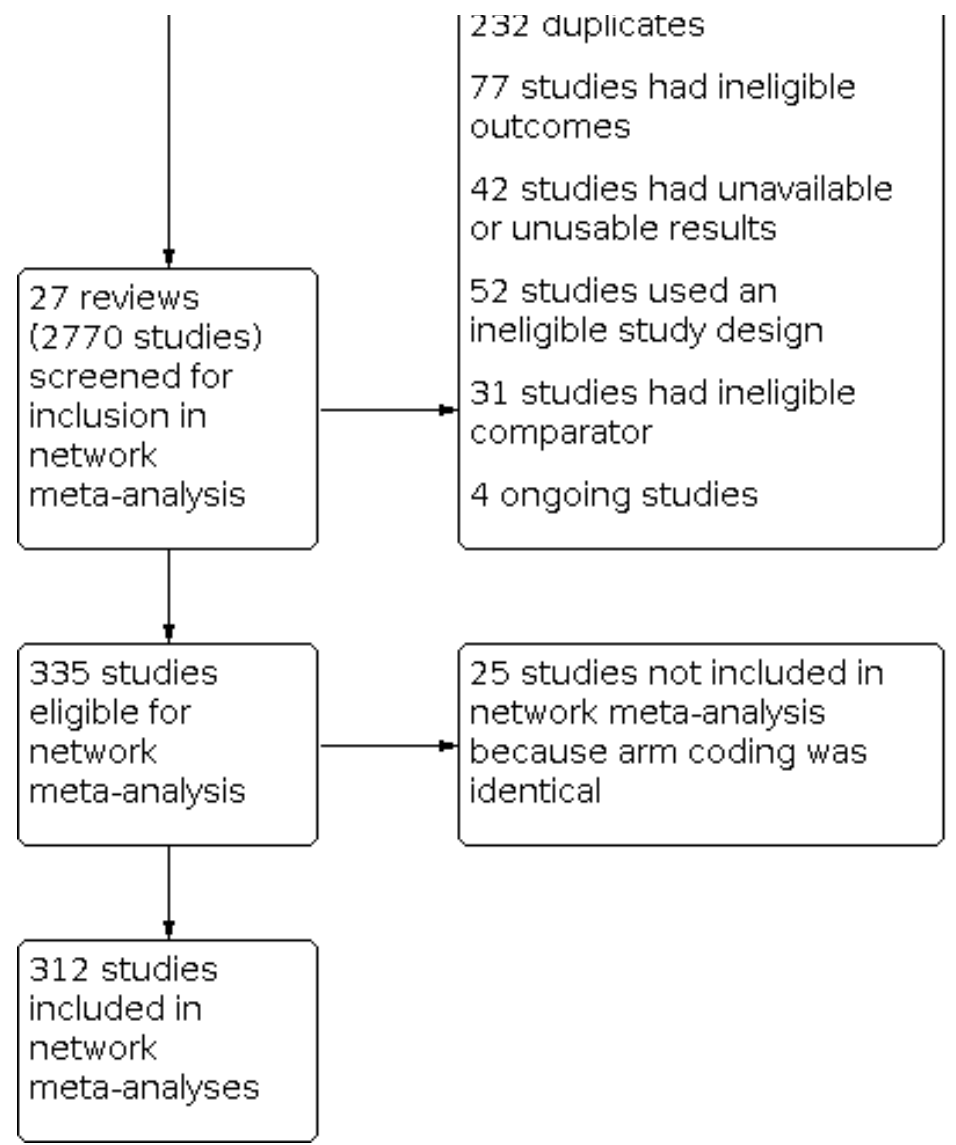

\section{Description of included reviews}

Reviews included from one to 104 studies of smoking cessation interventions, with a range of 615 to over 110,000 participants. In total, the reviews included 981 studies, with almost 600,000 participants. However, this included some double-counting (see 'Representation of and overlap between reviews').

Four reviews investigated several health behaviours, with smoking as one of them (Hollands 2010; Huibers 2007; Marteau 2010; Vodopivec-Jamsek 2012). We only considered the studies and analyses from these reviews that focused on smoking cessation.

Reviews typically searched a combination of the Cochrane Tobacco Addiction Group Specialised Register, CENTRAL, MEDLINE, Embase, PsycINFO, CINAHL, ClinicalTrials.gov, and the International Clinical Trials Registry Platform (ICTRP), with the most recent updates typically searching just the Register and clinical trial registries. The dates of the most recent searches ranged from November 2005 to August 2019.

\section{Population}

Reviews included studies of people who smoked tobacco cigarettes without restrictions on demographic information or motivation to quit. Livingstone-Banks 2019b also included studies of recent quitters, but these studies were not eligible for the CNMA. Five reviews focused on a wider range of health behaviours beyond smoking, and hence included non-smokers (though we were only interested in the smoking studies within them). Chamberlain
2017 focused on pregnant women who smoked, Maziak 2015 focused on people who smoke tobacco using waterpipes, Thomsen 2014 focused on smokers soon to undergo surgery, Behbod 2018 focused on adult smokers responsible for caring for children, and Cahill 2014 focused on employees who smoked. These reviews were not eligible for inclusion in the CNMA as the interventions they tested were not considered 'jointly randomisable' (e.g. a non-pregnant person could not be randomised to receive an intervention designed for pregnant people; someone without caring responsibilities could not be randomised to an intervention designed to protect children under their care from environmental tobacco exposure).

\section{Interventions}

We grouped the review interventions into four categories.

\section{Intervention type/modality}

Sixteen reviews investigated intervention modality. Three reviews looked at the effects of presenting smokers with test results that demonstrated exposure to, or damage from, smoking, or genetic disposition to risk from smoking-related disease (Clair 2019; Hollands 2010; Marteau 2010). Four reviews investigated the effects of smoking cessation counselling, delivered face-toface (Lancaster 2017; Stead 2017), via telephone (Matkin 2019), or via video call (Tzelepis 2019). Four reviews investigated self-help materials, including printed self-help materials (Livingstone-Banks 2019a), resources and reminders provided using mobile phone messages or apps (Vodopivec-Jamsek 2012; Whittaker 2019), 
or websites (Taylor 2017). Two reviews investigated the effects of rewarding smokers for quitting, through either guaranteed financial incentives (Notley 2019), or entry into competitions (Fanshawe 2019). Other intervention types included exercise-based interventions (Ussher 2019), and hypnotherapy (Barnes 2019). Hajek 2001 investigated the effect of aversive smoking on cessation.

\section{Intervention provider}

Five reviews focused on interventions delivered by specific providers. The providers were general practitioners (Huibers 2007), physicians (Stead 2013), nurses (Rice 2017), community pharmacy personnel (Carson-Chahhoud 2019), and dental professionals (Carr 2012).

\section{Theoretical basis}

Two reviews investigated interventions based on a specific theoretical basis. Lindson 2019a included studies testing motivational interviewing (MI). Cahill 2010 included studies testing interventions based on the stages of change model.

\section{Other focus}

Ten reviews investigated other intervention focuses. LivingstoneBanks 2019b investigated interventions intended to prevent relapse in smokers who had successfully quit, or as an addition to cessation interventions in current smokers. Faseru 2018 investigated smoking cessation support that incorporated a partner support component. Hollands 2019 investigated behavioural interventions intended to improve adherence to pharmacotherapy. Lindson 2019b investigated smoking reduction as a method of quitting smoking. Hartmann-Boyce 2019 investigated the effect of behavioural interventions provided in addition to cessation pharmacotherapy. Chamberlain 2017 investigated behavioural interventions for pregnant women who smoke. Maziak 2015 investigated behavioural interventions for people who smoke tobacco using waterpipes. Thomsen 2014 investigated behavioural interventions for smokers soon to undergo surgery. Behbod 2018 investigated behavioural interventions targeting adult smokers responsible for caring for children, with a goal of reducing the children's exposure to environmental tobacco smoke. Cahill 2014 investigated workplace interventions designed to help employees quit smoking.

\section{Comparators}

Comparators in the included reviews included: no-intervention, usual or standard care, less intensive versions of the tested interventions, and alternative interventions (of equal or lower intensity, potentially with a different theoretical basis or intervention provider).

\section{Outcomes}

All reviews measured tobacco use abstinence, in most cases at six months or longer. Eleven reviews measured some form of adverse events. Some reviews included other outcomes, such as short-term abstinence, number of quit attempts, and quality of life measures. All additional outcomes are reported in S1 Characteristics of included studies.

\section{Study types}

All reviews included randomised controlled trials, with some also including quasi-randomised studies. Vodopivec-Jamsek 2012 also included controlled before-after studies and interrupted time series with at least three time points before and after the intervention.

\section{Excluded reviews}

We excluded four potentially relevant reviews at the full-text screening stage. Two reviews had ineligible interventions: one focused on preventing weight gain rather than smoking cessation (Farley 2012), and the other only included one study that addressed smoking, but this was as part of a multi-behaviour intervention (Dale 2008). One review focused on an ineligible population (i.e. adolescents only) (Fanshawe 2017), and one review was withdrawn from the Cochrane Library (Cahill 2008) because it had been superseded by another review included in this overview (Fanshawe 2019). We list reasons for exclusion in Table 1.

\section{Description of included studies}

Three-hundred and thirty-five randomised controlled trials from 26 reviews met the initial inclusion criteria for our CNMA (see PRISMA diagram: Figure 1). Twenty-three of these studies were excluded because participants were randomised to interventions which did not differ on the components of interest (see Table 2). Therefore, 312 studies were eligible for inclusion in the final analyses, representing 845 study arms and 250,563 participants. Characteristics of these studies are summarised below. S2 Details of included studies contains further details on study and intervention characteristics as they related to our analysis, as well as information on the review from which initial data were extracted ('Primary review' column). Seventeen eligible studies were identified from excluded studies lists of included reviews; further contextual information on these studies can be found in S3 Additional characteristics of previously excluded studies. For contextual information on characteristics of all other included studies, readers are encouraged to refer to the original review from which the study was identified.

\section{Population}

Most studies took place in the USA or Western Europe; 115 studies took place in healthcare settings and 195 in community settings. The median number of study participants per arm was 173 (range 7 to 3357). The median age of study participants was 42 years (range 18 to 63 ) in the 277 studies which reported it; the median percentage of women was 54\% (range $0 \%$ to 100\%). Of the 179 studies that reported it, 109 enrolled a population where the majority of participants were of high SES according to our criteria. Of the 668 studies which reported data on pre-existing conditions, 51 were judged to be 'healthy' as per the methods set out above. No studies mentioned including pregnant people; 65 explicitly stated that they excluded this group. In the 237 studies which reported it, the median number of cigarettes smoked per day at baseline was 20 (range 3.5 to 37). Thirty-six studies recruited people already seeking help to quit, an additional 104 were restricted to participants motivated to quit, eight explicitly recruited people who were not interested in quitting smoking, and the remainder did not report selection based on motivation.

\section{Interventions and comparators}

We considered comparator groups to also represent interventions, and hence descriptions here apply to all study arms. Sixty-one studies had control arms which included no smoking cessation support whatsoever (i.e. no behavioural components, and no 
pharmacotherapy) ("minimal interventions"); this category is used as the reference group in the CNMA. Components are summarised in Table 3 and Figure 2. Of the 603 study arms that reported intervention duration, the median duration was eight weeks (range zero to 104). Of the 350 arms where length of session was relevant and reported, the median length was 18 minutes (range eight to 180). In the 602 arms where number of sessions was relevant and reported, the median number offered was four (range zero to 64). We restricted studies to those where pharmacotherapy was equivalent across arms: 71 studies offered nicotine replacement therapy, seven offered bupropion, two offered varenicline, 26 offered other pharmacotherapies or a combination of pharmacotherapies, and the remainder did not involve pharmacotherapy.

Figure 2. Heat map showing frequency and combinations of components across study arms. The numbers indicate the number of study arms included in the network meta-analysis that contained the components in the corresponding row and column. For cells where the row and column component are the same, the frequency of that component is shown. app: mobile phone application; audio: audio recording; IVR: interactive voice response; SMS: short messaging service (text message); Web: Internet.

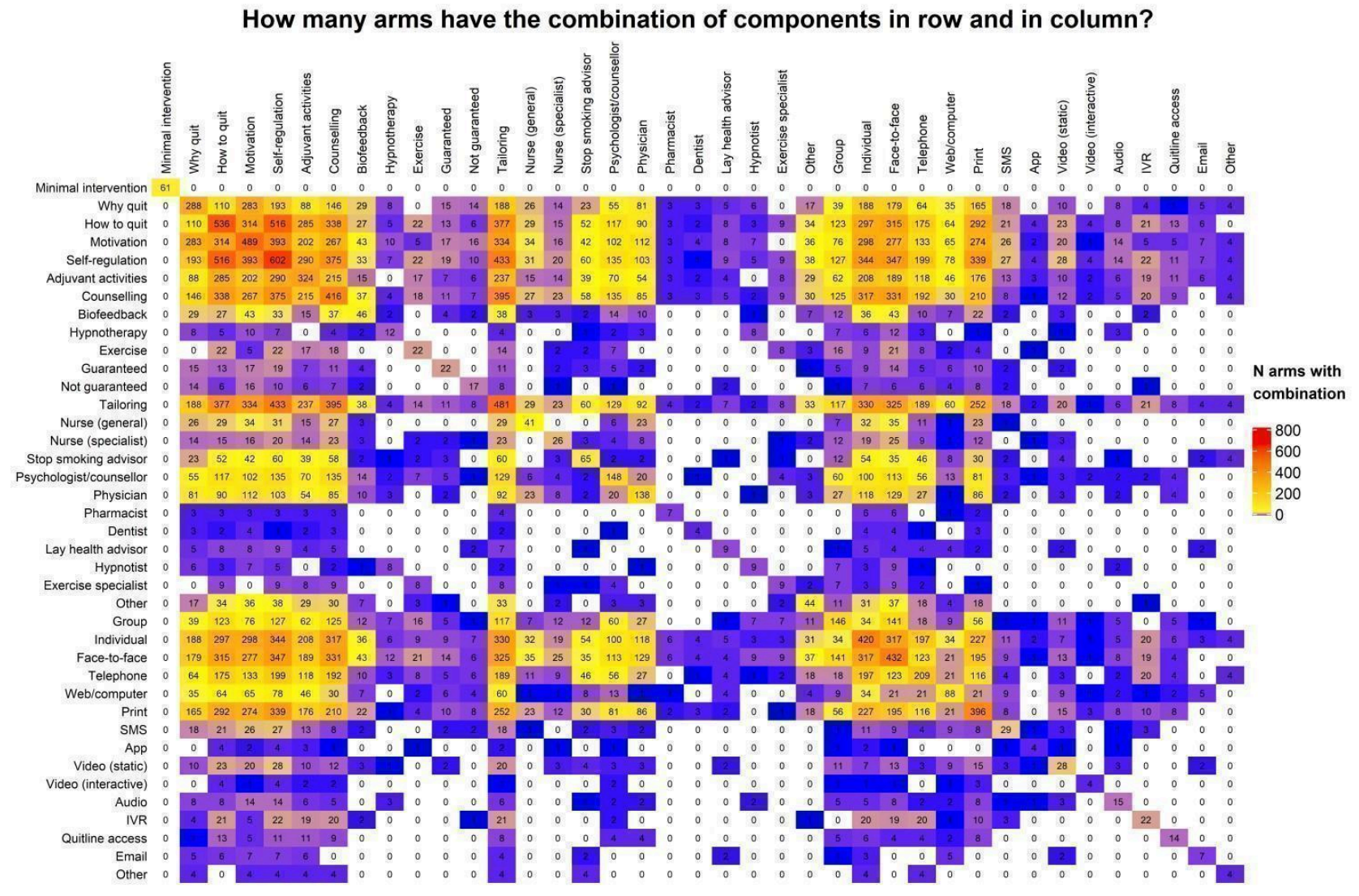

\section{Outcomes}

The mean length of follow-up for included studies was 10.5 months (range six to 34). One hundred and sixty-eight studies biochemically validated smoking status. Two-hundred and eighty studies reported how abstinence was defined; of these, 149 used point prevalence and the remainder used a measure of sustained (56 studies), prolonged (23 studies), or continuous (52 studies) abstinence.

\section{Excluded studies}

Of the 2770 studies included in or listed as excluded from the included reviews, 2433 were ineligible for our CNMA. Following deduplication (removal of 230 studies) and removal of 1171 studies identified as irrelevant based on information reported in the reviews, the primary reasons for exclusion were ineligible population (526 studies); ineligible intervention (300 studies), and ineligible outcomes (77 studies). Further details can be found in S4 Excluded studies.

\section{Representation of and overlap between reviews}

Many trials were included in two or more of the included reviews. This is illustrated by the 337 studies which met our inclusion criteria for our CNMA. Of these, 94 were included in two reviews and 19 were included in three reviews.

The number of eligible studies included in the CNMA from each review can be seen in Figure 3. 
Figure 3. Number of included studies in the network meta-analysis, per included review. Note, many studies were included in more than one review.

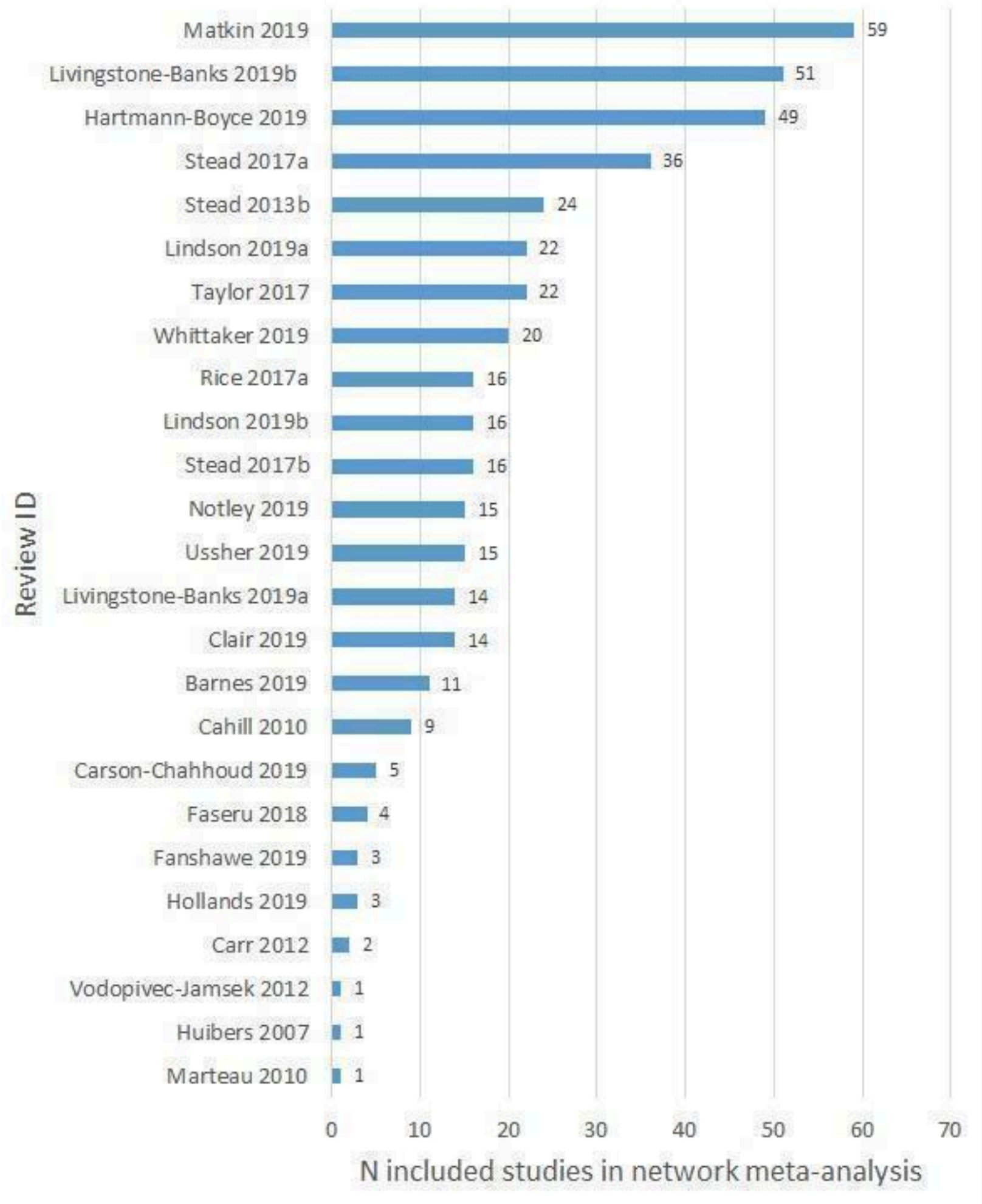

\section{Methodological quality of included reviews}

AMSTAR 2 ratings for the included reviews are summarised in S5 AMSTAR2 judgements. Of the 33 included reviews, the majority had an overall AMSTAR 2 rating of low (15 reviews) or critically low (five reviews) confidence in review results because of at least one critical weakness. Nine reviews were rated moderate and four rated high. 
Of the critical domains, 18/33 reviews had accessible protocols. An additional 14 reviews reported a protocol publication date with or without discussion of protocol deviations which also suggests an a priori protocol was followed. All reviews used a comprehensive literature search strategy, but some reviews only partially adhered to this standard because the authors did not report searching the reference lists of included studies or did not consult content experts in the field, or both. All review authors provided a list of excluded studies with justifications for exclusions, and most reviews reported an appropriate method for statistical combination of results when meta-analyses were performed. Thirteen reviews reported satisfactory techniques for assessing risk of bias in individual studies. This standard was partially met by an additional 15 review authors who did not assess for selective reporting. Thirty-one reviews discussed the impact of risk of bias in individual studies, but only 14 reviews adequately investigated and discussed the impact of publication bias on review findings.

Of the non-critical domains, the majority of reviews included the components of PICO in their research questions and inclusion criteria, although only one review provided an explanation for their selection of study designs (which in most cases was solely randomised controlled trials). Most reviews performed study selection and extraction in duplicate, but six reviews provided inadequate descriptions of the study settings, population or comparator (or both) groups of included studies. When metaanalysis was conducted, most review authors investigated the potential impact of risk of bias in individual studies on results and satisfactorily explained any heterogeneity observed. Thirty of the 33 reviews reported on sources of conflict of interest and adequately discussed how this was managed, when necessary.

\section{Risk of bias in included studies}

Risk of bias ratings for the studies eligible for the CNMA can be found in S2 Details of included studies. Reasons for these judgements as they apply to individual studies can be found in the primary reviews from which the studies were identified. A subset of studies was listed in included reviews but did not have full risk of bias assessments; reasons for risk of bias judgements for these studies can be found in S3 Additional characteristics of previously excluded studies and in S6 Additional risk of bias domains for the two reviews (Rice 2017; Stead 2013), which did not originally assess all core domains as set out above. Overall, $50 / 312$ included studies were judged at low risk of bias (low risk across all domains), 125 were judged at high risk of bias (high risk in at least one domain), and 137 were judged at unclear risk of bias. A summary of the risk of bias judgements for individual domains can be found in Figure 4. Most studies were at unclear risk of selection bias due to inadequate reporting of methods for random sequence generation or allocation concealment (or both). The domain contributing the most 'high risk' judgements was blinding of outcome assessment; in 72 studies, detection bias was a potential issue to differential amounts of support between study arms and self-reported outcome measures, introducing the risk of differential misreport, though the majority of studies were still at low risk in this domain (216/312 studies). The majority of studies (221/312) were also at low risk of attrition bias, 55 did not provide sufficient information with which to judge, and 36 were at high risk due to substantial attrition overall or substantial differences in attrition rates by study arm. We only assessed 'other risk of bias' when we suspected it to be present.

Figure 4. Risk of bias judgements for studies included in the network meta-analysis by domain.

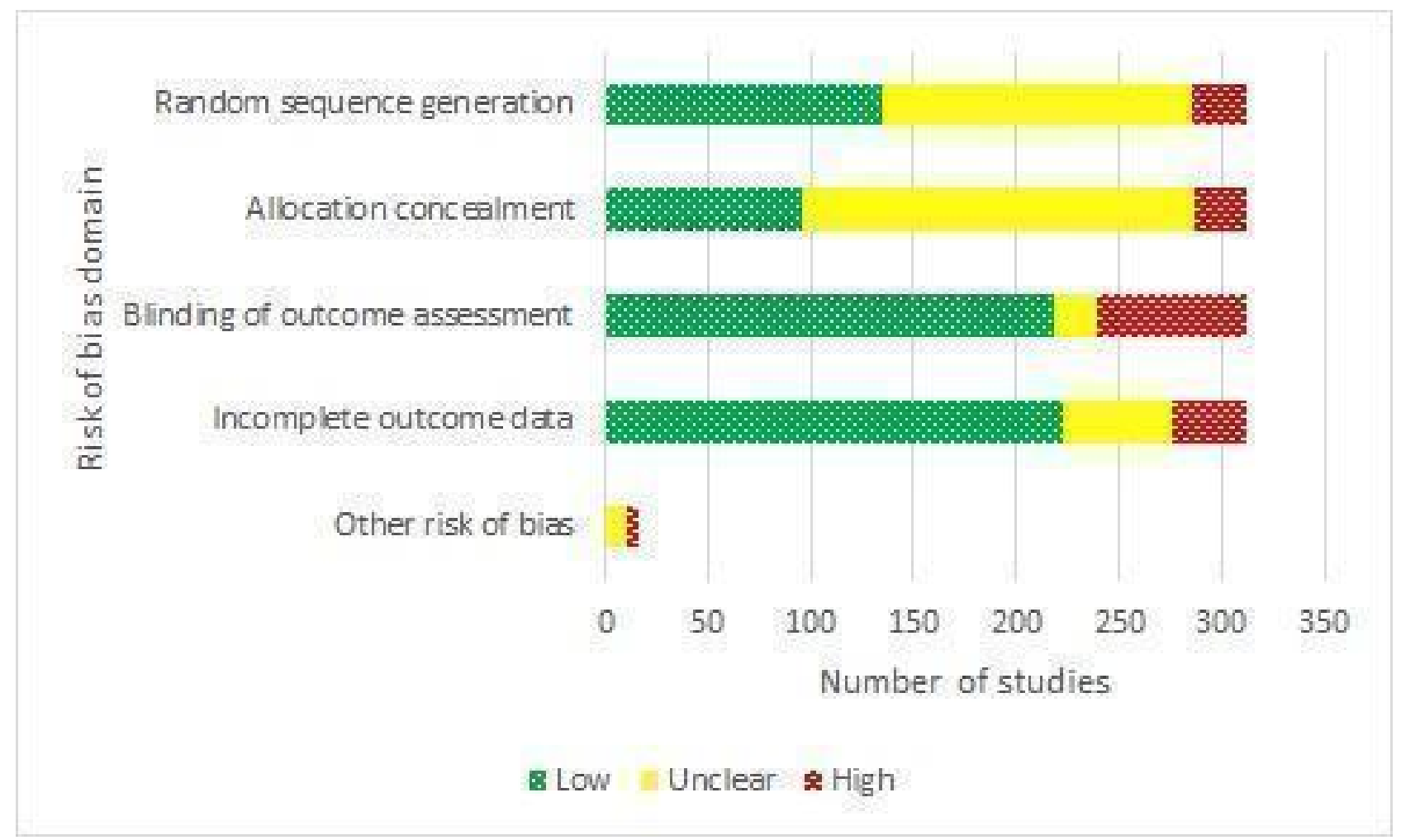




\section{Effect of interventions}

Below we report information on the effects of the interventions on cessation (reviews and CNMA) and adverse events (reviews only). Additionally, findings from the primary analyses in each included review as they relate to the outcomes and interventions of interest for this overview can be found in S7 Details of primary analyses from included studies. Where reviews reported multiple outcomes or comparisons of relevance to our research questions, we focused on the main findings from the individual reviews as identified in their 'Summary of findings' tables. If 'Summary of findings' tables were not available, we completed the table using findings reported in the review abstracts. Some reviews reported findings beyond those reported in their 'Summary of findings' tables. In these instances, the review findings summarised below go beyond those reported in table S7 Details of primary analyses from included studies.

\section{Cessation}

\section{Review findings}

Intervention type/modality

\section{Effect(s) detected}

Livingstone-Banks 2019a found moderate-certainty evidence that when no other support was available, printed self-help materials helped more people to stop smoking than no intervention (RR 1.19, $95 \%$ confidence interval $(\mathrm{Cl}) 1.03$ to $1.37 ; \mathrm{I}^{2}=0 \% ; 11$ studies, $\mathrm{n}$ $=13,241)$. However, there was no evidence that printed materials increased cessation compared with not providing them when participants also received advice from a health professional or use of nicotine replacement therapy (RR $0.99,95 \% \mathrm{Cl} 0.76$ to 1.28 ; $\mathrm{R}^{2}=32 \% ; 11$ studies, $\left.\mathrm{n}=5365\right)$. They found moderate-certainty evidence that tailored self-help materials were more effective than no intervention (RR $1.34,95 \% \mathrm{Cl} 1.19$ to $1.51 ; \mathrm{I}^{2}=0 \% ; 10$ studies, $n=14,359)$. However, when compared with non-tailored materials delivered with the same amount of contact, there was no evidence of benefit (RR $1.07,95 \% \mathrm{Cl} 0.89$ to $1.30 ; \mathrm{I}^{2}=50 \% ; 10$ studies, $\mathrm{n}=$ 11,024).

Stead 2017 reported a benefit of group counselling compared with self-help (RR 1.88, 95\% Cl 1.52 to 2.33 ; $\left.\right|^{2}=0 \% ; 13$ studies, $n=4395$; moderate-certainty evidence), and brief support (RR $1.25,95 \% \mathrm{Cl}$ 1.07 to $1.46 ;\left.\right|^{2}=60 \% ; 16$ studies, $n=7601$; low-certainty evidence). However, they found no evidence of a difference between group and individual counselling (RR $1.11,95 \% \mathrm{Cl} 0.93$ to $1.33 ; \mathrm{I}^{2}=0 \% ; 5$ studies, $n=1523$; moderate-certainty evidence).

Lancaster 2017 found high-certainty evidence that individually delivered smoking cessation counselling can assist smokers to quit compared with usual care, brief advice, or self-help materials (RR $1.57,95 \% \mathrm{Cl} 1.40$ to $1.77 ; 1^{2}=0 \% ; 27$ studies, $n=11,100)$. They also reported smaller relative benefits when counselling was provided as an adjunct to pharmacotherapy compared with pharmacotherapy plus usual care, brief advice, or self-help materials (RR $1.24,95 \% \mathrm{Cl} 1.01$ to $1.51 ; \mathrm{I}^{2}=0 \% ; 6$ studies, $\mathrm{n}=2662$; moderate-certainty evidence), and of more-intensive counselling compared with less-intensive counselling (RR 1.29, 95\% $\mathrm{Cl} 1.09$ to $1.53 ; \mathrm{I}^{2}=48 \%$; 11 studies, $\mathrm{n}=2920$; high-certainty evidence).
Taylor 2017 found evidence that interactive and tailored Internetbased interventions provided increased abstinence compared with non-active controls, both when as an adjunct to behavioural support (RR 1.69, $95 \% \mathrm{Cl} 1.30$ to $2.18 ; \mathrm{I}^{2}=60 \%$; 5 studies, $\mathrm{n}=2334$; moderate-certainty evidence), or without additional behavioural support (RR 1.15, 95\% Cl 1.01 to 1.30; $\left.\right|^{2}=58 \%$; 8 studies, $n=6786$; low-certainty evidence). However, compared with another smoking cessation intervention, there was no evidence of a benefit from Internet-based interventions with additional behavioural support (RR $1.00,95 \% \mathrm{Cl} 0.84$ to $1.18 ; \mathrm{I}^{2}=0 \%$; 4 studies, $\mathrm{n}=2769$; moderatecertainty evidence), or without additional behavioural support (RR $0.92,95 \% \mathrm{Cl} 0.78$ to $1.09 ; \mathrm{I}^{2}=0 \%$; 5 studies, $\mathrm{n}=3806$; moderatecertainty evidence). They also found no evidence of a benefit when comparing tailored and interactive interventions with non-tailored non-interactive comparators, for Internet programmes (RR 1.10, $95 \% \mathrm{Cl} 0.99$ to $1.22 ; \mathrm{I}^{2}=0 \% ; 7$ studies, $\mathrm{n}=14623$; moderate-certainty evidence) or Internet messaging (RR $1.17,95 \% \mathrm{Cl} 0.97$ to $1.41 ; 1^{2}=$ 57\%; 3 studies, $n=4040$; low-certainty evidence).

Notley 2019 reported high-certainty evidence that, compared with no incentives, guaranteed financial incentives improved smoking cessation rates in general-population smokers (RR 1.49, 95\% Cl 1.28 to $1.73 ; 1^{2}=33 \% ; 33$ comparisons from 30 studies, adjusted $n=$ $20,097)$, and moderate-certainty evidence of benefit in pregnant people who smoked (RR $2.38,95 \% \mathrm{Cl} 1.54$ to $3.69 ;\left.\right|^{2}=41 \%$; 9 studies, $n=2273)$.

Whittaker 2019 reported moderate-certainty evidence of benefit from automated text message-based smoking cessation interventions compared with minimal support (RR $1.54,95 \% \mathrm{Cl} 1.19$ to $2.00 ; 1^{2}=71 \% ; 13$ studies, $n=14,133$ ). They also found moderatecertainty evidence of benefit from text messaging interventions as an adjunct to cessation support compared with cessation support alone (RR $1.59,95 \% \mathrm{Cl} 1.09$ to $2.33 ; \mathrm{l} 2=0 \% ; 4$ studies, $\mathrm{n}=997$ ). However, they did not detect a benefit from smartphone apps compared with less-intensive support (RR 1.00, 95\% Cl 0.66 to 1.52; $\mathrm{I}^{2}=59 \%$; 5 studies, $\mathrm{n}=3079$; very low-certainty evidence).

Matkin 2019 found moderate-certainty evidence that, compared with self-help materials or brief counselling at a single call, proactive telephone counselling aided smokers who sought help from quitlines (RR $1.38,95 \% \mathrm{Cl} 1.19$ to $1.16 ; \mathrm{I}^{2}=72 \%$; 14 studies, $n=32,484)$, and moderate-certainty evidence of benefit in other settings (RR $1.25,95 \% \mathrm{Cl} 1.15$ to $1.35 ; \mathrm{I}^{2}=52 \%$; 65 studies, $\mathrm{n}$ $=41,233)$. Subgroup analysis investigating potential variation in effect from differences in the number of contacts, type or timing of telephone counselling, or when telephone counselling was provided as an adjunct to other smoking cessation therapies, found no evidence of a difference between subgroups $(P=0.21,12=33 \%)$.

\section{No effect detected/effect very uncertain}

None of the three reviews testing risk assessment feedback detected clear evidence of an effect. Clair 2019 found no evidence of a benefit of biomedical risk assessment feedback for smoking cessation compared with standard care or minimal intervention. They found moderate-certainty evidence narrowly missing a benefit of spirometry and carotid ultrasound test results to show the harm of smoking (RR $1.26,95 \% \mathrm{Cl} 0.99$ to $1.61 ; \mathrm{I}^{2}=34 \%$; 11 studies, $n=3314)$. There was moderate-certainty evidence on the effect of feedback on smoking exposure by carbon monoxide monitoring (RR $1.00,95 \% \mathrm{Cl} 0.83$ to $1.21 ; \mathrm{I}^{2}=0 \% ; 5$ studies, $\mathrm{n}=2368$ ). 
There was low-certainty but no evidence of benefit from feedback on smoking-related risk by genetic marker testing (RR $0.80,95 \% \mathrm{Cl}$ 0.63 to $1.01 ; 12=0 \% ; 5$ studies, $n=2064$ ). Hollands 2010 pooled three studies testing visual feedback and explanation of individuals' medical imaging results compared with mixed control conditions and detected a benefit (OR $2.81,95 \% \mathrm{Cl} 1.23$ to $6.41 ; \mathrm{I}^{2}=0 \%$; $\mathrm{n}$ $=214$; GRADE evaluation not performed). However, they reported that due to limited available evidence, no strong statements could be made about the effectiveness of communicating medical imaging results to change health behaviour. Marteau 2010 did not detect a benefit from communicating DNA-based disease risk estimates for smoking cessation when compared with non-DNAbased disease risk estimates or no estimate (OR 1.03, 95\% Cl 0.66 to $1.61 ; 1^{2}=50 \% ; 5$ studies, $n=2166$; GRADE evaluation not performed).

Fanshawe 2019 found no evidence of a benefit from performancebased eligibility competitions (RR $1.16,95 \% \mathrm{Cl} 0.77$ to 1.74 ; $\mathrm{I}^{2}=57 \% ; 6$ studies, $\mathrm{n}=3201$; very low-certainty evidence), or from performance-based reward competition ( 5 studies, unable to pool due to clinical and methodological heterogeneity) compared with no intervention or non-competition-based smoking cessation interventions.

Ussher 2019 found no evidence that adding exercise to smoking cessation support improved abstinence compared with support alone (RR $1.08,95 \% \mathrm{Cl} 0.96$ to $1.22 ;\left.\right|^{2}=0 \% ; 21$ studies, $\mathrm{n}=6607$; lowcertainty evidence).

Barnes 2019 found no evidence of a benefit from hypnotherapy for smoking cessation compared with attention-matched behavioural support (RR $1.21,95 \% \mathrm{Cl} 0.91$ to $1.61 ; \mathrm{I}^{2}=36 \% ; 6$ studies, $\mathrm{n}=957$; low-certainty evidence), brief advice (RR $0.98,95 \% \mathrm{Cl} 0.57$ to 1.69 ; $\mathrm{I}^{2}=0 \% ; 2$ studies, $\mathrm{n}=269$; very low-certainty evidence), or intensive behavioural support ( $\mathrm{RR} 0.93,95 \% \mathrm{Cl} 0.47$ to $1.18 ; \mathrm{I}^{2}=0 \% ; 2$ studies, $\mathrm{n}=211$; very low-certainty evidence). They did detect a benefit when hypnotherapy was compared with no treatment (RR 19, 95\% $\mathrm{Cl} 1.18$ to 305.88 ; 1 study, $\mathrm{n}=40$; very low-certainty evidence). However, this was based on a single study of which they judged the certainty of evidence to be very low.

Hajek 2001 did detect a statistical benefit from aversive rapid smoking for smoking cessation compared with attention-matched placebo (OR 2.01, 95\% Cl 1.36 to $2.95 ; \mathrm{I}^{2}=0 \% ; 12$ studies, $\mathrm{n}$ = 536; GRADE evaluation not performed). However, despite this, the authors recommended interpreting this result with caution because of suspected publication bias and serious problems with study methods that the authors deemed likely to lead to spurious positive results. They concluded that there was insufficient evidence to determine the efficacy of rapid smoking.

Two other reviews examined methods of offering behavioural support for cessation, finding no evidence of effectiveness, but with substantial imprecision due to small numbers of included studies. Tzelepis 2019 found no evidence of a difference between video counselling and telephone counselling for assisting people to quit smoking (RR 2.15, $95 \% \mathrm{Cl} 0.38$ to $12.04 ; \mathrm{I}^{2}=66 \% ; 2$ studies, $\mathrm{n}=$ 608 ; very low-certainty evidence). Vodopivec-Jamsek 2012 found only one study of preventive healthcare mobile phone messaging interventions for smoking cessation compared with usual care, which favoured the intervention.

\section{Intervention provider}

\section{Effect(s) detected}

Stead 2013 reported that brief advice from a physician, compared with usual care or no advice, increased cessation rates (RR 1.76, $95 \% \mathrm{Cl} 1.58$ to $1.96 ; \mathrm{I}^{2}=40 \% ; 26$ studies, $\mathrm{n}=22,239$; GRADE evaluation not performed).

Rice 2017 reported moderate-certainty evidence that, compared with usual care or minimal intervention, behavioural support to motivate and sustain smoking cessation delivered by nurses could lead to a modest increase in the number of people who achieve prolonged abstinence (RR $1.29,95 \% \mathrm{Cl} 1.21$ to $1.38 ; \mathrm{I}^{2}=50 \% ; 44$ studies, $n=20,881$ ).

Carson-Chahhoud 2019 reported that community pharmacists can provide effective behavioural smoking cessation support compared with lower-intensity support (RR $2.30,95 \% \mathrm{Cl} 1.33$ to $3.97 ;\left.\right|^{2}=54 \%$; 6 studies, $n=1614$; low-certainty evidence).

Carr 2012 reported that, compared with usual care, no contact, or less-intensive treatment, oral health professionals providing a behavioural intervention to support tobacco cessation alongside oral care may increase tobacco abstinence rates among both cigarette smokers and smokeless tobacco users (adjusted OR 1.71, $95 \% \mathrm{Cl} 1.44$ to $2.03 ; \mathrm{I}^{2}=61 \% ; 14$ studies, $\mathrm{n}=10,535 ;$ GRADE evaluation not performed).

\section{No effect detected/effect very uncertain}

Huibers 2007 only found two studies of the use of psychosocial interventions by general practitioners for smoking cessation, and were unable to pool results because of statistical and methodological heterogeneity. Both tested a more-intensive intervention against a single contact control, and each favoured the intervention.

\section{Theoretical basis}

\section{Effect(s) detected}

Cahill 2010 found that stage-based counselling interventions were effective for promoting smoking cessation compared with any standard self-help materials (RR 1.27, 95\% Cl 1.01 to 1.59 ; $\left.\right|^{2}=28 \%$; 6 studies, $n=5947$; GRADE evaluation not performed), but were neither more nor less effective that non-stage-based counselling interventions ( $\mathrm{RR} 1.00,95 \% \mathrm{Cl} 0.82$ to $1.22 ; \mathrm{I}^{2}=0 \%$; 2 studies, $\mathrm{n}=$ 1138; GRADE evaluation not performed). They also did not detect a benefit from stage-based self-help materials compared with nonstage-based materials (RR $0.93,95 \% \mathrm{Cl} 0.62$ to $1.39 ; \mathrm{I}^{2}=21 \% ; 2$ studies, $n=2117$; GRADE evaluation not performed).

\section{No effect detected/effect very uncertain}

Lindson 2019a found insufficient evidence to determine whether MI helps people to stop smoking compared with no intervention (RR $0.84,95 \% \mathrm{Cl} 0.63$ to $1.12 ; \mathrm{I}^{2}=0 \% ; 4$ studies, adjusted $\mathrm{n}=684$; lowcertainty evidence), as an addition to other types of behavioural support for smoking cessation (RR $1.07,95 \% \mathrm{Cl} 0.85$ to 1.36 ; 12 $=47 \%$; 12 studies, adjusted $n=4167$; low-certainty evidence), or compared with other types of behavioural support for smoking cessation (RR 1.24, 95\% Cl 0.91 to $1.69 ; 1^{2}=54 \% ; 19$ studies, $n=5192$; low-certainty evidence). They also found inconclusive evidence of possible benefit of higher- compared with lower-intensity MI (RR 
$1.23,95 \% \mathrm{Cl} 1.11$ to $1.37 ; \mathrm{I}^{2}=0 \% ; 5$ studies, adjusted $\mathrm{n}=5620 ;$ lowcertainty evidence).

\section{Other focus}

\section{Effect(s) detected}

Hollands 2019 reported that, in people who were stopping smoking and receiving behavioural support, enhanced behavioural support focusing on adherence to smoking cessation medications could modestly improve adherence (standardised mean difference (SMD) $0.10,95 \% \mathrm{Cl} 0.03$ to $0.18 ; \mathrm{I}^{2}=6 \% ; 10$ studies, $\mathrm{n}=3655$; moderatecertainty evidence) compared with behavioural support without this focus. They found low-certainty evidence of benefit for cessation, both short-term (RR $1.08,95 \% \mathrm{Cl} 0.96$ to $1.21 ; 12=0 \% ; 5$ studies, $\mathrm{n}=1795$; low-certainty evidence), and at six month or more (RR $1.16,95 \% \mathrm{Cl} 0.96$ to $1.40 ; \mathrm{I}^{2}=48 \%$; 5 studies, $\mathrm{n}=3593$; lowcertainty evidence).

Hartmann-Boyce 2019 found high-certainty evidence that providing behavioural support in person or via telephone for people using pharmacotherapy to stop smoking increased quit rates compared with not providing that support (RR $1.15,95 \% \mathrm{Cl}$ 1.08 to $1.22 ;\left.\right|^{2}=8 \% ; 65$ studies, $n=23,331$ ).

Chamberlain 2017 reported a benefit from psychosocial smoking cessation interventions in pregnant women both in pregnancy (RR $1.35,95 \% \mathrm{Cl} 1.23$ to $1.48 ; \mathrm{I}^{2}=44 \%$; 97 studies, $\mathrm{n}=26,637$; moderate-certainty evidence), and postpartum, compared with not providing support for smoking cessation (RR $1.32,95 \% \mathrm{Cl} 1.17$ to $1.50 ; 1^{2}$ not reported; 35 studies, $\mathrm{n}=8366$; high-certainty evidence).

Thomsen 2014 reported that providing behavioural support prior to planned surgery increased abstinence at the time of surgery compared with no cessation support or brief advice to stop. The effect appeared larger for intensive support (RR 10.76, 95\% Cl 4.55 to $25.46 ; 1^{2}=0 \%$; 2 studies, $\mathrm{n}=210$; moderate-certainty evidence), than brief support ( $\mathrm{RR} 1.30,95 \% \mathrm{Cl} 1.16$ to $1.46 ; \mathrm{I}^{2}=75 \% ; 7$ studies, $\mathrm{n}=1141$; high-certainty evidence).

Cahill 2014 reported a benefit of workplace-based smoking cessation support compared with less-intensive or no support in groups (OR $1.71,95 \% \mathrm{Cl} 1.05$ to $2.80 ; \mathrm{I}^{2}=15 \%$; 8 studies, $\mathrm{n}=$ 1309; moderate-certainty evidence), and individually (OR 1.51, 95\% Cl 1.51 to $2.54 ; \mathrm{I}^{2}=24 \%$; 8 studies, $\mathrm{n}=3516$; moderate-certainty evidence). They also found benefits from workplace incentives schemes compared with no incentives (OR $1.60,95 \% \mathrm{Cl} 1.12$ to 2.30 ; $\mathrm{I}^{2}=43 \%$; 5 studies, $\mathrm{n}=1928$; moderate-certainty evidence), and from multiple workplace interventions (OR $1.55,95 \% \mathrm{Cl} 1.13$ to 2.13; $\mathrm{I}^{2}=30 \%$; 6 studies, $\mathrm{n}=5018$; moderate-certainty evidence). They did not detect a benefit from providing self-help materials in the workplace (OR $1.16,95 \% \mathrm{Cl} 0.74$ to $1.82 ; \mathrm{I}^{2}=0 \% ; 6$ studies, $\mathrm{n}=1906$; high-certainty evidence).

Maziak 2015 found three studies of behavioural support for waterpipe smoking cessation compared with usual care or no intervention, which were not pooled due to methodological heterogeneity. However, all three studies reported results favouring behavioural interventions on waterpipe smoking cessation.

\section{No effect detected/effect very uncertain}

Behbod 2018 examined the effect of behavioural support for smoking cessation in parents and carers where the motivation was to reduce environmental tobacco smoke exposure in children. They did not pool studies due to heterogeneity of intervention type and trial methods, but judged the certainty of the evidence to be low to very low. They judged that there was insufficient evidence to make any conclusions on whether this support was more effective than usual care or minimal intervention.

Faseru 2018 found no evidence of a benefit from interventions that aimed to enhance partner support for smoking cessation compared with interventions without partner support components, either at six to nine months (RR $0.97,95 \% \mathrm{Cl} 0.83$ to $1.14 ; 1^{2}=0 \% ; 13$ studies, $n=2818$; low-certainty evidence), or at 12 or more months (RR $1.04,95 \% \mathrm{Cl} 0.88$ to $1.22 ; \mathrm{I}^{2}=0 \% ; 7$ studies, $\mathrm{n}$ $=2573$; low-certainty evidence).

Lindson 2019b reported moderate-certainty evidence that reduction-to-quit interventions produced similar quit rates to quitting abruptly (RR $1.01,95 \% \mathrm{Cl} 0.87$ to $1.17 ; 12=29 \% ; 22$ studies, $\mathrm{n}=9219)$. Evidence comparing the efficacy of reduction-to-quit interventions with no treatment was inconclusive and of very low certainty (RR 1.74, $95 \% \mathrm{Cl} 0.90$ to $3.38 ; 1^{2}=45 \% ; 6$ studies, $\mathrm{n}=1599$ ).

Livingstone-Banks 2019b found no benefit for smoking abstinence from relapse prevention behavioural interventions that taught assisted abstainers to recognise situations that were high risk for relapse along with strategies to cope with them compared with no intervention (RR $0.98,95 \% \mathrm{Cl} 0.87$ to $1.11 ; \mathrm{I}^{2}=52 \% ; 11$ studies, $\mathrm{n}=$ 5523; moderate-certainty evidence).

\section{Component network meta-analysis}

Note: throughout this section, when discussing SD, we were referring to the median of the posterior SD.

\section{Main analysis}

Figure 5 shows results from our CNMA including all eligible studies before any adjustment for covariates. This main analysis did not include trials where arms varied only in intensity, and hence included 284 studies and 659 study arms. There was some variability between studies which was not fully explained by the components (median between-trial SD $0.337,95 \% \mathrm{Crl} 0.281$ to 0.398 ). We chose to present this model (without covariates) as our primary model as it was the most parsimonious (DIC 4137), and adding in the covariates (as described below) did not substantially improve model fit (i.e. did not significantly reduce DIC). Components were grouped by component type, with minimal intervention as the reference category. Point estimates for the effect of each component, with $95 \%$ Crls and the numbers of trials, arms, and participants contributing data, can be seen in Figure 5. Trace plots indicated good convergence. For some components, Crls were wide, but for three components, the point estimate suggested clinically important benefit, and the Crl excluded no clinically important difference: 
Figure 5. Forest plot, using all available data, showing effect estimates for each component as related to smoking cessation (excluding covariates). app: mobile phone application; audio: audio recording; Crl: credibility interval; Guaranteed: guaranteed financial incentives; IVR: interactive voice response; Not guaranteed: Non-guaranteed financial incentives (e.g. competitions); OR: odds ratio; SMS: short messaging service (text message); Web: Internet.

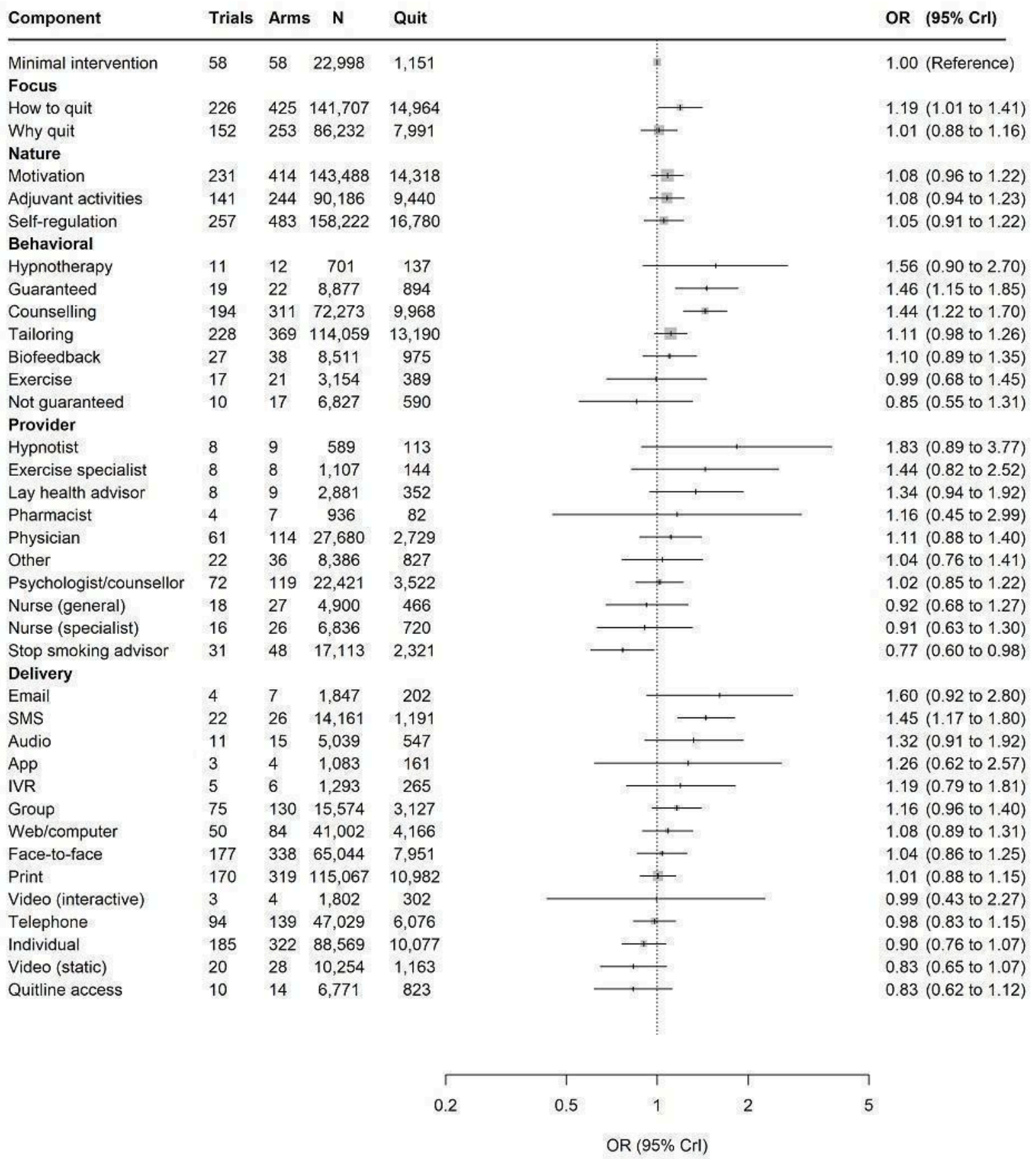

- guaranteed financial incentives;

- counselling;

- text-messaging (SMS).
A further four components had point estimates suggesting clinically significant benefit (judged as OR greater than 1.04) and Crls that included no clinically significant difference, but that excluded clinically significant harm: 
- a focus on 'how to quit';

- intervention content including motivational techniques;

- tailoring;

- delivery in a group setting.

All other components had Crls where the lower bound included meaningful reductions in the likelihood of achieving abstinence. Delivery by a stop smoking advisor had a point estimate indicating a reduction in cessation, though the $\mathrm{Crl}$ included no clinically significant difference. Two components (delivery by a dentist, and 'other' delivery mode) were represented by a very small number of comparisons and are not displayed in the forest plot as the Crls were too wide to be represented graphically along with other more precise component effects, or contribute any meaningful information; this was also apparent from the posterior density plots for these components.

This analysis assumed that component effects were additive and, therefore, combinations of them could easily be calculated by multiplying component effects. For example, the effect of group face-to-face counselling could be calculated by multiplying the effects of delivery of an intervention to a group (OR 1.16, 95\% Crl 0.96 to 1.40$)$, by the effect of face-to-face delivery of an intervention (OR $1.04,95 \% \mathrm{Crl} 0.86$ to 1.25 ), by the effect of counselling (OR $1.44,95 \% \mathrm{Crl} 1.22$ to 1.70 ), that is $1.16 \times 1.04 \times 1.44=1.74$, which means the odds of smoking cessation are $74 \%$ greater for group face-to-face counselling compared to minimal intervention (note, behavioural and motivational components based on programme content or provider components (or both), could also be added in, further impacting the estimate). Similarly, the effects of one component versus another one could be calculated by dividing the effect of one component by the other. For example, the effect of group face-to-face counselling versus individual faceto-face counselling could be calculated by dividing $1.16 / 0.90$ $=1.29$, which means the odds of smoking cessation are $29 \%$ greater for group versus individual face-to-face counselling. With 37 estimated component effects, one could calculate more than one billion combinations of component effects (237), although only 437 different combinations of two or more components were observed in contributing studies. Combinations of two components and their frequencies are shown in Figure 2. In our protocol, we did not prespecify combining specific components; we plan to explore this in a subsequent publication. Readers should note the assumption of additivity is at this point only an assumption, and may not hold for certain components.

\section{Excluding studies at high risk of bias}

We ran a prespecified sensitivity analysis excluding studies at high risk of bias (Figure 6), which did not substantially alter the median between-trials SD (from 0.337 to 0.315). Crls were wider for all component effects, as would be expected from the reduced sample size, and one component (e-mail) no longer had any studies contributing data. With the exception of substantially decreased point estimates for delivery by physicians and pharmacists, there were no clinically significant changes to point estimates. 
Figure 6. Sensitivity analysis excluding studies at high risk of bias. app: mobile phone application; audio: audio recording; Crl: credibility interval; Guaranteed: guaranteed financial incentives; IVR: interactive voice response; Not guaranteed: Non-guaranteed financial incentives (e.g. competitions); OR: odds ratio; SMS: short messaging service (text message); Web: Internet.

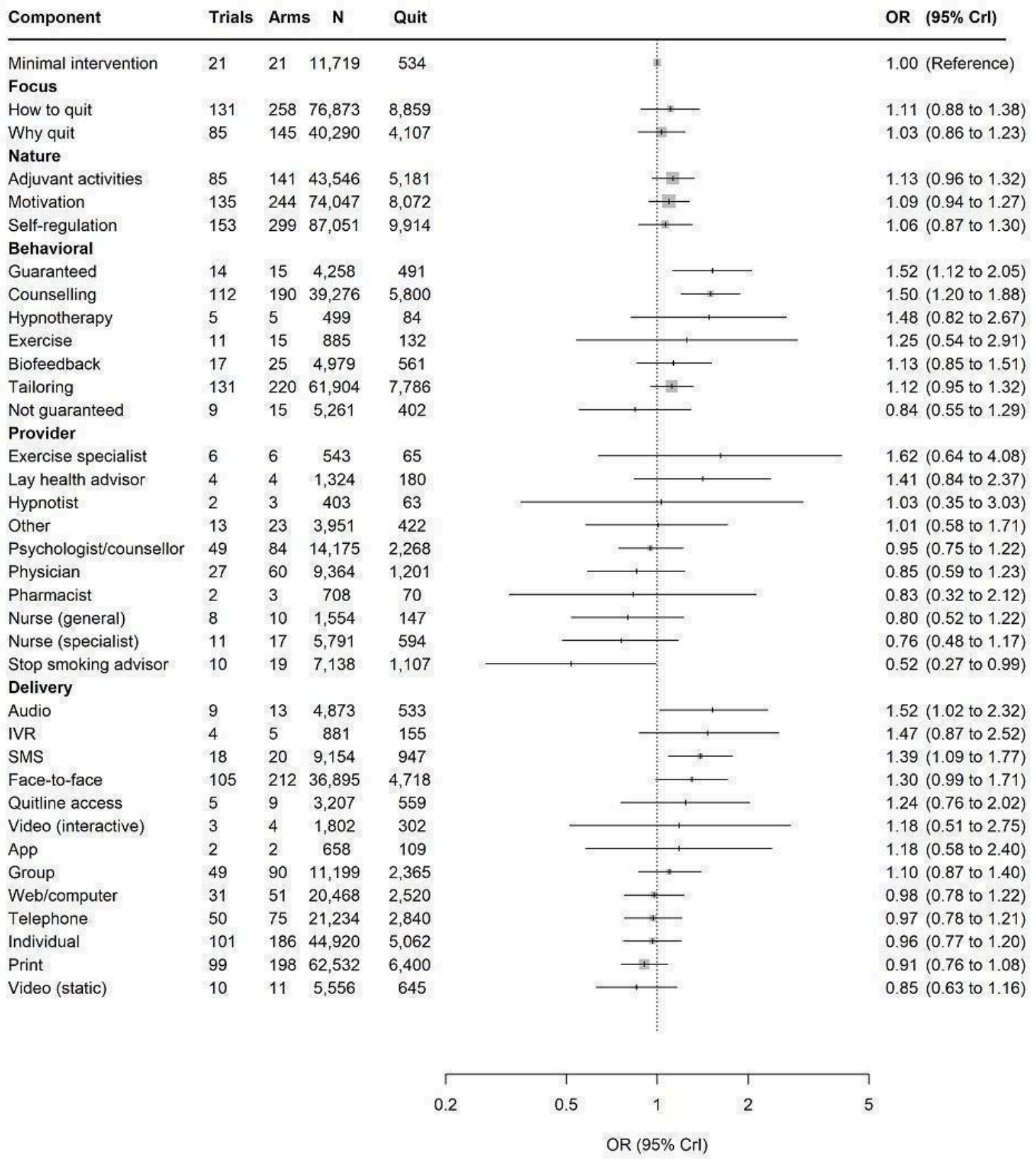

Investigating variability

We created a contour plot displaying deviance residuals and leverage by study arm (Figure 7; Appendix 2). We used this plot to identify studies contributing higher than expected residual deviance; of the 17 studies for which this was the case, all were either judged to be at high risk of bias (10/17), had an arm or multiple arms with very low smoking cessation event rates or no events (8/17), or had unexpectedly high smoking cessation event rates (13/17). To investigate the impact of variability on component 
effect estimates, we ran three post hoc analyses. In the first of these, as arms with no events emerged as important contributors to total residual deviance, we first applied a continuity correction of 0.5 to these studies. In model 2, we excluded arms with no events. In model 3, we ran a sensitivity analysis excluding arms with a contribution to overall DIC greater than 3. Model 1 slightly reduced
SD (from 0.337 to 0.333 ). Model 2 also only slightly reduced SD (to $0.313)$. Model 3 had the most impact on variation, reducing the SD to 0.237 . None of these models substantially altered component effect estimates, though in some cases Crls narrowed. In model 3 , Crls for delivery by email and delivery by recorded audio no longer included no difference.

\section{Figure 7. Contour plot of leverage showing individual arm contributions to residual deviance. Each point is an} individual study arm. Red: study at high risk of bias; yellow: study at unclear risk of bias; green: study at low risk of bias. DIC: Deviance Information Criterion.

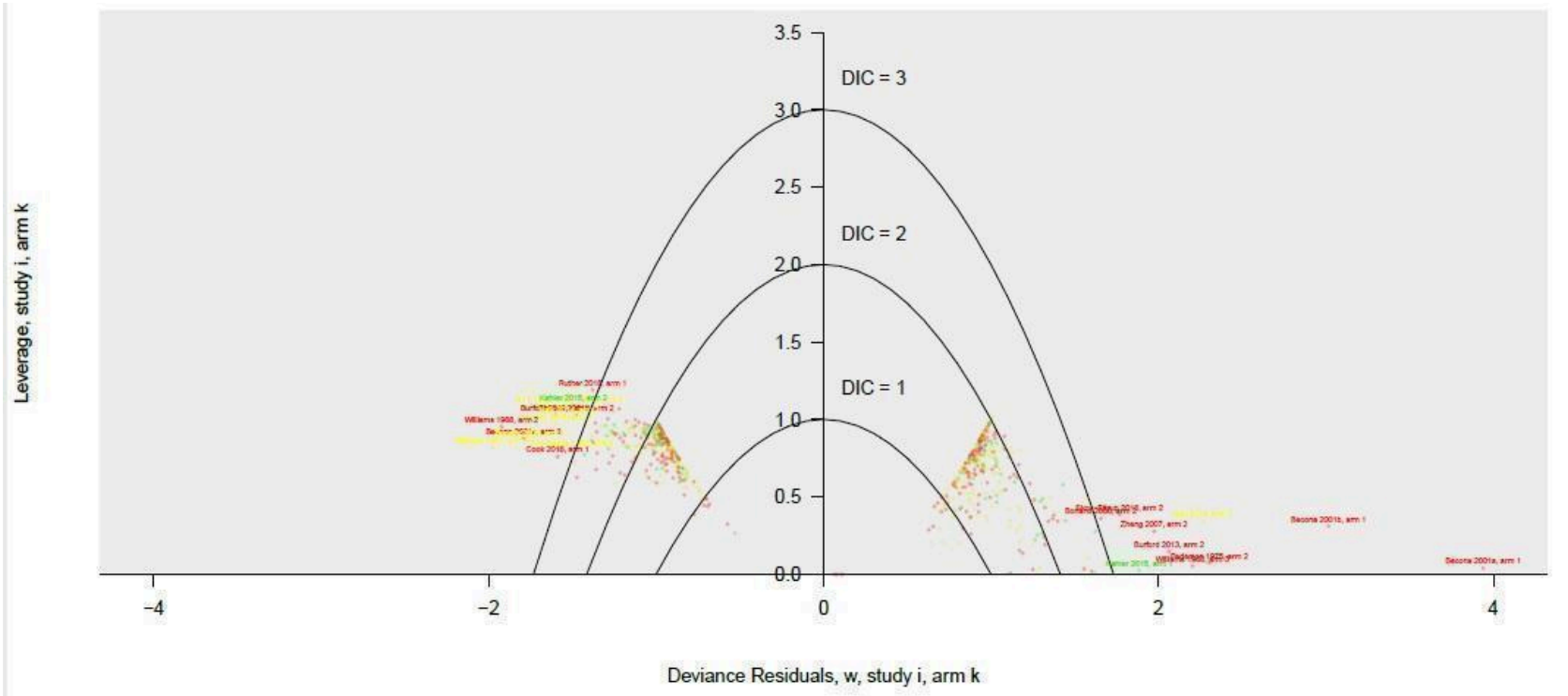

\section{Intensity covariates}

In the subset of 92 studies, we first fitted a model without the intensity components, then included all three components together. The SD decreased (from 0.314 to 0.276 ) and made a modest difference to the DIC (from 1408 to 1411).

For all three intensity variables, Crls included no difference, but each point estimate suggested that increasing intensity increased the odds of smoking cessation. In the model including all three variables:

- each additional week of an intervention was associated with an increase in odds of smoking cessation of 1.003 (95\% Crl 0.997 to 1.009);

- for mean length of individual sessions, each additional 10 minutes was associated with an increase in odds of smoking cessation of 1.040 ( $95 \%$ Crl 0.963 to 1.122 );

- each additional session was associated with an increase in odds of smoking cessation of 1.016 (95\% Crl 0.997 to 1.036 ).

Because of likely collinearity between duration of intervention and number of sessions, we also fitted these independently of one another, which increased the effect estimates and reduced the bounds of the Crls:

- the effect of duration of the intervention increased to OR 1.051 (95\% Crl 0.990 to 1.116) after excluding number of sessions;

- the effect of number of sessions increased to OR 1.019 (95\% Crl 1.000 to 1.037 ), after excluding duration.
Thus, an additional 40-minute increase in length per session increased the odds of cessation by 1.17 (95\% Crl 0.86 to 1.59$)$, or adding five extra sessions of behavioural support gave an OR of 1.08 (95\% $\mathrm{Cl} 0.99$ to 1.19$)$.

\section{Study-level covariates}

Table 4 gives estimates of the effect of characteristics of the population or co-intervention with pharmacotherapy on the component effects in the model. Overall, there was no evidence that characteristics of the population or the duration of the study moderated the component effects. All interaction terms showed convergence.

The provision of pharmacotherapy was associated with slightly weaker (1.5\% weaker) component effect sizes (OR 0.985, 95\% Crl 0.975 to 0.996 ) and slightly reduced heterogeneity (SD reduced from 0.337 to 0.330 ; DIC from 4137 to 4135 ). This is a multiplicative effect that was calculated as a mean across all components.

None of our prespecified population covariates significantly moderated component effects or improved model fit. Length of study follow-up (i.e. the last time point at which an assessment of cessation was made) also appeared to have no impact, neither did quit rate in the control arm. All interaction terms between covariates and component effects included the null effect, and estimates were very precise (very narrow Crls for covariates).

\section{Adverse events}

Eleven reviews measured some form of adverse events or harms. None indicated an excess of adverse events in people receiving 
behavioural support for smoking cessation. A summary of relevant information from each review can be found in Table 5 .

\section{DISCUSSION}

\section{Summary of main results}

Evidence from existing Cochrane Reviews and from CNMA showed that behavioural interventions for smoking cessation can increase quit rates at six months or longer, but effectiveness varies based on the characteristics of the behavioural support provided (Table 6; Table 7; Table 8). Two elements of interventions consistently and with high certainty demonstrated benefit when taking into account both data from pair-wise meta-analyses and findings from our CNMA, namely: the provision of guaranteed financial incentives (as per Notley 2019) and the provision of counselling (as per Lancaster 2017 and Stead 2017). In absolute terms, our analyses suggest that the inclusion of financial incentives in a programme may lead to an additional 3 per 100 people quitting, compared to a background quit rate of 6 per 100 people. The effect of counselling was similar (Table 6). These estimates are incremental for individual components, and none of these components would be delivered independent of other components; the anticipated absolute effect should not be misinterpreted as an intervention effect, but as the independent effect of one of the components of said intervention.

Our CNMA showed moderate-certainty evidence of benefit for a further four components of behavioural support. For three of these, Crls also encompassed no clinically significant differences: intervention content focused on how to quit (no relevant pairwise meta-analysis); inclusion of content related to motivation (no relevant pair-wise meta-analysis); and tailoring behavioural support to individual characteristics (supported by evidence from pair-wise meta-analysis in Livingstone-Banks 2019a and Taylor 2017). There was also moderate-certainty evidence of benefit for text-message delivery, with Crls excluding one, and supported by moderate-certainty evidence from pair-wise metaanalysis in Whittaker 2019; however, certainty was downgraded due to unexplained statistical heterogeneity in the pair-wise metaanalysis. There were no data to suggest an increase in harms in groups receiving behavioural support for smoking cessation. There were also no data to suggest that population characteristics influenced component effectiveness, but data here were limited due to some trials not reporting these data, and the absence of evidence should not be interpreted as evidence of absence. Increasing intensity of behavioural support, as measured through number of contacts, duration of each contact, and length of programme, was associated with modestly increased chances of success, though effect estimates included no difference, and the analysis assumed a constant increase in chances of cessation with every unit of intensity component. In a CNMA meta-regression, an interaction between pharmacotherapy and the component effects suggested that the component effects may be slightly weaker in studies where all participants were given pharmacotherapy to support cessation; this is consistent with data from a contributing review which found high-certainty evidence that behavioural support increased quit rates in people given pharmacotherapy for smoking cessation, but that the magnitude of effect was smaller than in studies in which no pharmacotherapy was offered (Hartmann-Boyce 2019).

\section{Overall completeness and applicability of evidence}

Thirty-three Cochrane reviews and 312 randomised controlled trials contributed data to this review; a further 23 analyses were covered in our brief economic commentary (see below). We believe that makes this the largest review to date within this subject area, and hope this will make it particularly helpful to decision makers. Despite the volume of data reviewed, many contributing reviews and component effect estimates would be strengthened by further data, as imprecision was an important issue affecting certainty (see Quality of the evidence) and some unexplained variability between studies remains. There are recognised issues with under-reporting of intervention content in this area (de Bruin 2020), and we were missing data from many of the included studies, with quantitative data on intervention intensity and certain population characteristics (e.g. SES) particularly poorly reported. Due to variation and lack of reporting regarding population characteristics, we were unable to determine with any certainty whether population characteristics influence the comparative effectiveness of the interventions and components evaluated. Individual participant data (particularly for population characteristics) meta-analysis or network meta-analysis using original datasets may be the best way to investigate this in the future. This may be of particular importance when evaluating the impact of interventions on groups bearing disproportionate smoking-related burdens, for example less-advantaged communities and people living with mental health disorders. As in most areas of research, the majority of studies were set in higher-income countries and usually in higher SES groups within those countries. We have no reason to believe that the effects of behavioural support would vary across countries, but no data to support this either, so it is unclear whether cultural responses to behavioural support moderate its effectiveness.

Following the approach taken in Cahill 2013, we restricted this overview to Cochrane Reviews, and the CNMA to studies identified through those reviews. Due to the sheer volume of literature and the need to make pragmatic decisions regarding resource, we chose this approach as both feasible and minimally compromising the completeness of the data, because these reviews cover almost all common components of behavioural support and are considered the gold-standard in this area. For all reviews contributing data to the CNMA and not judged stable or updated within the past three years, we ran new searches and published updates to capture recent studies and ensure our CNMA was as up-todate as possible. We are very grateful to the individual author teams contributing to these updates. Despite these efforts, we may have missed relevant reviews and trials existing outside of these Cochrane Reviews. We may have particularly missed studies comparing different interventions, though some reviews included these in their analyses and all others should list them as excluded; for the latter we included these studies. We have also inevitably missed some recently published trials, particularly those published in 2019 and 2020; this is the case with all systematic reviews and particularly those of this size, but is perhaps more of a pronounced issue given our approach to identifying studies through relevant Cochrane Reviews. For intervention components such as counselling, the lack of recent trials is unlikely to make a meaningful difference to the effect estimate, as the body of literature here is large and has remained consistent over time. For components with fewer studies contributing data, particularly those incorporating emerging technologies (e.g. real-time video 
counselling; mobile phone applications), newer trials may well impact effect estimates moving forward. We hope to update this review over the coming years.

When considering the applicability of the effect estimates presented, it is important to note that each component effect estimate is for the contribution of that component to an intervention. None of our components could be delivered independently of other components tested. The analysis presented here assumed additivity, but this needs to be tested further. For example, the evidence from the contributing review of individual counselling for smoking cessation shows high certainty evidence of a benefit when compared to minimal support (RR $1.57,95 \% \mathrm{Cl}$ 1.40 to 1.77; Lancaster 2017). Our component effect estimate for individual mode of delivery of an intervention was OR 0.90 (95\% $\mathrm{Crl} 0.90$ to 1.07). Though at first glance this seems incongruent, in reality the effect estimate from the pair-wise comparison represents a combination of components. For example, a study contributing to this pair-wise meta-analysis may be a combination of individual delivery (OR $0.90,95 \% \mathrm{Crl} 0.90$ to 1.07 ); counselling (OR 1.44, 95\% Crl 1.22 to 1.70); and is likely to focus on how to quit (OR 1.19, 95\% Crl 1.01 to 1.41); motivation (OR 1.08, 95\% Crl 0.96 to 1.22 ); self-regulation (OR $1.05,95 \% \mathrm{Crl} 0.91$ to 1.22 ); be delivered by a psychologist/counsellor (OR $1.02,95 \% \mathrm{Crl} 0.85$ to 1.22); with face-to-face delivery (OR $1.04,95 \% \mathrm{Crl} 0.86$ to 1.25 ), and delivered over two sessions (for each session increase, OR 1.016 , $95 \% \mathrm{Crl} 0.997$ to 1.036 ). If we assume additivity, then multiplying these effect estimates results in an illustrative OR of 1.88 , which is not incongruent with the observed effect estimate from the pairwise meta-analysis (ORs are typically higher than RRs in studies of smoking cessation). Of note, the latter is an illustrative estimate only and does not consider the imprecision as indicated by the Crls or how to assess certainty across combinations of components; we intend to explore methods for combining component effect sizes and measures of precision in more depth in a subsequent publication, but, in the meantime, hope this worked example demonstrates the way in which the effect sizes for an intervention with specific component combinations could be estimated. That said, our model assumed additive effects and we have not tested for departure from this assumption. It is possible that effect of some components is lowered by the presence of other effective components, as appears to be the case for the effect of behavioural support when used with pharmacotherapy.

\section{Quality of the evidence}

Of the included reviews, the majority (20/33) were rated as low or critically low using the AMSTAR 2 tool. For 19 of these, the critical weakness in question was a failure to discuss the possible impact of publication bias on review findings. This was typically the case in reviews which did not have sufficient studies contributing to any meta-analyses to test for publication bias using a funnel plot, and which did not mention publication bias in the results or discussion sections. The other critical weakness impacting some of the reviews for which a first version was published over a decade ago, a protocol was not accessible. Importantly, we did not judge these weaknesses as likely to impact the contribution of these reviews to our CNMA, as we judged these weaknesses as unlikely to impact study identification or data extraction for the contributing reviews. However, they do highlight the need for Cochrane Reviews in this area to address these oversights moving forward; new reporting standards should go some way to rectifying this. Though a significant proportion of studies included in our CNMA were at high risk of bias, sensitivity analyses removing these studies provided reassurance in most cases.

GRADE judgements and reasons for downgrading (where applicable) for each component can be found in Table 6 ('Summary of findings table: behavioural and motivational components of behavioural interventions for smoking cessation'), Table 7 ('Summary of findings table: person delivering behavioural interventions for smoking cessation'), and Table 8 ('Summary of findings table: mode of delivery of behavioural interventions for smoking cessation'). Of the 37 components evaluated, we judged evidence to be of high certainty for two (guaranteed financial incentives, counselling). This means that the remainder of our component effect estimates, particularly those judged to be of low or very low certainty, should not be overinterpreted. The majority of our component effect estimates were downgraded one or two levels due to imprecision, with Crls spanning no effect and clinically significant increases or reduction in the likelihood of abstinence. In reality, this represents both issues with imprecision and inconsistency as defined by GRADE, as in our model statistical heterogeneity also widened Crls. Therefore, though in the footnotes we described downgrading based on imprecision in instances with wide Crls, such 'downgrades' actually may capture issues with both domains. Inconsistency, risk of bias, and publication bias also reduced certainty for some components.

GRADE judgements made in the contributing reviews highlighted similar issues to those in our component GRADE judgements, with imprecision and risk of bias the main reasons for downgrading certainty in the evidence, and inconsistency and publication bias also reducing certainty in some cases. As seen in S7 Details of primary analyses from included studies, of the 74 analyses on which GRADE judgements were made within contributing reviews, effect estimates from only 10 were judged to be of high certainty. This included five comparisons which directly aligned with highcertainty evidence from component effect estimates from our network meta-analysis (two comparisons relating to guaranteed financial incentives, three comparisons related to counselling). Evidence was also judged to be of high certainty, showing evidence of a benefit across multiple studies, for:

- behavioural interventions as adjuncts to pharmacotherapy versus pharmacotherapy alone;

- self-help interventions delivered in the workplace compared to less intensive or no support;

- brief behavioural interventions for people awaiting surgery;

- behavioural support for pregnant women who smoke, including a subgroup of studies evaluating social support interventions.

Certainty was judged to be moderate for a further 33 comparisons, and low or very low for the remainder.

\section{Potential biases in the overview process}

We followed Cochrane methods, which are considered best practice. However, potential biases in our processes remain. As described above, we restricted this overview to Cochrane Reviews; some relevant reviews and trials will have been missed as a result, and we consider implications of this above (Overall completeness and applicability of evidence). Our approach may also have run the risk of propagating data extraction errors from original reviews. In addition, there may have been differences in the ways 
review authors assessed certainty. Though review authors will have all used the same guidelines for assessing certainty, and though Cochrane editors will have checked assessments, there could still be variability in judgements between author teams, including for example in what was considered 'null effect' or 'no evidence of clinically significant difference'. In some cases, there was significant overlap between reviews, which means that some studies will be over-represented in our summary of findings across reviews. However, each study only contributed once to our CNMA. Additionally, some of the authors of this overview are authors of included reviews; authors of included reviews were not involved in data extraction or quality assessment for their own reviews to attempt to mitigate any impact of this.

CNMA remains a relatively new method. We are not aware of any established or agreed way to judge certainty, present 'Summary of findings' tables, or evaluate publication bias within CNMA. We therefore consulted with experts within Cochrane and made informed decisions about our approach to each of these areas (see Methods); we are very cognisant that better methods may emerge over time, and hope to incorporate them in the future. In the meantime, our approach means there may be some considerations we have been unable to fully take into account. In regards to publication bias, where contributing reviews highlighted possible or suspected publication bias, we took this into account in our evaluation of certainty. It may be that, when comparing individual components to one another, publication bias is less of an issue as studies across the spectrum will represent a range of these components, but it could be that effect estimates overall are more positive than they would have been if publication bias was not present. Furthermore, with CNMA a pragmatic decision had to be made regarding which components to include. This decision can have important implications for analyses and findings (MelendezTorres 2015). Our decisions were made a priori with support from an advisory team and after reviewing relevant literature, but there are other ways to subdivide interventions in this area, including by behaviour change techniques (see Agreements and disagreements with other studies or reviews). It would be difficult to conceive a meaningful CNMA that would include our 37 components and the 93 behaviour change techniques identified by Michie and colleagues (Michie 2013), so we hope that our approach can serve as a companion approach to analyses using different frameworks to characterise these interventions.

In evaluating the impact of covariates, some important caveats should be reiterated.

- The data collected on population characteristics was limited to the extent that some preplanned variables could not be evaluated (i.e. baseline motivation to quit) and some had to be more crudely defined than would have been done had more detail been available (i.e. SES), meaning that absence of evidence for these covariates should not be considered as evidence of absence.

- Our analysis of intensity variables (duration of intervention, mean length per session, number of sessions) assumed linearity. In reality, the relationship between these variables and intervention effectiveness is very unlikely to be linear, as at a certain point, for example, people are likely to not continue to attend sessions (it is difficult to imagine that 300 sessions would be more effective than 200 , for example). In a previous review (Hartmann-Boyce 2019), we had tried modelling intensity using a non-linear method but the data did not support such an approach, hence the assumption of linearity used in our present model.

- Covariates were averaged across participants in the study, rather than measured at the individual level.

\section{Agreements and disagreements with other studies or reviews}

The nature of this review means results from our CNMA have been compared to those from individual Cochrane Reviews as an integral part of our approach. Where applicable, our component effect estimates were consistent with those from relevant pair-wise metaanalyses.

We are unaware of another directly comparable review. Worldwide, guidelines recommend the use of behavioural support for smoking cessation. 2008 US Clinical Practice Guidelines (currently in the process of being updated (Clinical Practice Guideline 2008) include many of the reviews covered in this overview (albeit older versions) and recommend the provision of counselling with practical problem-solving and skills training components (which could be conceptualised as 'how to quit' and 'self-regulation' components in our analysis). Like us, the Clinical Practice Guideline 2008 identifies a dose-response relationship regarding session length and number of sessions, and does not find evidence of a clinically significant difference in effect between face-to-face and telephone support. In the UK, National Institute for Health and Care Excellence (NICE) guidelines from 2018 recommend commissioners ensure behavioural support (defined as scheduled face-to-face meetings between someone who smokes and a counsellor trained in smoking cessation, typically over four weeks) and very brief advice are available for adults who smoke, and that text-messaging be considered as an adjunct to behavioural support (NICE 2018). Both US and UK guidelines recommend quitlines, but both the Cochrane Review pair-wise meta-analysis and our CNMA found no evidence that this form of support increased abstinence (Clinical Practice Guideline 2008; NICE 2018). However, data in this area were sparse and this intervention is perhaps better evaluated outside of randomised controlled trials. Two reviews of smoking cessation interventions in primary care supported the use of behavioural interventions, but found high levels of statistical heterogeneity (Martín Cantera 2015; Papadakis 2010). Martín Cantera 2015 also found some evidence of a dose-response effect and evidence of substantial heterogeneity.

The above guidelines and reviews cover multiple areas beyond behavioural support, and therefore do not focus on intervention components in the same level of detail as we do here. The most relevant work we are aware of in this field that takes such in-depth approach is a systematic review evaluating behaviour change techniques used in randomised controlled trials of smoking cessation interventions. Black 2020, which restricted included trials to those that were biochemically validated and used a date restriction, included over 100 trials and found that techniques targeting associative (cues to prompt behaviour) and self-regulatory processes were associated with success in persondelivered interventions, and that interventions including rewards were associated with success in written interventions. Mode of delivery was found to moderate intervention effects. We also found delivery mode was associated with intervention effects, and our effect estimate for self-regulation content suggested 
benefit. We did not explicitly evaluate whether interventions addressed associative processes, though in Black 2020 associative processes included rewards. Guaranteed financial incentives could be considered a form of reward, and we found high-certainty evidence supporting their use.

\section{Brief economic commentary}

To supplement this overview and CNMA, we sought to identify economic evaluations which compared interventions of interest to one another. A supplementary search for economic evaluations (see Search methods for identification of reviews) identified 23 relevant studies of health economic evaluations comparing at least two different behavioural interventions for smoking cessation (see Figure 8). The majority of studies were published from 2010 onwards (range 1996 to 2019), were model-based, and came from the US (see Table 9). The vast majority of comparisons were based on delivery mode; we summarised the evidence by intervention type below. 
Figure 8. Study flow diagram for studies included in brief economic commentary.

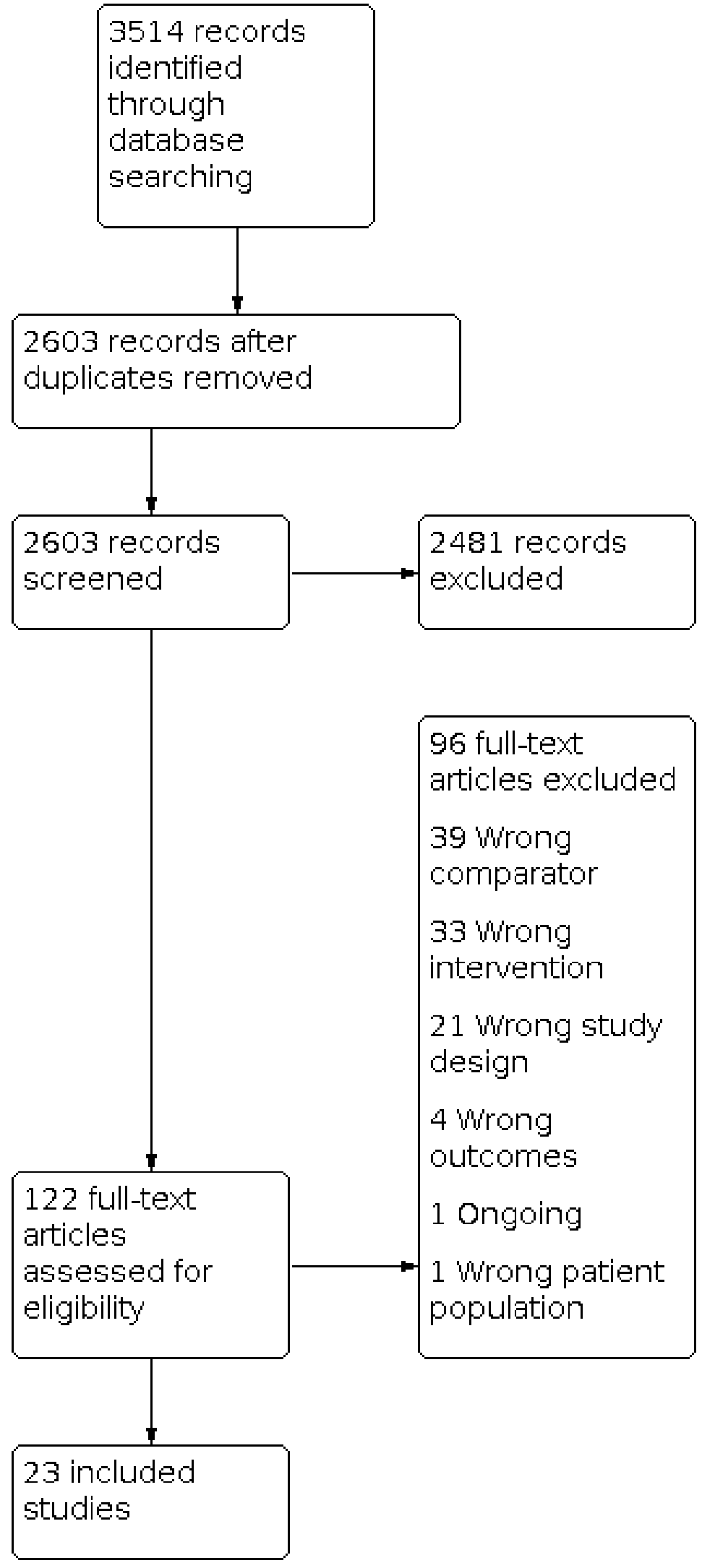


Eleven studies investigated individual face-to-face counselling (hereafter individual counselling). Five compared individual to group face-to-face counselling (hereafter group counselling): two found individual counselling more cost-effective than group counselling (Barnett 2013; Cromwell 2001); one found group counselling more cost-effective than individual counselling (Bauld 2011), and two found individual counselling to be dominated by group counselling (i.e. group counselling was more effective and less costly) (Boyd 2009; Healey 2019). Individual counselling delivered by community pharmacy personnel was more costeffective than group counselling in one study (Bauld 2011), but dominated by group counselling in another study (Boyd 2009). Two studies compared individual counselling to telephone counselling (An 2010; Feenstra 2005). Telephone counselling was more costeffective than individual counselling in one US study (An 2010), and dominated by individual counselling in one Dutch study (Feenstra 2005). An 2010 also found individual counselling to be more costeffective than a worksite intervention and a website, and Begh 2011 found a community-based outreach intervention to be more cost-effective than individual counselling. Three studies compared different intensities (minimal, brief, and intensive) of individual counselling (Cromwell 2001; Feenstra 2005; Nohlert 2013). Two studies suggested intensive more cost-effective than minimal/brief individual counselling (Cromwell 2001; Feenstra 2005), and another study found low-intensity individual counselling to be dominated by a high-intensity individual counselling (Nohlert 2013). In two studies comparing nurse-delivered individual counselling to telephone counselling, the counselling provided by the nurses was less effective and more costly (Berndt 2016; Tosanguan 2016). Ruger 2008 compared MI delivered via individual counselling to brief advice and found $\mathrm{MI}$ to be less effective despite being more expensive.

Beyond comparisons with individual counselling, four comparisons investigated group counselling. Two studies comparing group counselling with print-based self-help materials found group counselling more effective, but were inconsistent regarding relative costs (McGhan 1996; Mudde 1996). Calhoun 2016 found group counselling combined with telephone counselling was more effective and less costly than an internet-based intervention. Dino 2008 , conducted in teenagers, found that a multi-component same-gender group counselling intervention was cost-effective compared with a mixed-gender brief group counselling and selfhelp intervention.

Outside of comparisons with face-to-face interventions, seven comparisons evaluated telephone counselling. Three found telephone counselling more effective than internet or website interventions, but costs were higher for telephone counselling in two of these studies (An 2010; Javitz 2011), and surprisingly lower in Calhoun 2016, in which telephone counselling was used in conjunction with group counselling. Shearer 2006 found telephone counselling dominated brief physician advice, while Feenstra 2005 found the opposite. Lal 2014 found more intensive telephone counselling to be effective and cost-saving compared to brief telephone counselling.

Three remaining studies did not involve comparisons with counselling. Gilbert 2017 and Wu 2018 compared tailored against standard self-help materials; neither found tailored self-help to be cost-effective in the short term, but both agreed it may be cost-effective in the long term. Popp 2018 provided evidence that multiple contests were cost-effective when compared to a single contest.

It is important to highlight that we did not subject any of the 23 identified economic evaluations to critical appraisal and do not attempt to draw any firm or general conclusions regarding relative costs or efficiency of these interventions compared to one another. Because smoking is extremely costly (see Description of the condition), it is widely acknowledged that any effective smoking cessation intervention will also very likely be cost-effective (West 2007). However, evidence collected here did not consistently suggest one type of behavioural intervention for smoking cessation was more cost-effective than another. End users will need to assess the extent to which methods and results of these economic evaluations may apply to their own setting.

\section{AUTHORS' CONCLUSIONS}

\section{Implications for practice}

- Behavioural support for smoking cessation can increase quit rates at six months or longer. The evidence is strongest for counselling and guaranteed financial incentives. Effect estimates provided in our main analysis are based on delivery of individual components; in practice any given intervention will include multiple components which may increase effectiveness.

- There is moderate-certainty evidence suggesting that textmessage-based interventions and tailoring programme content to individuals may further increase quit rates. Interventions focused on how to quit, interventions involving motivational content, delivery by a lay health advisor, and delivery via email and audio recording were also associated with modest evidence of benefit, again of moderate certainty.

- Behavioural support increases quit rates regardless of concurrent use of smoking cessation pharmacotherapies, though the effect of behavioural support for smoking cessation is slightly less pronounced when people are already receiving smoking cessation pharmacotherapies.

- There is no evidence of an excess of adverse events or other harms from behavioural interventions for smoking cessation.

\section{Implications for research}

- Despite over 30 systematic reviews and 300 randomised controlled trials contributing data to this review, evidence is still uncertain in some areas. This is particularly the case for emerging technologies (e.g. text-message, mobile phone app, real-time video counselling).

- Future studies need to be well-conducted and well-described, including adequate randomisation and allocation concealment. Biochemical validation should be used where possible, and particularly when differential levels of support are provided between intervention and comparator arms. Continuous or prolonged abstinence should be measured where feasible. Interventions and comparators should be described in sufficient detail to identify their behavioural content; the person delivering the intervention; and the length, duration, and number of sessions provided. Populations should be described in respect to key variables, including socioeconomic factors and health status. More studies are also needed in lower-income settings. 
- Cochrane Reviews in this area could be improved by ensuring all key risk of bias domains are covered and that publication bias is discussed and assessed where possible.

- Component network meta-analysis is a relatively new method, and consensus needs to be reached on best ways to manage, evaluate, and present data from these analyses, particularly within the framework of Cochrane Reviews. This should include methods for assessing certainty and presence of possible publication bias.

\section{A CKN OWLEDGEMENTS}

This project was supported by the National Institute for Health Research (NIHR), via Cochrane Infrastructure and Cochrane Programme Grant funding to the Cochrane Tobacco Addiction Group, and via the NIHR Complex Reviews Support Unit (AS and SF). The views and opinions expressed herein are those of the authors and do not necessarily reflect those of the Systematic Reviews Programme, NIHR, National Health Service, or the Department of Health and Social Care. PA is an NIHR senior investigator and is funded by NIHR Oxford Biomedical Research Centre (BRC) and the NIHR Collaboration for Leadership in Applied Health Research and Care (CLAHRC) Oxford.

This project represents a truly collaborative team effort and we are grateful to all of those who contributed their time, particularly during the challenges posed by the COVID-19 pandemic. Numerous authors of individual reviews which were eligible for inclusion updated their reviews in tight timelines such that they could feed in the most up-to-date information into this work; we are grateful to them for doing so and for graciously responding to our frequent requests for progress updates.

We thank Lee Bromhead and Sandra Wilcox for providing patient and public perspectives on this work and the reviews contributing to this work. We thank Luke Vale from the Cochrane Economics Methods Group for advising on the methods planned for our brief economic commentary and members of the Cochrane Editorial Team for their support on methods and formatting of this nonstandard and considerably larger than usual review. Thanks also go to Andy McEwen from the National Centre for Smoking Cessation Training for his input on this project. We would also like to thank Mona Hersi from the Knowledge Synthesis Group, Ottawa Hospital Research Institute, and Gregory Traversy from the Global Health and Guidelines Division, Centre for Chronic Disease Prevention and Health Equity, Public Health Agency of Canada for performing peer review on this overview.

We thank Kerstin Frie, Moeko Hayashi, Thayla Santino, and Rodrigo Torres Castro for translating published reports of studies included in the network meta-analysis.

We thank Sarah King and Karen Rees, freelance systematic reviewers, for their help with data extraction for the network metaanalysis. 


\section{REFERE N C E S}

\section{References to included reviews}

\section{Barnes 2019}

Barnes J, McRobbie H, Dong CY, Walker N, Hartmann-Boyce J. Hypnotherapy for smoking cessation. Cochrane Database of Systematic Reviews 2019, Issue 6. Art. No: CD001008. [DOI: 10.1002/14651858.CD001008.pub3]

\section{Behbod 2018}

Behbod B, Sharma M, Baxi R, Roseby R, Webster P. Family and carer smoking control programmes for reducing children's exposure to environmental tobacco smoke. Cochrane Database of Systematic Reviews 2018, Issue 1. Art. No: CD001746. [DOI: 10.1002/14651858.CD001746.pub4]

\section{Cahill 2010}

Cahill K, Lancaster T, Green N. Stage-based interventions for smoking cessation. Cochrane Database of Systematic Reviews 2010, Issue 11. Art. No: CD004492. [DOI: 10.1002/14651858.CD004492.pub4]

\section{Cahill 2014}

Cahill K, Lancaster T. Workplace interventions for smoking cessation. Cochrane Database of Systematic Reviews 2014, Issue 2. Art. No: CD003440. [DOI: 10.1002/14651858.CD003440.pub4]

\section{Carr 2012}

Carr AB, Ebbert J. Interventions for tobacco cessation in the dental setting. Cochrane Database of Systematic Reviews 2012, Issue 6. Art. No: CD005084. [DOI: 10.1002/14651858.CD005084.pub3]

\section{Carson-Chahhoud 2019}

Carson-Chahhoud KV, Livingstone-Banks J, Sharrad KJ, Kopsaftis Z, Brinn MP, To-A-Nan R, et al. Community pharmacy personnel interventions for smoking cessation. Cochrane Database of Systematic Reviews 2019, Issue 10. Art. No: CD003698. [DOI: 10.1002/14651858.CD003698.pub3]

\section{Chamberlain 2017}

Chamberlain C, O'Mara-Eves A, Porter J, Coleman T, Perlen SM, Thomas J, et al. Psychosocial interventions for supporting women to stop smoking in pregnancy. Cochrane Database of Systematic Reviews 2017, Issue 2. Art. No: CD001055. [DOI: 10.1002/14651858.CD001055.pub5]

\section{Clair 2019}

Clair C, Mueller Y, Livingstone-Banks J, Burnand B, Camain JY, Cornuz J, et al. Biomedical risk assessment as an aid for smoking cessation. Cochrane Database of Systematic Reviews 2019, Issue 3. Art. No: CD004705. [DOI: 10.1002/14651858.CD004705.pub5]

\section{Fanshawe 2019}

Fanshawe TR, Hartmann-Boyce J, Perera R, Lindson N. Competitions for smoking cessation. Cochrane Database of Systematic Reviews 2019, Issue 2. Art. No: CD013272. [DOI: 10.1002/14651858.CD013272]

\section{Faseru 2018}

Faseru B, Richter KP, Scheuermann TS, Park EW. Enhancing partner support to improve smoking cessation. Cochrane Database of Systematic Reviews 2018, Issue 8. Art. No: CD002928. [DOI: 10.1002/14651858.CD002928.pub4]

\section{Hajek 2001}

Hajek P, Stead LF. Aversive smoking for smoking cessation. Cochrane Database of Systematic Reviews 2001, Issue 3. Art. No: CD000546. [DOI: 10.1002/14651858.CD000546.pub2]

\section{Hartmann-Boyce 2019}

Hartmann-Boyce J, Hong B, Livingstone-Banks J, Wheat H, Fanshawe TR. Additional behavioural support as an adjunct to pharmacotherapy for smoking cessation. Cochrane Database of Systematic Reviews 2019, Issue 6. Art. No: CD009670. [DOI: 10.1002/14651858.CD009670.pub4]

\section{Hollands 2010}

Hollands GJ, Hankins M, Marteau TM. Visual feedback of individuals' medical imaging results for changing health behaviour. Cochrane Database of Systematic Reviews 2010, Issue 1. Art. No: CD007434. [DOI: 10.1002/14651858.CD007434.pub2]

\section{Hollands 2019}

Hollands GJ, Naughton F, Farley A, Lindson N, Aveyard P. Interventions to increase adherence to medications for tobacco dependence. Cochrane Database of Systematic Reviews 2019, Issue 8. Art. No: CD009164. [DOI: 10.1002/14651858.CD009164.pub3]

\section{Huibers 2007}

Huibers MJ, Beurskens A, Bleijenberg G, van Schayck CP. Psychosocial interventions by general practitioners. Cochrane Database of Systematic Reviews 2007, Issue 3. Art. No: CD003494. [DOI: 10.1002/14651858.CD003494.pub2]

\section{Lancaster 2017}

Lancaster T, Stead LF. Individual behavioural counselling for smoking cessation. Cochrane Database of Systematic Reviews 2017, Issue 3. Art. No: CD001292. [DOI: 10.1002/14651858.CD001292.pub3]

\section{Lindson 2019a}

Lindson N, Thompson TP, Ferrey A, Lambert JD, Aveyard P. Motivational interviewing for smoking cessation. Cochrane Database of Systematic Reviews 2019, Issue 7. Art. No: CD006936. [DOI: 10.1002/14651858.CD006936.pub4]

\section{Lindson 2019b}

Lindson N, Klemperer E, Hong B, Ordóñez-Mena JM, Aveyard P. Smoking reduction interventions for smoking cessation. Cochrane Database of Systematic Reviews 2019, Issue 9. Art. No: CD013183. [DOI: 10.1002/14651858.CD013183.pub2]

\section{Livingstone-Banks 2019a}

Livingstone-Banks J, Ordóñez-Mena JM, Hartmann-Boyce J. Print-based self-help interventions for smoking cessation. 
Cochrane Database of Systematic Reviews 2019, Issue 1. Art. No: CD001118. [DOI: 10.1002/14651858.CD001118.pub4]

\section{Livingstone-Banks 2019b}

Livingstone-Banks J, Norris E, Hartmann-Boyce J, West R, Jarvis M, Chubb E, et al. Relapse prevention interventions for smoking cessation. Cochrane Database of Systematic Reviews 2019, Issue 10. Art. No: CD003999. [DOI: 10.1002/14651858.CD003999.pub6]

\section{Marteau 2010}

Marteau TM, French DP, Griffin SJ, Prevost AT, Sutton S, Watkinson C, et al. Effects of communicating DNA-based disease risk estimates on risk-reducing behaviours. Cochrane Database of Systematic Reviews 2010, Issue 10. Art. No: CD007275. [DOI: 10.1002/14651858.CD007275.pub2]

\section{Matkin 2019}

Matkin W, Ordóñez-Mena JM, Hartmann-Boyce J. Telephone counselling for smoking cessation. Cochrane Database of Systematic Reviews 2019, Issue 5. Art. No: CD002850. [DOI: 10.1002/14651858.CD002850.pub4]

\section{Maziak 2015}

Maziak W, Jawad M, Jawad S, Ward KD, Eissenberg T, Asfar T. Interventions for waterpipe smoking cessation. Cochrane Database of Systematic Reviews 2015, Issue 7. Art. No: CD005549. [DOI: 10.1002/14651858.CD005549.pub3]

\section{Notley 2019}

Notley C, Gentry S, Livingstone-Banks J, Bauld L, Perera R, Hartmann-Boyce J. Incentives for smoking cessation. Cochrane Database of Systematic Reviews 2019, Issue 7. Art. No: CD004307. [DOI: 10.1002/14651858.CD004307.pub6]

\section{Rice 2017}

Rice VH, Heath L, Livingstone-Banks J, Hartmann-Boyce J. Nursing interventions for smoking cessation. Cochrane Database of Systematic Reviews 2017, Issue 12. Art. No: CD001188. [DOI: 10.1002/14651858.CD001188.pub5]

\section{Stead 2013}

Stead LF, Buitrago D, Preciado N, Sanchez G, HartmannBoyce J, Lancaster T. Physician advice for smoking cessation. Cochrane Database of Systematic Reviews 2013, Issue 5. Art. No: CD000165. [DOI: 10.1002/14651858.CD000165.pub4]

\section{Stead 2017}

Stead LF, Carroll AJ, Lancaster T. Group behaviour therapy programmes for smoking cessation. Cochrane Database of Systematic Reviews 2017, Issue 3. Art. No: CD001007. [DOI: 10.1002/14651858.CD001007.pub3]

\section{Taylor 2017}

Taylor GM, Dalili MN, Semwal M, Civljak M, Sheikh A, Car J. Internet-based interventions for smoking cessation. Cochrane Database of Systematic Reviews 2017, Issue 9. Art. No: CD007078. [DOI: 10.1002/14651858.CD007078.pub5]

\section{Thomsen 2014}

Thomsen T, Villebro N, Møller AM. Interventions for preoperative smoking cessation. Cochrane Database of Systematic Reviews 2014, Issue 3. Art. No: CD002294. [DOI: 10.1002/14651858.CD002294.pub4]

\section{Tzelepis 2019}

Tzelepis F, Paul CL, Williams CM, Gilligan C, Regan T, Daly J, et al. Real-time video counselling for smoking cessation. Cochrane Database of Systematic Reviews 2019, Issue 10. Art. No: CD012659. [DOI: 10.1002/14651858.CD012659.pub2]

\section{Ussher 2019}

Ussher MH, Faulkner GE, Angus K, Hartmann-Boyce J, Taylor AH. Exercise interventions for smoking cessation. Cochrane Database of Systematic Reviews 2019, Issue 10. Art. No: CD002295. [DOI: 10.1002/14651858.CD002295.pub6]

\section{Vodopivec-Jamsek 2012}

Vodopivec-Jamsek V, de Jongh T, Gurol-Urganci I, Atun R, Car J. Mobile phone messaging for preventive health care. Cochrane Database of Systematic Reviews 2012, Issue 12. Art. No: CD007457. [DOI: 10.1002/14651858.CD007457.pub2]

\section{Whittaker 2019}

Whittaker R, McRobbie H, Bullen C, Rodgers A, Gu Y, Dobson R. Mobile phone text messaging and app-based interventions for smoking cessation. Cochrane Database of Systematic Reviews 2019, Issue 10. Art. No: CD006611. [DOI: 10.1002/14651858.CD006611.pub5]

\section{References to excluded reviews \\ Cahill 2008}

Cahill K, Perera R. Quit and Win contests for smoking cessation. Cochrane Database of Systematic Reviews 2008, Issue 4. Art. No: CD004986. [DOI: 10.1002/14651858.CD004986.pub3]

\section{Dale 2008}

Dale J, Caramlau IO, Lindenmeyer A, Williams SM. Peer support telephone calls for improving health. Cochrane Database of Systematic Reviews 2008, Issue 4. Art. No: CD006903. [DOI: 10.1002/14651858.CD006903.pub2]

\section{Fanshawe 2017}

Fanshawe TR, Halliwell W, Lindson N, Aveyard P, Livingstone-Banks J, Hartmann-Boyce J. Tobacco cessation interventions for young people. Cochrane Database of Systematic Reviews 2017, Issue 11. Art. No: CD003289. [DOI: 10.1002/14651858.CD003289.pub6]

\section{Farley 2012}

Farley AC, Hajek P, Lycett D, Aveyard P. Interventions for preventing weight gain after smoking cessation. Cochrane Database of Systematic Reviews 2012, Issue 1. Art. No: CD006219. [DOI: 10.1002/14651858.CD006219.pub3] 


\section{Additional references}

\section{An 2010}

An LC, Betzner A, Schillo B, Luxenberg MG, Christenson M, Wendling $A$, et al. The comparative effectiveness of clinic, worksite, phone, and web-based tobacco treatment programs. Nicotine \& Tobacco Research 2010;12(10):989-6.

\section{ASH 2016}

Action on Smoking and Health (ASH). ASH briefing: health inequalities and smoking. ash.org.uk/information-andresources/briefings/ash-briefing-health-inequalities-andsmoking/ (accessed 12 November 2018).

\section{Barnett 2013}

Barnett PG, Wong W, Jeffers A, Munoz R, Humfleet G, Hall S. Cost-effectiveness of extended cessation treatment for older smokers. Addiction 2013;109(2):314-22.

\section{Bauld 2011}

Bauld L, Boyd KA, Briggs AH, Chesterman J, Ferguson J, Judge $\mathrm{K}$, et al. One-year outcomes and a cost-effectiveness analysis for smokers accessing group-based and pharmacyled cessation services. Nicotine \& Tobacco Research 2011;13(2):135-45

\section{Begh 2011}

Begh RA, Aveyard P, Upton P, Shopal RS, White M, Amos A, et al. Promoting smoking cessation in Pakistani and Bangladeshi men in the UK: pilot cluster randomised controlled trial of trained community outreach workers. Trials 2011;12:197.

\section{Berndt 2016}

Berndt N, Bolman C, Lechner L, Max W, Mudde A, de Vries H, et al. Economic evaluation of a telephone- and face-to-facedelivered counseling intervention for smoking cessation in patients with coronary heart disease. European Journal of Health Economics 2016;17(3):269-85.

\section{Black 2020}

Black N, Johnston M, Michie S, Hartmann-Boyce J, West R, Viechtbauer W, et al. Behaviour change techniques associated with smoking cessation in intervention and comparator groups of randomized controlled trials: a systematic review and meta-regression. Addiction 2020;115(11):2008-20. [DOI: doi.org/10.1111/add.15056]

\section{Boyd 2009}

Boyd KA, Briggs AH. Cost-effectiveness of pharmacy and group behavioural support smoking cessation services in Glasgow. Addiction 2009;104(2):317-25.

\section{Brose 2011}

Brose LS, West R, McDermott MS, Fidler JA, Croghan E, McEwen A. What makes for an effective stop-smoking service? Thorax 2011;66(10):924-6.

\section{Cahill 2013}

Cahill K, Stevens S, Perera R, Lancaster T. Pharmacological interventions for smoking cessation: an overview and network meta-analysis. Cochrane Database of
Systematic Reviews 2013, Issue 5. Art. No: CD009329. [DOI: 10.1002/14651858.CD009329.pub2]

\section{Calhoun 2016}

Calhoun PS, Datta S, Olsen M, Smith VA, Moore SD, Hair LP, et al. Comparative effectiveness of an internet-based smoking cessation intervention versus clinic-based specialty care for veterans. Journal of Substance Abuse Treatment 2016;69:19-27.

\section{Chaiton 2016}

Chaiton M, Diemert L, Cohen JE, Bondy SJ, Selby P, Philipneri A, et al. Estimating the number of quit attempts it takes to quit smoking successfully in a longitudinal cohort of smokers. $B M J$ Open 2016;6(6):1-9.

\section{Clinical Practice Guideline 2008}

Clinical Practice Guideline Treating Tobacco Use and Dependence 2008 Update Panel, Liaisons, and Staff. A clinical practice guideline for treating tobacco use and dependence: 2008 update. A U.S. Public Health Service report. American Journal of Preventive Medicine 2008;35(2):158-76.

\section{Cromwell 2001}

Cromwell J, Bartosch WJ, Fiore MC, Hasselblad V, Baker T. Costeffectiveness of the clinical practice recommendations in the AHCPR guideline for smoking cessation. Journal of the American Medical Association 2001;278(11):1759-66.

\section{de Bruin 2020}

de Bruin M, Black N, Javornik N, Viechtbauer W, Eisma MC, Hartman-Boyce J, et al. Underreporting of the active content of behavioural interventions: a systematic review and meta-analysis of randomised trials of smoking cessation interventions. Health Psychology Review 2020;Epub ahead of print. [DOI: 10.1080/17437199.2019.1709098]

\section{Dino 2008}

Dino G, Horn K, Abdulkadri A, Kalsekar I, Branstetter S. Cost-effectiveness analysis of the Not On Tobacco program for adolescent smoking cessation. Prevention Science 2008;9(1):38-46.

\section{Dobbie 2015}

Dobbie F, Hiscock R, Leonardi-Bee J, Murray S, Shahab L, Aveyard P, et al. Evaluating Long-term Outcomes of NHS Stop Smoking Services (ELONS): a prospective cohort study. Health Technology Assessment 2015;19(95):1-156.

\section{Doll 2004}

Doll R, Peto R, Boreham J, Sutherland I. Mortality in relation to smoking: 50 years' observations on male British doctors. BMJ 2004;328(7455):1519.

\section{ERS 2013}

European Respiratory Society. European Lung White Book. Sheffield (UK): European Respiratory Society, 2013.

\section{Feenstra 2005}

Feenstra TL, Hamberg-van Reenen HH, Hoogenveen RT, Ruttenvan Molken MP. Cost-effectiveness of face-to-face smoking 
cessation interventions: a dynamic modeling study. Value Health 2005;8(3):178-90.

\section{Freeman 2018}

Freeman SC, Scott NW, Powell R, Johnston M, Sutton AJ, Cooper NJ. Component network meta-analysis identifies the most effective components of psychological preparation for adults undergoing surgery under general anesthesia. Journal of Clinical Epidemiology 2018;98:105-16. [DOI: 10.1016/ j.jclinepi.2018.02.012]

\section{GBD 2016}

Global Burden of Disease 2016 Risk Factors Collaborators. Global, regional, and national comparative risk assessment of 84 behavioural, environmental and occupational, and metabolic risks or clusters of risks, 1990-2016: a systematic analysis for the Global Burden of Disease Study 2016. Lancet 2017;390(10100):1345-422.

\section{Gilbert 2017}

Gilbert H, Sutton S, Morris R, Petersen I, Wu Q, Parrot S, et al. Start2quit: a randomised clinical controlled trial to evaluate the effectiveness and cost-effectiveness of using personal tailored risk information and taster sessions to increase the uptake of the NHS Stop Smoking Services. Health Technology Assessment 2017;21(3):1-206.

\section{Goodchild 2018}

Goodchild M, Nargis N, Tursan d'Espaignet E. Global economic cost of smoking-attributable diseases. Tobacco Control 2018;27:58-64.

\section{Hartmann-Boyce 2014a}

Hartmann-Boyce J, Stead LF, Cahill K, Lancaster T. Efficacy of interventions to combat tobacco addiction: Cochrane update of 2013 reviews. Addiction 2014;109(9):1414-25.

\section{Healey 2019}

Healey A, Roberts S, Sevdalis N, Goulding L, Wilson S, Shaw K, et al. Cost-effectiveness analysis of stop smoking interventions in substance-use disorder populations. Nicotine \& Tobacco Research 2019;21(5):623-30.

\section{Higgins 2011}

Higgins JP, Green S, editor(s). Cochrane Handbook for Systematic Reviews of Interventions Version 5.1.0 (updated March 2011). The Cochrane Collaboration, 2011. Available from www.handbook.cochrane.org.

\section{Javitz 2011}

Javitz HS, Zbikowski SM, Deprey M, McAfee TA, McClure JB, Richards J, et al. Cost-effectiveness of varenicline and three different behavioral treatment formats for smoking cessation. Translational Behavioral Medicine 2011;1(1):182-90.

\section{Lal 2014}

Lal A, Mihalopoulos C, Wallace A, Vos T. The cost-effectiveness of call-back counselling for smoking cessation. Tobacco Control 2014;23(5):437-42.

\section{Martín Cantera 2015}

Martín Cantera C, Puigdomènech E, Ballvé JL, Arias OL, Clemente L, Casas R, et al. Effectiveness of multicomponent interventions in primary healthcare settings to promote continuous smoking cessation in adults: a systematic review. BMJ Open 2015;5:e008807.

\section{McGhan 1996}

McGhan WF, Smith MD. Pharmacoeconomic analysis of smoking-cessation interventions. American Journal of HealthSystem Pharmacy 1996;53(1):45-52.

\section{Melendez-Torres 2015}

Melendez-Torres GJ, Bonell C, Thomas J. Emergent approaches to the meta-analysis of multiple heterogeneous complex interventions. BMC Medical Research Methodology 2015;15:47.

\section{Michie 2011}

Michie S, Hyder N, Walia A, West R. Development of a taxonomy of behaviour change techniques used in individual behavioural support for smoking cessation. Addictive Behaviours 2011;36(4):315-9.

\section{Michie 2013}

Michie S, Richardson M, Johnston M, Abraham C, Francis J, Hardeman W, et al. The behavior change technique taxonomy (v1) of 93 hierarchically clustered techniques: building an international consensus for the reporting of behavior change interventions. Annals of Behavioral Medicine 2013;46(1):81-95.

\section{Mons 2015}

Mons U, Müezzinler A, Gellert C, Schöttker B, Abnet CC, Bobak M, et al. Impact of smoking and smoking cessation on cardiovascular events and mortality among older adults: metaanalysis of individual participant data from prospective cohort studies of the CHANCES consortium. BMJ 2015;350:h1551.

\section{Mudde 1996}

Mudde AN, De Vries H, Strecher VJ. Cost-effectiveness of smoking cessation modalities: comparing apples with oranges? Preventive Medicine 1996;25(6):708-16.

\section{Müezzinler 2015}

Müezzinler A, Mons U, Gellert C, Schöttker B, Jansen E, Kee F, et al. Smoking and all-cause mortality in older adults: results from the CHANCES consortium. American Journal of Preventive Medicine 2015;49(5):e53-63.

\section{NICE 2018}

National Institute for Health and Care Excellence. Stop smoking interventions and services. NICE guideline (NG92). www.nice.org.uk/guidance/ng92 (accessed 29 July 2020). [www.nice.org.uk/guidance/ng92]

\section{Nohlert 2013}

Nohlert E, Helgason AR, Tillgren P, Tegelberg A, Johansson P. Comparison of the cost-effectiveness of a high and a low-intensity smoking cessation intervention in Sweden: a randomized trial. Nicotine \& Tobacco Research 2013;15(9):1519-27. 


\section{Ordóñez-Mena 2016}

Ordóñez-Mena JM, Schöttker B, Mons U, Jenab M, Freisling H, Bueno-de-Mesquita $B$, et al. Quantification of the smokingassociated cancer risk with rate advancement periods: metaanalysis of individual participant data from cohorts of the CHANCES consortium. BMC Medicine 2016;14(1):62.

\section{Papadakis 2010}

Papadakis S, McDonald P, Mullen KA, Reid R, Skulsky K, Pipe A. Strategies to increase the delivery of smoking cessation treatments in primary care settings: a systematic review and meta-analysis. Preventative Medicine 2010;51:199-213.

\section{Pirie 2013}

Pirie K, Peto R, Reeves GK, Green J, Beral V, Million Women Study Collaborators. The 21st century hazards of smoking and benefits of stopping: a prospective study of one million women in the UK. Lancet 2013;12(381):9861.

\section{Pollock 2020}

Pollock M, Fernandes RM, Becker LA, Pieper D, Hartling L. Chapter V: overviews of reviews. In: Higgins JP, Thomas J, Chandler J, Cumpston MS, Li T, Page MJ, et al, editor(s). Cochrane Handbook for Systematic Reviews of Interventions version 6.1 (updated September 2020). Cochrane, 2020. Available from training.cochrane.org/handbook.

\section{Popp 2018}

Popp J, Nyman JA, Luo X, Bengtson J, Lust K, An L, et al. Costeffectiveness of enhancing a Quit-and-Win smoking cessation program for college students. European Journal of Health Economics 2018;19(9):1319-33.

\section{Puhan 2014}

Puhan MA, Schünemann HJ, Murad MH, Li T, BrignardelloPeterson R, Sing JA, et al. A GRADE Working Group approach for rating the quality of treatment effect estimates from network meta-analysis. BMJ 2014;349:g5630.

\section{$\mathbf{R}$ (version 4.0.0) [Computer program]}

R Foundation for Statistical Computing R: a language and environment for statistical computing. R Core Team, Version 4.0.0. Vienna (Austria): R Foundation for Statistical Computing 2020. Available at www.R-project.org.

\section{Ruger 2008}

Ruger JP, Weinstein MC, Hammond SK, Kearney MH, Emmons KM. Cost-effectiveness of motivational interviewing for smoking cessation and relapse prevention among low-income pregnant women: a randomized controlled trial. Value Health 2008;11(2):191-8.

\section{Shea 2017}

Shea BJ, Reeves BC, Wells G, Thuku M, Hamel C, Moran J, et al. AMSTAR 2: a critical appraisal tool for systematic reviews that include randomised or non-randomised studies of healthcare interventions, or both. BMJ 2017;358:j4008. [DOI: 10.1136/ bmj.j4008]

\section{Shearer 2006}

Shearer J, Shanahan M. Cost effectiveness analysis of smoking cessation interventions. Australian and New Zealand Journal of Public Health 2006;30(5):428-34.

\section{Shemilt 2020}

Shemilt I, Aluko P, Graybill E, Craig D, Henderson C, Drummond $\mathrm{M}$, et al. Chapter 20: economics evidence. In: Higgins JP, Thomas J, Chandler J, Cumpston MS, Li T, Page MJ, et al, editor(s). Cochrane Handbook for Systematic Reviews of Interventions version 6.1 (updated September 2020). Cochrane, 2020. Available from training.cochrane.org/handbook.

\section{SIGN 2018}

Scottish Intercollegiate Guideline Network. Search filters. www.sign.ac.uk/search-filters.html (accessed 1 October 2018).

\section{Smit 2013}

Smit ES, Evers SM, de Vries H, Hoving C. Cost-effectiveness and cost-utility of Internet-based computer tailoring for smoking cessation. Journal of Medical Internet Research 2013;15(3):e57.

\section{Stead 2016}

Stead LF, Koilpillai P, Fanshawe T, Lancaster T. Combined pharmacotherapy and behavioural interventions for smoking cessation. Cochrane Database of Systematic Reviews 2016, Issue 3. Art. No: CD008286. [DOI: 10.1002/14651858.CD008286.pub3]

\section{Sturtz 2005}

Sturtz S, Ligges U, Gelman A. R2WinBUGS: a package for running WinBUGSfrom R. Journal of Statistical Software 2005;12(3):1-16.

\section{Tosanguan 2016}

Tosanguan J, Chaiyakunapruk N. Cost-effectiveness analysis of clinical smoking cessation interventions in Thailand. Addiction 2016;111(2):340-50.

\section{Tsoi 2013}

Tsoi DT, Porwal M, Webster AC. Interventions for smoking cessation and reduction in individuals with schizophrenia. Cochrane Database of Systematic Reviews 2013, Issue 2. Art. No: CD007253. [DOI: 10.1002/14651858.CD007253.pub3]

\section{USDHHS 2014}

US Department of Health and Human Services. The Health Consequences of Smoking - 50 Years of Progress: a Report of the Surgeon General. Atlanta (GA): U.S. Department of Health and Human Services, Centers for Disease Control and Prevention, National Center for Chronic Disease Prevention and Health Promotion, Office on Smoking and Health, 2014.

\section{van der Meer 2013}

van der Meer RM, Willemsen MC, Smit F, Cuijpers P. Smoking cessation interventions for smokers with current or past depression. Cochrane Database of Systematic Reviews 2013, Issue 8. Art. No: CD006102. [DOI: 10.1002/14651858.CD006102.pub2]

\section{Vangeli 2011}

Vangeli E, Stapleton J, Smit ES, Borland R, West R. Predictors of attempts to stop smoking and their success in adult 
general population samples: a systematic review. Addiction 2011;106(12):2110-21.

\section{West 2005}

West R, Hajek P, Stead L, Stapleton J. Outcome criteria in smoking cessation trials: proposal for a common standard. Addiction 2005;100(3):299-303.

\section{West 2007}

West R. The clinical significance of 'small' effects of smoking cessation treatments. Addiction 2007;102:506-9. [DOI: 10.1111/ j.1360-0443.2007.01750.x]

\section{West 2013}

West R, May S, West M, Croghan E, McEwen A. Performance of English stop smoking services in first 10 years: analysis of service monitoring data. BMJ 2013;347:f4921.

\section{WHO 2018}

World Health Organization. World Health Organization fact sheets. Tobacco. www.who.int/news-room/fact-sheets/detail/ tobacco (accessed 3 September 2018).

\section{WinBUGS 2015 [Computer program]}

Medical Research Council Biostatistics Unit WinBUGS. Version 1.4.3. Cambridge (UK): Medical Research Council Biostatistics
Unit, 2015. Available at www.mrc-bsu.cam.ac.uk/software/ bugs/the-bugs-project-winbugs/.

\section{Wu 2018}

Wu Q, Gilbert H, Nazareth I, Sutton S, Morris R, Petersen I, et al. Cost-effectiveness of personal tailored risk information and taster sessions to increase the uptake of the NHS stop smoking services: the Start2quit randomized controlled trial. Addiction 2018;113(4):708-18.

\section{Yepes-Nuñez 2019}

Yepes-Nuñez JJ, Li SA, Guyatt G, Jack SM, Brozek JL, Beyen J, et al. Development of the summary of findings table for network meta-analysis. Journal of Clinical Epidemiology 2019;115:1-13.

\section{References to other published versions of this review Hartmann-Boyce 2018}

Hartmann-Boyce J, Fanshawe TR, Lindson N, LivingstoneBanks J, Ordóñez-Mena JM, Aveyard P. Behavioural interventions for smoking cessation: an overview and network meta-analysis. Cochrane Database of Systematic Reviews 2018, Issue 12. Art. No: CD013229. [DOI: 10.1002/14651858.CD013229]

\section{ADDITIONAL TABLES}

Table 1. Characteristics of excluded reviews

\begin{tabular}{ll}
\hline Review ID & Reason for exclusion \\
\hline Cahill 2008 & Review withdrawn from the Cochrane Library as superseded by Fanshawe 2019 \\
\hline Dale 2008 & $\begin{array}{l}\text { Ineligible intervention: only } 1 \text { included study addressed smoking and that was a multiple behav- } \\
\text { iour intervention that also involved changes to diet }\end{array}$
\end{tabular}

Fanshawe $2017 \quad$ Ineligible participant population: adolescents

Table 2. Studies eligible for analysis but excluded because the components did not differ by trial arm

\begin{tabular}{ll}
\hline Review & Study ID \\
\hline Hartmann-Boyce 2019 & Begh 2015 \\
\cline { 2 - 2 } & Garvey 2012 (listed as excluded in original review) \\
\cline { 2 - 2 } & Warner 2016 \\
\hline Hollands 2019 & Marteau 2012 \\
\hline Lindson 2019a & Davis 2011 \\
\hline Lindson 2019b & Cinciripini 1995 \\
\cline { 2 - 2 }
\end{tabular}


Table 2. Studies eligible for analysis but excluded because the components did not differ by trial arm (Continued)

\begin{tabular}{|c|c|}
\hline & Glasgow 1989 \\
\hline & Gunther 1992 \\
\hline & Hao 2017 \\
\hline & Ho 2018 \\
\hline & Lindson-Hawley 2016b \\
\hline Livingstone-Banks 2019a & Berman 1995 \\
\hline & Lando 1988 \\
\hline & Webb 2013 \\
\hline Livingstone-Banks 2019b & Buchkremer 19912 \\
\hline & Davis 1986 \\
\hline Stead 2017 & Ward 2001 \\
\hline Taylor 2017 & Moskowitz 2016 \\
\hline & Muñoz 2006 Study 3 \\
\hline & Muñoz 2006 Study 4 \\
\hline Whittaker 2019 & Augustson 2017 \\
\hline & BinDhim 2018 \\
\hline & Garrison 2018 \\
\hline
\end{tabular}

Table 3. Frequency of components across included study arms

\begin{tabular}{llc}
\hline Component & n arms & \% arms \\
\hline N total arms & 845 & 100 \\
\hline Minimal intervention & 61 & 7.46 \\
\hline Focus & 574 & 67.9 \\
\hline How & 306 & 36.2 \\
\hline Why & & 61.3 \\
\hline Nature & 518 & 76.7 \\
\hline Motivation & 648 & \\
\hline Self-regulation & & \\
\hline Behavioural interventions for smoking cessation: an overview and network meta-analysis (Review) & \\
Copyright $\odot 2021$ The Cochrane Collaboration. Published by John Wiley \& Sons, Ltd. & $\mathbf{3 7}$
\end{tabular}


Table 3. Frequency of components across included study arms (Continued)

\begin{tabular}{|c|c|c|}
\hline Adjuvant activities & 342 & 40.5 \\
\hline \multicolumn{3}{|l|}{ Behavioural components } \\
\hline Counselling & 439 & 52.0 \\
\hline Biofeedback & 48 & 5.68 \\
\hline Hypnotherapy & 13 & 1.54 \\
\hline Exercise & 23 & 2.72 \\
\hline Financial incentives: guaranteed & 25 & 2.96 \\
\hline Financial incentives: not guaranteed & 18 & 2.13 \\
\hline Tailoring & 510 & 60.36 \\
\hline \multicolumn{3}{|l|}{ Intervention provider } \\
\hline Nurse (general) & 42 & 4.97 \\
\hline Nurse (specialist) & 26 & 3.08 \\
\hline Stop smoking advisor & 74 & 8.76 \\
\hline Psychologist/counsellor & 155 & 18.3 \\
\hline Physician & 145 & 17.2 \\
\hline Pharmacist & 9 & 1.07 \\
\hline Dentist & 4 & 0.47 \\
\hline Lay health advisor & 10 & 1.18 \\
\hline Hypnotist & 10 & 1.18 \\
\hline Exercise specialist & 9 & 1.07 \\
\hline Other provider & 45 & 5.33 \\
\hline \multicolumn{3}{|l|}{ Delivery mode } \\
\hline Group & 158 & 18.7 \\
\hline Individual & 441 & 52.2 \\
\hline Face-to-face & 457 & 54.1 \\
\hline Telephone & 220 & 26.0 \\
\hline Web/computer & 91 & 10.8 \\
\hline Print & 428 & 50.7 \\
\hline
\end{tabular}


Table 3. Frequency of components across included study arms (Continued)

\begin{tabular}{|c|c|c|}
\hline SMS & 31 & 3.67 \\
\hline App & 4 & 0.47 \\
\hline Video (static) & 29 & 3.43 \\
\hline Video (interactive) & 4 & 0.47 \\
\hline Audio & 15 & 1.78 \\
\hline Interactive voice response & 22 & 2.60 \\
\hline Quitline & 14 & 1.66 \\
\hline Email & 8 & 0.95 \\
\hline Other & 4 & 0.47 \\
\hline \multicolumn{3}{|l|}{ Pharmacology } \\
\hline Nicotine replacement therapy & 213 & 25.2 \\
\hline Bupropion & 17 & 2.01 \\
\hline Varenicline & 5 & 0.59 \\
\hline Other & 65 & 7.69 \\
\hline
\end{tabular}

$\mathrm{n}$ : number.

Table 4. Effect estimates and credibility intervals for study-level covariates

\begin{tabular}{llc}
\hline Covariate & OR & 95\% CrI \\
\hline Age (continuous) & 1.000 & 0.999 to 1.001 \\
\hline Cigarettes per day at baseline (continuous) & 1.000 & 0.999 to 1.002 \\
\hline Control arm quit rate (\% quit) (continuous) & 0.999 & 0.992 to 1.005 \\
\hline Women (\%) (continuous) & 1.000 & 0.999 to 1.000 \\
\hline Length of follow-up (in months) (6 months vs > 6 months) $a$ & 1.005 & 0.992 to 1.017 \\
\hline Pharmacotherapy (pharmacotherapy vs no pharmacotherapy) & 0.985 & 0.975 to 0.996 \\
\hline Pre-existing conditions (less healthy vs more healthy) & 1.018 & 0.981 to 1.054 \\
\hline Setting (healthcare vs community) & 1.002 & 0.991 to 1.012 \\
\hline Socioeconomic status (low vs high) & 1.008 & 0.994 to 1.023
\end{tabular}

aThis was calculated as a binary variable as opposed to continuous as the data were not normally distributed (positively skewed). Crl: credibility interval; OR: odds ratio. 
Table 5. Adverse events/harms reported in included reviews

$\begin{array}{ll}\text { Review } & \begin{array}{l}\text { Number of studies Summary of key findings } \\ \text { measuring }\end{array}\end{array}$

\begin{tabular}{lll}
\hline Barnes 2019 & 2 & $\begin{array}{l}\text { Neither reported any resulting from hypnotherapy, though } 1 \text { reported on vomiting } \\
\text { in an arm receiving rapid smoking as an intervention. }\end{array}$
\end{tabular}

\begin{tabular}{lll}
\hline Cahill 2010 & Unclear & Stated adverse events was an outcome, but did not report any in their results. \\
\hline $\begin{array}{l}\text { Carson-Chahhoud } \\
2019\end{array}$ & 1 & All attributable to study medications participants were receiving. \\
\hline Chamberlain 2017 & 13 & None reported. \\
\hline Fanshawe 2019 & 5 & $\begin{array}{l}\text { No studies indicated that adverse events were related to the competition compo- } \\
\text { nent of the intervention. }\end{array}$ \\
\hline Hollands 2019 & 4 & $\begin{array}{l}\text { No adverse events were considered plausibly related to the behavioural component } \\
\text { of the intervention. }\end{array}$ \\
\hline Lindson 2019b & 18 & $\begin{array}{l}\text { 11 studies reported the number of participants who reported adverse events or se- } \\
\text { rious adverse events during the prequit period, and } 7 \text { studies reported prequit with- } \\
\text { drawal symptoms. For serious adverse events, either none were reported or rates } \\
\text { were low and well-balanced between trial arms. Adverse events were measured in } \\
\text { studies where nicotine replacement therapy was used prequit and appeared to be } \\
\text { those usually attributed to these medications. Data on withdrawal and craving were } \\
\text { sparse and conclusions varied making it impossible to draw conclusions. No studies } \\
\text { reported adverse effects of behavioural support, however. }\end{array}$
\end{tabular}

\begin{tabular}{lll}
\hline Marteau 2010 & 0 & - \\
\hline Notley 2019 & 1 & $\begin{array}{l}\text { Some evidence on the likelihood of the participants 'gaming' to receive unmerited } \\
\text { rewards. }\end{array}$ \\
\hline Taylor 2017 & 6 & $\begin{array}{l}\text { Review authors gave no indication that these adverse events were related to Inter- } \\
\text { net-based smoking cessation interventions. }\end{array}$ \\
\hline $\begin{array}{l}\text { Vodopivec-Jamsek } \\
2012\end{array}$ & 1 & $\begin{array}{l}\text { Study looked for differences in finger and joint pain and car crashes resulting from } \\
\text { texting. They reported no difference between study groups. }\end{array}$ \\
\hline
\end{tabular}


Table 6. Summary of findings table: behavioural and motivational components of behavioural interventions for smoking cessation

Benefits: behavioural and motivational components of behavioural interventions for smoking cessation

Population: adults (aged $\geq 18$ years) who smoked cigarettes

Components: behavioural and motivational components of behavioural interventions for smoking cessation

Comparator: minimal intervention (no smoking cessation support)

Outcome: smoking cessation at 6-34 months

Setting: healthcare and community, predominantly USA and Western Europe

\begin{tabular}{|c|c|c|c|c|c|c|c|}
\hline \multirow[t]{2}{*}{ Component } & \multirow{2}{*}{$\begin{array}{l}\text { No partici- } \\
\text { pants (stud- } \\
\text { ies) }\end{array}$} & \multirow{2}{*}{$\begin{array}{l}\text { Relative effect } \\
(95 \% \text { Crl) }\end{array}$} & \multicolumn{3}{|c|}{ Anticipated absolute effect ${ }^{\star \star}$} & \multirow{2}{*}{$\begin{array}{l}\text { Certainty of } \\
\text { the evidence }\end{array}$} & \multirow[t]{2}{*}{ Notes } \\
\hline & & & $\begin{array}{l}\text { Without in- } \\
\text { tervention }\end{array}$ & With intervention & Difference & & \\
\hline
\end{tabular}

Motivational components: focus

\begin{tabular}{|c|c|c|c|c|c|c|c|}
\hline How to quit & $\begin{array}{l}141,707 \\
\text { (226 RCTs) }\end{array}$ & $\begin{array}{l}\text { OR } 1.19 \\
\text { (1.01 to } 1.41)\end{array}$ & 60 per 1000 & 71 per 1000 (61 to 83$)$ & $\begin{array}{l}11 \text { per } 1000 \text { ( } 1 \text { to } \\
23)\end{array}$ & Moderate ${ }^{a}$ & - \\
\hline Why quit & $\begin{array}{l}86,232 \\
(152 \mathrm{RCTs})\end{array}$ & $\begin{array}{l}\text { OR } 1.01 \\
\text { (0.88 to } 1.16)\end{array}$ & 60 per 1000 & 61 per 1000 (54 to 70$)$ & $\begin{array}{l}1 \text { per } 1000 \\
\text { (-6 to } 10)\end{array}$ & Low $b$ & - \\
\hline
\end{tabular}

Motivational components: nature

\begin{tabular}{|c|c|c|c|c|c|c|c|}
\hline $\begin{array}{l}\text { Adjuvant ac- } \\
\text { tivities }\end{array}$ & $\begin{array}{l}90,186 \\
(141 \mathrm{RCTs})\end{array}$ & $\begin{array}{l}\text { OR } 1.08 \\
(0.94 \text { to } 1.23)\end{array}$ & 60 per 1000 & 65 per 1000 (57 to 73 ) & $\begin{array}{l}5 \text { per } 1000 \\
(-3 \text { to } 13)\end{array}$ & Low $b$ & - \\
\hline Motivation & $\begin{array}{l}143,488 \\
\text { (231 RCTs) }\end{array}$ & $\begin{array}{l}\text { OR } 1.08 \\
\text { (0.96 to } 1.22)\end{array}$ & 60 per 1000 & 65 per 1000 (58 to 73 ) & $\begin{array}{l}5 \text { per } 1000 \\
\text { (-2 to } 13)\end{array}$ & Moderate ${ }^{a}$ & - \\
\hline $\begin{array}{l}\text { Self-regula- } \\
\text { tion }\end{array}$ & $\begin{array}{l}158,222 \\
\text { (257 RCTs) }\end{array}$ & $\begin{array}{l}\text { OR } 1.05 \\
\text { (0.91 to } 1.22)\end{array}$ & 60 per 1000 & 63 per 1000 (55 to 73 ) & $\begin{array}{l}3 \text { per } 1000 \\
(-5 \text { to } 13)\end{array}$ & Low $b$ & - \\
\hline \multicolumn{8}{|c|}{ Behavioural components } \\
\hline Counselling & $\begin{array}{l}72,273 \\
\text { (194 RCTs) }\end{array}$ & $\begin{array}{l}\text { OR } 1.44 \\
(1.22 \text { to } 1.70)\end{array}$ & 60 per 1000 & 85 per 1000 (73 to 99) & $\begin{array}{l}25 \text { per } 1000 \text { (13 to } \\
39)\end{array}$ & High & $\begin{array}{l}\text { This is consistent with high- } \\
\text { and moderate-certainty evi- }\end{array}$ \\
\hline
\end{tabular}




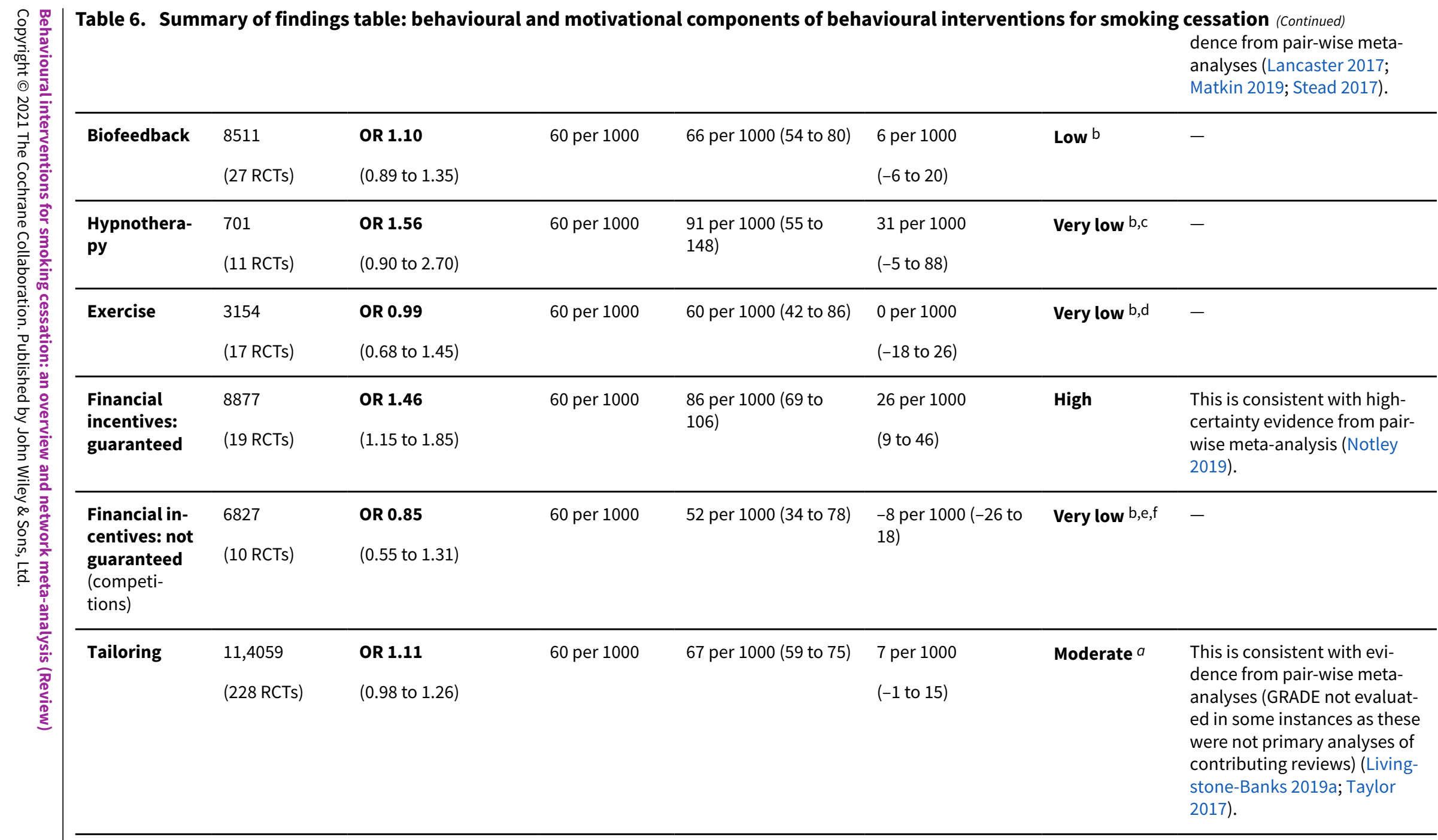

\section{Network meta-analysis 'Summary of findings' table definitions}

${ }^{\star}$ Estimates are reported as odds ratio. Results are expressed in credibility interval as opposed to the confidence intervals since a Bayesian analysis has been conducted.

**Anticipated absolute effect compared two risks by calculating the difference between the risks of the intervention component with the risk of the minimal intervention comparator (assumed to be 60 per 1000 based on mean quit rate in minimal intervention arms).

Crl: credibility interval; OR: odds ratio; $\mathbf{R C T}$ : randomised controlled trial. 


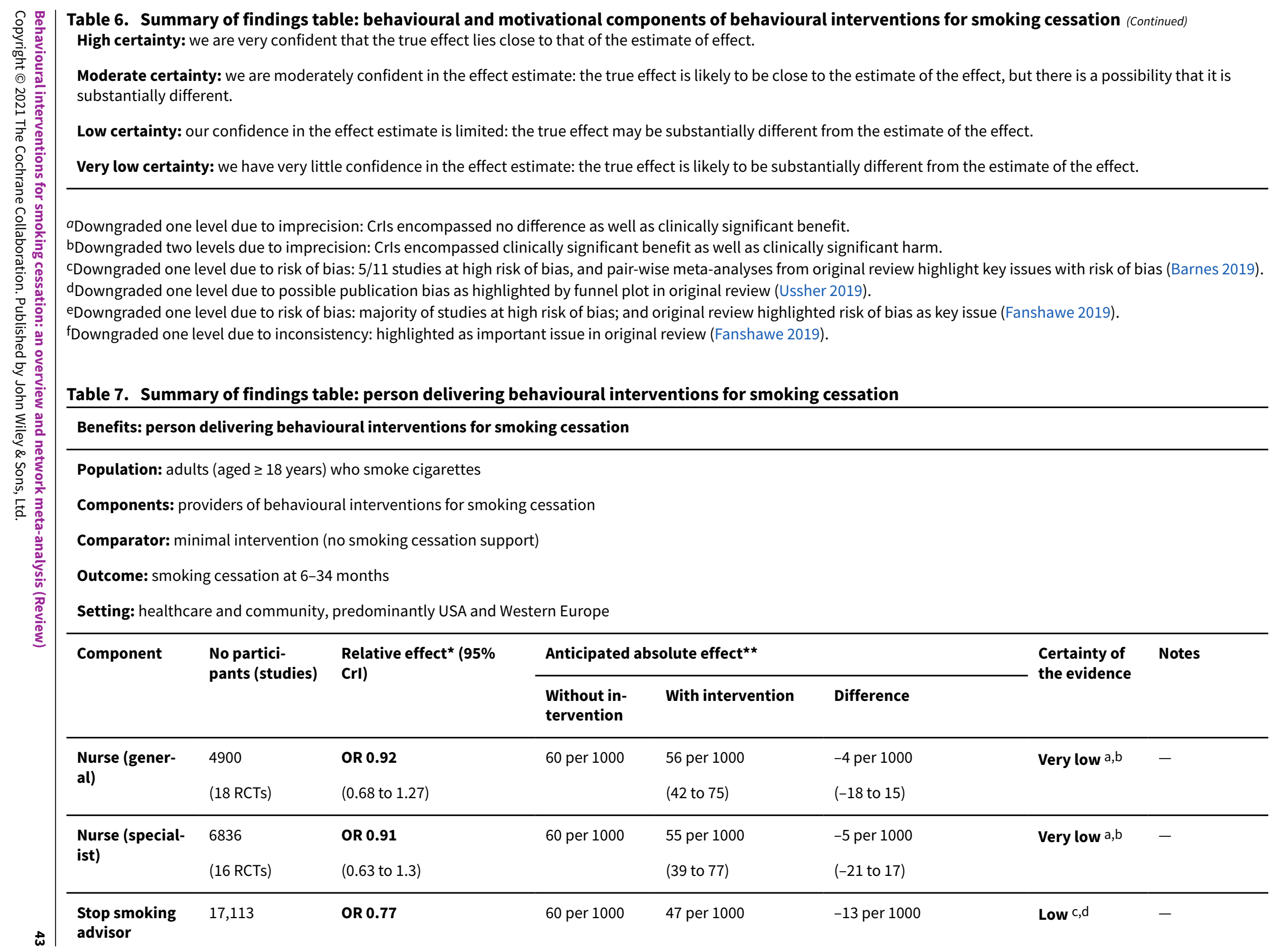




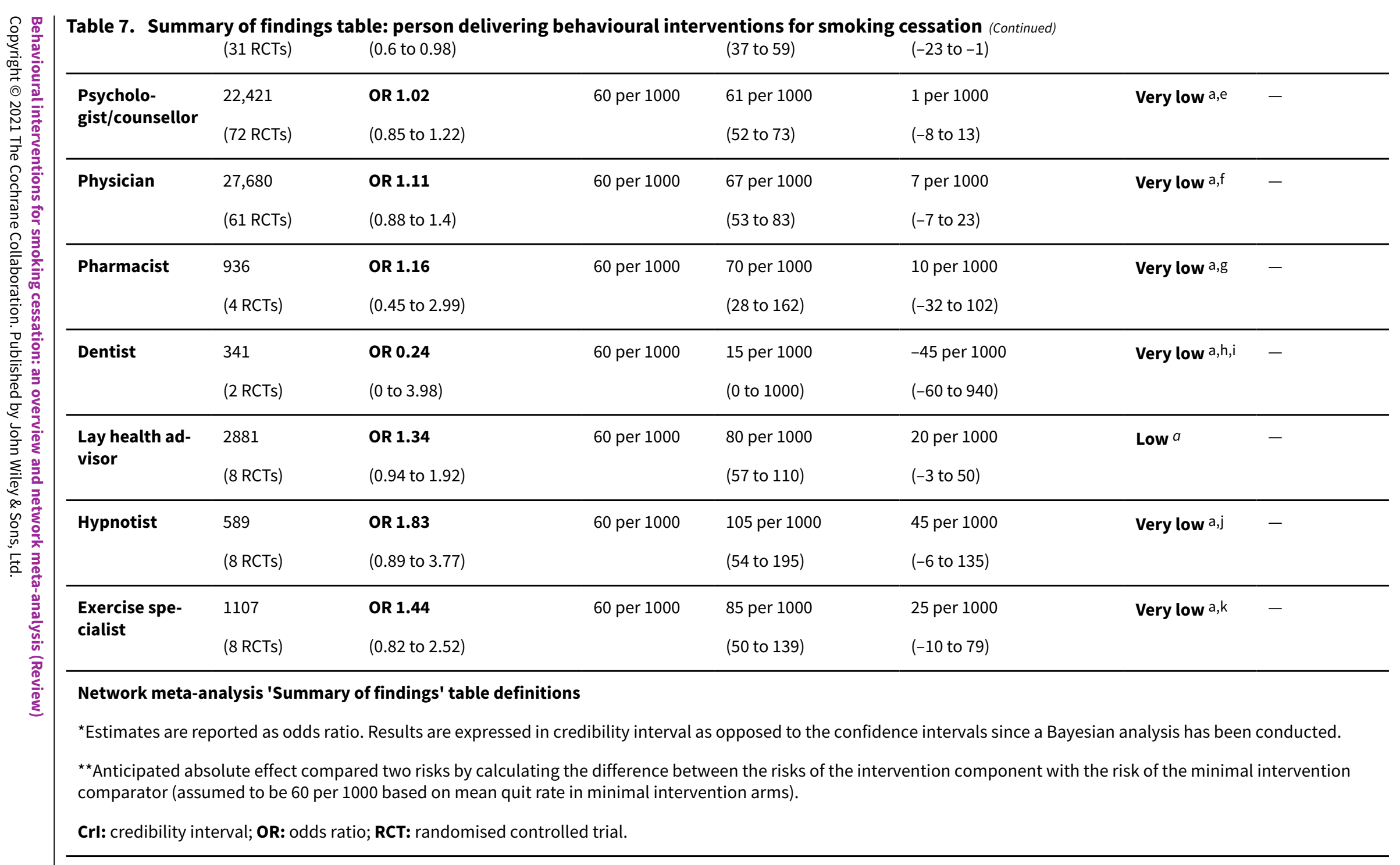

\section{GRADE Working Group grades of evidence}

High certainty: we are very confident that the true effect lies close to that of the estimate of effect.

Moderate certainty: we are moderately confident in the effect estimate: the true effect is likely to be close to the estimate of the effect, but there is a possibility that it is substantially different. 


\begin{tabular}{|c|c|c|c|c|c|c|c|}
\hline \multicolumn{8}{|c|}{ Very low certainty: we have very little confidence in the effect estimate: the true effect is likely to be substantially different from the estimate of the effect. } \\
\hline \multicolumn{8}{|c|}{$\begin{array}{l}\text { aDowngraded two levels due to imprecision: Crls encompass clinically significant benefit as well as clinically significant harm. } \\
\text { bDowngraded one level due to inconsistency: pair-wise meta-analyses indicated substantial unexplained statistical heterogeneity (Rice 2017). } \\
\text { cDowngraded one level due to imprecision: Crls encompass no difference as well as clinically significant harm. } \\
\text { dDowngraded one level due to indirectness: coding of 'stop smoking advisor' was based on author descriptions in individual studies and includes large level of variability across } \\
\text { different settings. } \\
\text { eDowngraded one level due to risk of bias: majority of studies contributing data judged to be at high risk of bias; removing these reduced the point estimate. } \\
\text { fDowngraded one level due to risk of bias: removing studies at high risk of bias clinically significantly decreased point estimate. } \\
\text { gDowngraded one level due to risk of bias: risk of bias downgraded } 1 \text { level in pair-wise comparison (Carson-Chahhoud 2019); removing studies at high risk of bias changed } \\
\text { direction of point estimate in component network meta-analysis. } \\
\text { hDowngraded one level due to risk of bias: component effect estimate could not be computed in risk of bias sensitivity analysis due to so few studies at low/unclear risk of bias } \\
\text { contributing data for this component. } \\
\text { iDowngraded one level due to risk of publication bias: authors of original review consider literature at risk of publication bias (Carr 2012). } \\
\text { jDowngraded one level due to risk of bias: original review highlights substantial issues regarding risk of bias (Barnes 2019). } \\
\text { kDowngraded one level due to possible publication bias as highlighted by funnel plot in original review (Ussher 2019). }\end{array}$} \\
\hline \multicolumn{8}{|c|}{ Benefits: mode of delivery of behavioural interventions for smoking cessation } \\
\hline $\begin{array}{l}\text { Population: } \\
\text { Component } \\
\text { Comparator } \\
\text { Outcome: sn } \\
\text { Setting: hea }\end{array}$ & $\begin{array}{l}\text { ults (aged } \geq 18 \text { years } \\
\text { elivery modes of be } \\
\text { inimal intervention } \\
\text { king cessation at 6- } \\
\text { care and communit }\end{array}$ & $\begin{array}{l}\text { who smoke cigarettes } \\
\text { avioural interventions for } \\
\text { no smoking cessation sup } \\
\text { months } \\
\text { predominantly USA and }\end{array}$ & $\begin{array}{l}\text { oking cessatio } \\
\text { t) } \\
\text { tern Europe }\end{array}$ & & & & \\
\hline \multirow[t]{2}{*}{ Component } & \multirow{2}{*}{$\begin{array}{l}\text { No participants } \\
\text { (studies) }\end{array}$} & \multirow{2}{*}{$\begin{array}{l}\text { Relative effect* }(95 \% \\
\text { Crl) }\end{array}$} & \multicolumn{3}{|c|}{ Anticipated absolute effect ${ }^{\star \star}$} & \multirow{2}{*}{$\begin{array}{l}\text { Certainty of } \\
\text { the evidence }\end{array}$} & \multirow[t]{2}{*}{ Notes } \\
\hline & & & $\begin{array}{l}\text { Without in- } \\
\text { tervention }\end{array}$ & With intervention & Difference & & \\
\hline Group & $\begin{array}{l}15,574 \\
\text { (75 RCTs) }\end{array}$ & $\begin{array}{l}\text { OR } 1.16 \\
(0.96 \text { to } 1.40)\end{array}$ & 60 per 1000 & 69 per 1000 (58 to 83$)$ & $\begin{array}{l}9 \text { per } 1000 \\
(-2 \text { to } 23)\end{array}$ & Low $\mathrm{a}, \mathrm{b}$ & - \\
\hline Individual & $\begin{array}{l}88,569 \\
(185 \mathrm{RCTs})\end{array}$ & $\begin{array}{l}\text { OR } 0.90 \\
\text { (0.76 to } 1.07)\end{array}$ & 60 per 1000 & 55 per 1000 (47 to 64$)$ & $\begin{array}{l}-5 \text { per } 1000 \\
(-13 \text { to } 4)\end{array}$ & Very low $c, d$ & - \\
\hline
\end{tabular}




\begin{tabular}{|c|c|c|c|c|c|c|c|}
\hline Face-to-face & $\begin{array}{l}65,044 \\
\text { (177 RCTs) }\end{array}$ & $\begin{array}{l}\text { OR } 1.04 \\
\text { (0.86 to } 1.25 \text { ) }\end{array}$ & 60 per 1000 & 63 per 1000 (52 to 75$)$ & $\begin{array}{l}3 \text { per } 1000 \\
\text { (-8 to } 15)\end{array}$ & Very low $c, e$ & - \\
\hline Telephone & $\begin{array}{l}47,029 \\
\text { (94 RCTs) }\end{array}$ & $\begin{array}{l}\text { OR } 0.98 \\
\text { (0.83 to } 1.15 \text { ) }\end{array}$ & 60 per 1000 & 59 per 1000 (51 to 69$)$ & $\begin{array}{l}-1 \text { per } 1000 \\
\text { (-9 to } 9)\end{array}$ & Very low e,f & - \\
\hline $\begin{array}{l}\text { Inter- } \\
\text { net/comput- } \\
\text { er }\end{array}$ & $\begin{array}{l}41,002 \\
\text { (50 RCTs) }\end{array}$ & $\begin{array}{l}\text { OR } 1.08 \\
\text { (0.89 to } 1.31)\end{array}$ & 60 per 1000 & 65 per 1000 (54 to 78 ) & $\begin{array}{l}5 \text { per } 1000 \\
(-6 \text { to } 18)\end{array}$ & Very low e,g & - \\
\hline Print & $\begin{array}{l}115,067 \\
(170 \text { RCTs) }\end{array}$ & $\begin{array}{l}\text { OR } 1.01 \\
\text { (0.88 to } 1.15 \text { ) }\end{array}$ & 60 per 1000 & 61 per 1000 (53 to 69$)$ & $\begin{array}{l}1 \text { per } 1000 \\
\text { (-7 to } 9)\end{array}$ & Low $\mathrm{e}$ & - \\
\hline $\begin{array}{l}\text { SMS (text- } \\
\text { message) }\end{array}$ & $\begin{array}{l}14,161 \\
\text { (22 RCTs) }\end{array}$ & $\begin{array}{l}\text { OR } 1.45 \\
(1.17 \text { to } 1.80)\end{array}$ & 60 per 1000 & 85 per 1000 (70 to 104$)$ & $\begin{array}{l}25 \text { per } 1000 \\
\text { (10 to } 44)\end{array}$ & Moderate $\mathrm{h}$ & - \\
\hline App & $\begin{array}{l}1083 \\
\text { (3 RCTs) }\end{array}$ & $\begin{array}{l}\text { OR } 1.26 \\
\text { (0.62 to } 2.57 \text { ) }\end{array}$ & 60 per 1000 & 75 per 1000 (38 to 142 ) & $\begin{array}{l}15 \text { per } 1000 \\
\text { (-22 to } 82)\end{array}$ & Very low e,i & - \\
\hline Video (static) & $\begin{array}{l}10,254 \\
\text { (20 RCTs) }\end{array}$ & $\begin{array}{l}\text { OR } \mathbf{0 . 8 3} \\
\text { (0.65 to } 1.07 \text { ) }\end{array}$ & 60 per 1000 & 51 per 1000 (40 to 65$)$ & $\begin{array}{l}-9 \text { per } 1000 \\
(-20 \text { to } 5)\end{array}$ & Low $\mathrm{e}$ & - \\
\hline $\begin{array}{l}\text { Video (inter- } \\
\text { active) }\end{array}$ & $\begin{array}{l}1802 \\
\text { (3 RCTs) }\end{array}$ & $\begin{array}{l}\text { OR } 0.99 \\
\text { (0.43 to } 2.27 \text { ) }\end{array}$ & 60 per 1000 & 60 per 1000 ( 27 to 127 ) & $\begin{array}{l}0 \text { per } 1000 \\
(-33 \text { to } 67)\end{array}$ & Low $\mathrm{e}$ & - \\
\hline Audio & $\begin{array}{l}5039 \\
\text { (11 RCTs) }\end{array}$ & $\begin{array}{l}\text { OR } 1.32 \\
\text { (0.91 to } 1.92)\end{array}$ & 60 per 1000 & 78 per 1000 ( 55 to 110 ) & $\begin{array}{l}18 \text { per } 1000 \\
(-5 \text { to } 50)\end{array}$ & Low $\mathrm{e}$ & - \\
\hline $\begin{array}{l}\text { Interactive } \\
\text { voice re- } \\
\text { sponse }\end{array}$ & $\begin{array}{l}1293 \\
\text { (5 RCTs) }\end{array}$ & $\begin{array}{l}\text { OR } 1.19 \\
\text { (0.79 to } 1.81)\end{array}$ & 60 per 1000 & 71 per 1000 (48 to 104 ) & $\begin{array}{l}11 \text { per } 1000 \\
(-12 \text { to } 44)\end{array}$ & Low $\mathrm{e}$ & - \\
\hline $\begin{array}{l}\text { Quitline ac- } \\
\text { cess }\end{array}$ & $\begin{array}{l}6771 \\
\text { (10 RCTs) }\end{array}$ & $\begin{array}{l}\text { OR } \mathbf{0 . 8 3} \\
\text { (0.62 to } 1.12 \text { ) }\end{array}$ & 60 per 1000 & 51 per 1000 (38 to 67 ) & $\begin{array}{l}-9 \text { per } 1000 \\
(-22 \text { to } 7)\end{array}$ & Very low e,j & - \\
\hline Email & 1847 & OR 1.61 & 60 per 1000 & 94 per 1000 (56 to 153 ) & 34 per 1000 & Low $\mathrm{e}$ & - \\
\hline
\end{tabular}


Table 8. Summary of findings table: mode of delivery of behavioural interventions for smoking cessation (Continued) (4 RCTs) (0.92 to 2.80$)$

\section{Network meta-analysis 'Summary of findings' table definitions}

*Estimates are reported as odds ratio. Results are expressed in credibility interval as opposed to the confidence intervals since a Bayesian analysis has been conducted.

**Anticipated absolute effect compared two risks by calculating the difference between the risks of the intervention component with the risk of the minimal intervention comparator (assumed to be 60 per 1000 based on mean quit rate in minimal intervention arms).

Crl: credibility interval; OR: odds ratio; $\mathbf{R C T}$ : randomised controlled trial.

\section{GRADE Working Group grades of evidence}

High certainty: we are very confident that the true effect lies close to that of the estimate of effect.

Moderate certainty: we are moderately confident in the effect estimate: the true effect is likely to be close to the estimate of the effect, but there is a possibility that it is substantially different.

Low certainty: our confidence in the effect estimate is limited: the true effect may be substantially different from the estimate of the effect.

Very low certainty: we have very little confidence in the effect estimate: the true effect is likely to be substantially different from the estimate of the effect.

aDowngraded one level due to imprecision: Crls encompassed no difference as well as clinically significant benefit.

bDowngraded one level due to risk of bias: 26/75 trials contributed data at high risk of bias, and pair-wise meta-analyses downgraded based on risk of bias issues (Stead 2017).

cDowngraded two levels due to inconsistency: component effect estimates not consistent with high- and moderate-certainty evidence from pair-wise meta-analyses suggesting clinically significant benefit of face-to-face and individual delivery modes (Lancaster 2017; Stead 2017).

dDowngraded one level due to imprecision: Crls encompassed no difference as well as clinically significant harm.

eDowngraded two levels due to imprecision: Crls encompassed clinically significant benefit as well as clinically significant harm.

fDowngraded one level due to inconsistency: substantial unexplained heterogeneity detected in pair-wise comparison (12=52\%) (Matkin 2019).

gDowngraded one level due to inconsistency: pair-wise meta-analyses indicated multiple analyses with substantial unexplained statistical heterogeneity (Taylor 2017).

hDowngraded one level due to inconsistency: substantial unexplained heterogeneity detected in pair-wise comparison (I2 = 71\%) (Whittaker 2019).

iDowngraded one level due to inconsistency: pair-wise meta-analysis indicated substantial heterogeneity (Whittaker 2019).

jDowngraded two levels due to inconsistency: component effect estimates not consistent with evidence from pair-wise meta-analysis (two trials) suggesting clinically significant benefit of quitline access (Matkin 2019). 
Table 9. Key characteristics of evaluations included in brief economic commentary

\begin{tabular}{|c|c|c|c|}
\hline Study ID & Country & Evaluation type & Analysis type \\
\hline An 2010 & USA & Observational study-based & Cost-effectiveness \\
\hline Barnett 2013 & USA & Model-based & Cost-effectiveness and cost-utility \\
\hline Bauld 2011 & UK & Model-based & Cost-effectiveness and cost-utility \\
\hline Begh 2011 & UK & Trial-based & Cost-utility \\
\hline Berndt 2016 & Netherlands & Trial-based & Cost-effectiveness and cost-utility \\
\hline Boyd 2009 & USA & Model-based & Cost-effectiveness \\
\hline Calhoun 2016 & USA & Trial-based & Cost-effectiveness and cost-utility \\
\hline Cromwell 2001 & USA & Model-based & Cost-effectiveness and cost-utility \\
\hline Dino 2008 & USA & Model-based & Cost-effectiveness \\
\hline Feenstra 2005 & Netherlands & Model-based & Cost-effectiveness and cost-utility \\
\hline Gilbert 2017 & UK & Trial-based & Cost-effectiveness and cost-utility \\
\hline Healey 2019 & UK & Model-based & Cost-effectiveness and cost-utility \\
\hline Javitz 2011 & USA & Trial and model-based & Cost-effectiveness and cost-utility \\
\hline Lal 2014 & Australia & Model-based & Cost-effectiveness \\
\hline McGhan 1996 & USA & Model-based & Cost-effectiveness \\
\hline Mudde 1996 & Netherlands & Observational study-based & Cost-effectiveness \\
\hline Nohlert 2013 & Sweden & Trial and model-based & Cost-effectiveness and cost-utility \\
\hline Popp 2018 & USA & Trial and model-based & Cost-effectiveness and cost-utility \\
\hline Ruger 2008 & USA & Trial-based & Cost-effectiveness and cost-utility \\
\hline Shearer 2006 & Australia & Model-based & Cost-effectiveness \\
\hline Smit 2013 & Netherlands & Trial-based & Cost-effectiveness and cost-utility \\
\hline Tosanguan 2016 & Thailand & Model-based & Cost-utility \\
\hline Wu 2018 & UK & Trial and model-based & Cost-effectiveness and cost-utility \\
\hline
\end{tabular}

\section{AP PEN DICES}

\section{Appendix 1. MEDLINE search strategy for identifying economic evidence}

1. (cost? adj2 (illness or disease or sickness)).tw. 
2. (burden? adj2 (illness or disease? or condition? or economic $\left.{ }^{\star}\right)$ ).tw.

3. ("quality-adjusted life years" or "quality adjusted life years" or QALY?).tw.

4. Quality-adjusted life years/

5. "cost of illness"/

6. Health expenditures/

7. (out-of-pocket adj2 (payment? or expenditure? or cost? or spending or expense?)).tw.

8. (expenditure? adj3 (health or direct or indirect)).tw.

9. ((adjusted or quality-adjusted) adj2 year?).tw.

10. or $/ 1-9$

11 tobacco OR smok* OR cigaret* OR nicotine

1210 AND 11

${ }^{\star *}$ Will be restricted to entries added since 1 December $2015^{\star *}$

\section{Appendix 2. Contour plot}

Figure 7 displays a contour plot. Each point represents an individual study arm. Leverage is mapped on the y-axis; studies with higher leverage are those with more extreme values for contributing covariates. Deviance residuals are plotted on the $x$-axis. Points in red are from studies at high risk of bias, points in yellow are from studies at unclear risk of bias, and points in green are from studies at low risk of bias. Studies with larger deviance residuals indicate larger differences between predicted and actual values, with studies on the right having lower quit rates and studies on the left having higher quit rates than would be predicted. We used this plot to identify studies contributing the most deviance, and performed a sensitivity analysis removing these studies.

\section{H IST O R Y}

Protocol first published: Issue 12, 2018

Review first published: Issue 12, 2020

\section{CONTRIBUTIONS OF AUTHORS}

JHB, NL, JLB, PA and TF conceived the original review, with support from JOM, AS and SF.

JLB designed and ran searches.

JHB and JLB screened reviews and studies for inclusion.

JHB, JLB, and TF conducted data extraction and quality assessment for studies included in the network meta-analysis, with support from KR and SK (freelance systematic reviewers).

JHB, JLB, AT, and NL conducted data extraction and quality assessment for included reviews.

JOM led statistical analysis with support from TF, AS, and SF.

JOM conducted all elements of the brief economic commentary.

JHB, JLB, AT, and JOM drafted the text.

All authors edited and approved the final version of the manuscript.

\section{DECLARATIONS OF INTEREST}

JHB: is an author of some of the Cochrane Reviews that are included in the overview.

JLB: is an author of some of the Cochrane Reviews that included in the overview.

JMOM: is an author of some of the Cochrane Reviews that are included in the overview.

TRF: is an author of some of the Cochrane Reviews that are included in the overview.

Behavioural interventions for smoking cessation: an overview and network meta-analysis (Review) 
$\mathrm{NL}$ : is an author of some of the Cochrane Reviews that are included in the overview.

SF: none.

AS: none.

AT: none.

PA: is an author of some of the Cochrane Reviews included in the overview.

\section{SOURCES OF SUPPORT}

\section{Internal sources}

- No sources of support supplied

\section{External sources}

- National Institute of Health Research (NIHR), UK

\section{DIFFERENCES BETWEEN PROTOCOLANDREVIEW}

The methods section was updated to clarify the following regarding inclusion criteria for studies in the network meta-analysis: we excluded interventions tailored to specific population groups as these violate the assumption of joint-randomisability; excluded historical interventions which would not plausibly be offered in the present day (i.e. aversive smoking); excluded interventions which targeted multiple lifestyle changes (e.g. dietary change as well as smoking cessation); and excluded interventions targeted at smoking outcomes other than abstinence (i.e. smoking reduction).

We had originally planned to create GRADE ratings for reviews that did not contain these; we later deemed this inappropriate due to our limited knowledge of the evidence base within these reviews.

We had originally planned to use the CINeMA tool to assesses certainty in our network meta-analysis findings, but were unable to do so as this tool is not yet designed to be compatible with component network meta-analyses (cinema.ispm.ch/).

We had originally stated we would run sensitivity analyses excluding studies in which cessation was not biochemically validated. As this is taken into account in our risk of bias assessments, for which we have run a prespecified sensitivity analysis, we did not run a separate sensitivity analysis looking just at this variable.

We conducted three post hoc analyses to explore the impact of reducing possible causes of variation in our network meta-analysis. 